\title{
Dynamic Inter-Cell Interference Coordination in Cellular
}

\section{OFDMA Networks}

\author{
by
}

Md Mahmudur Rahman

A thesis sulmited to The Facolty of Graduate and Postedectoral Affairs in partial fulfillment of the requirements for the clegree of

\section{Doctor of Philosophy in Electrical Engineering}

\author{
Otlawa Carleton lustitute for Electrical and Computer Enginerring \\ Department of Systems and Computer Enginecring \\ Carleton University. Ottawa, Ontario. Canada
}

(9) 2011 Ma Mahmudur Rahman 
Library and Archives Canada

Published Heritage

Branch

395 Wellington Street Ottawa ON K1A ON4 Canada
Bibliothèque et

Archives Canada

Direction du

Patrimoine de l'édition

395, rue Wellington

Ottawa ON K1A ON4

Canada
Your file Votre référence
ISBN: $978-0-494-83224-0$
Our file Notre référence
ISBN: $978-0-494-83224-0$
NOTICE:

The author has granted a nonexclusive license allowing Library and Archives Canada to reproduce, publish, archive, preserve, conserve, communicate to the public by telecommunication or on the Internet, loan, distribute and sell theses worldwide, for commercial or noncommercial purposes, in microform, paper, electronic and/or any other formats.

The author retains copyright ownership and moral rights in this thesis. Neither the thesis nor substantial extracts from it may be printed or otherwise reproduced without the author's permission.
AVIS:

L'auteur a accordé une licence non exclusive permettant à la Bibliothèque et Archives Canada de reproduire, publier, archiver, sauvegarder, conserver, transmettre au public par télécommunication ou par l'Internet, prêter, distribuer et vendre des thèses partout dans le monde, à des fins commerciales ou autres, sur support microforme, papier, électronique et/ou autres formats.

L'auteur conserve la propriété du droit d'auteur et des droits moraux qui protège cette thèse. $\mathrm{Ni}$ la thèse ni des extraits substantiels de celle-ci ne doivent être imprimés ou autrement reproduits sans son autorisation.
In compliance with the Canadian Privacy Act some supporting forms may have been removed from this thesis.

While these forms may be included in the document page count, their removal does not represent any loss of content from the thesis.
Conformément à la loi canadienne sur la protection de la vie privée, quelques formulaires secondaires ont été enlevés de cette thèse.

Bien que ces formulaires aient inclus dans la pagination, il n'y aura aucun contenu manquant. 


\section{Abstract}

Inter-cell interference has been traditionally handled by fixed partition hased rense shemes since the beginning of cellular cra. Although effective for the then voice orlented networks, it is insufficient for modern day data communications ats aggensibe reme in meded to support

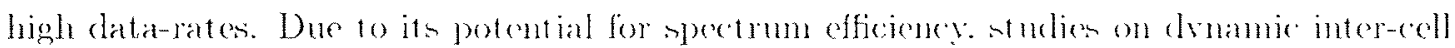
interferenere coordination (ICIC) has gained moment um recently. Thin thesis presents arome of the drnamic inter-cell interference coordination schomen for systems ning orthogonal frequency division multiple accesin (OFDNA) air-interface.

A general sum-utility optimisation problem is formulated using integer linear progranming for the dynamic interference coordination problem. Due to the size and nat ure of the problem. a global optimal solution is computationally prohibitive. Therefore. three different sub-optimal approaches have been nod to othe the problem:

1. A wo-level algorithun with partial central processing.

2. A distributad algorithm with neighboring cell coordination. and

3. A cluster-based fully centralized approach.

All presented schemes are based on the fact that only dominant interferers affect the signal quality of a desired transmission: therefore. coordination locally among a set of neighboring transmittess (called interference chuster) taking into account inter-cluster interforence dependency is sufficient to provide aroidance gain. 
The solutione reflect defferent coordination arehitectures with different levels of aroidance gain and complexity. The perfomance of these propesed ethemen has been compared with these of a number of reference schemes. According to obtained performanes results. the proposed schernes always outperform the corresponding reforence sehemen with significant gain in the coll-edge thronghput without impacting the total cell thronghput. 


\section{Acknowledgments}

It is a pleasure to express my gadutude to many people who dinectly and indinectly helped and made this thenis possible.

First and foremost. I am geatly infeloted to mo sujervivol. Profenson Halim Yambomeroglu. for his guidance and support with he hnowlerge and patience whilst allowing me the room to work in my own way. He has porided me with a lifetime opportmity to work in the Wireless World INitiative NEw Rarlio (MTNNER) project which tmuly enhanced my knowledge through global research exposue. It wh never an orerstatement to saly that one simply rould not wish for a better super risor.

I convey my acknowledgment to my supervisor at Industry Canadd. Mr. Adrian Flored. for his support and encouragement without which it rould not have been possible for me to write my thesis on-tine.

I express my gratitude to the commitee members of my thens popesal whone mabable comments. suggest ions. and insights have enriched the content of this thesis.

1 wish to thank all $m$ frionds and colleagues at Carleton Inivorsity. Commmix ations Reserach Centre and Industry Canada for their encouragement. I extend special apperectation to the administrative and computing staffs of the department of Systems and Computer Engineering for their continung support.

Sincere thanks go to my wife and danghter who always stool by une with great patience and good wishes. 
I dedieate this thesis to my late parents to whom this thesio wonld have nattered the mont. 


\section{Contents}

Acknowledgments

List of Figures $\quad x$

List of Tables $\quad$ xii

List of Symbols $\quad$ xiii

List of Abbreviations $\quad$ xvi

1 Introduction 1

11 Introduction 1

12 Motration 1

13 Problem Statement 3

11 llesectontubutions 1

15 Orciven of Remults

16 Orgamiation of the Thess 7

17 Summary 8

2 Literature Review $\quad 9$

21 Introduktion 9

22 Inter-Cell Interference Aroulance 9 
2.2 .1 Interference Avodance uning Rerource Partitioning . . . . . . . 11

2.2 .2 Comparison Among Partition-based Sihomes . . . . . . . . 19

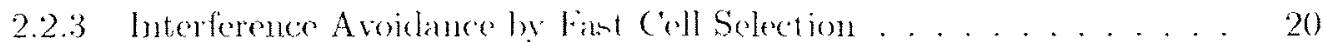

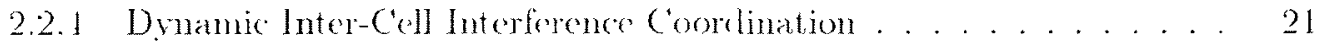

2.3 Mntti-Cell OFDMA Resourer Allocation ning Optimization Famework . . 24

2.4 Resource Seheduling Algorithms . . . . . . . . . . . . . 25

2.4 .1 Humgarian Scherduler . . . . . . . . . . . . . 25

2.4 .2 Proportional Fair schedules . . . . . . . . . . . . . . . 29

2.5 Summary . . . . . . . . . . . . . . . . . 30

3 A General Optimization Framework for Interference Coordination $\quad 31$

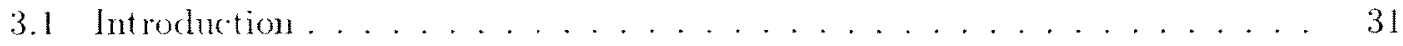

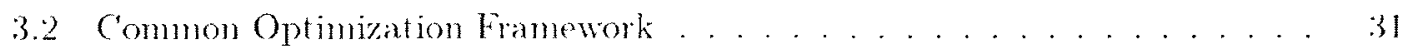

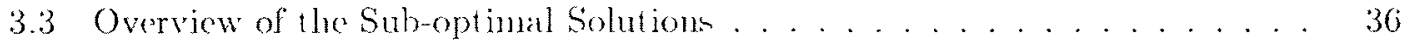

3.3.1 A Two-Level Algorithm with Partial Central Processing . . . . . . 37

3.3.2 A Distributed Algorithn with Neighboring Cell Coordination . . . . 38

3.3.3 A Centralized Approach with Clusters . . . . . . . . . . . 39

3.4 Summary . . . . . . . . . . . . . . . . . . . . . . . . . 39

4 A Two-Level Algorithm with Partial Central Processing 40

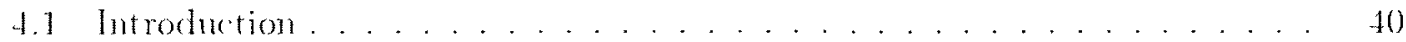

1.2 System Model . . . . . . . . . . . . . . . . . 11

4.3 Description of the Proposed Scheme ................. 42

4.4 Effects of Schertuling and Dominant Interference on Throughput and Fairness 45

4.5 Interference Avoidance Algorithms . . . . . . . . . . . . . . . . 48

$4 . \overline{3} .1$ Sector-Level Algorithm . . . . . . . . . . . . . 49

4.5 .2 Ceutral-Level Algorithm . . . . . . . . . . . . . . . 51 


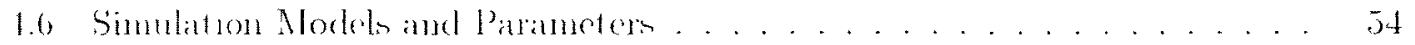

4.7 Simmlation Rennlts . . . . . . . . . . . . . . . . . 56

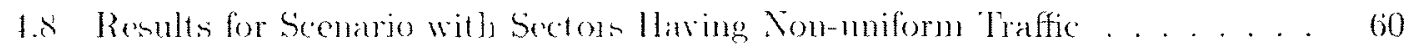

1.9 Implementation Complexity losues . . . . . . . . . . . . . 61

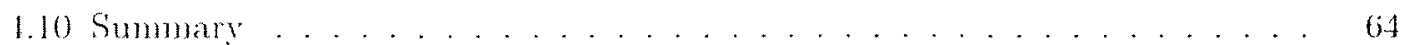

5 A Distributed Algorithn with Neighboring Cell Coordination 70

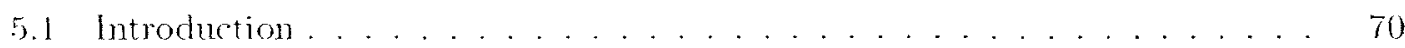

5.2 Desciption of the Proposed Stheme . . . . . . . . . . . . . 71

5.2 .1 Intra-eNB Inter-Cell Interference Avoidance . . . . . . . . 71

5.2 .2 Inter-eXB Inter-Cell Interference Avoidance . . . . . . . . 74

5.3 Simulation System and Paranetem ................. T8

5.4 Simulation Results and Discussions . . . . . . . . . . . . . . 80)

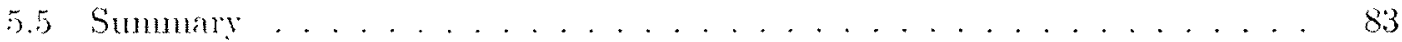

6 A Cluster-Based Centralized Approach $\quad 84$

6.1 Introduction . . . . . . . . . . . . . . . . . . . . 84

6.2 System Model . . . . . . . . . . . . . . . . . . . . . 85

6.3 Problem Formulation $\ldots \ldots \ldots \ldots \ldots \ldots$

6.1 System and Simulation Parametern . . . . . . . . . . . . . 91

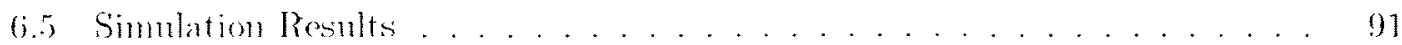

6.6 Simulation Time Comparison . . . . . . . . . . . . . . . . 94

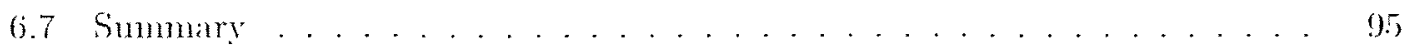

$\begin{array}{lll}7 & \text { Conclusions } & 96\end{array}$

$\begin{array}{ll}\text { References } & 100\end{array}$

$\begin{array}{lr}\text { List of Publications } & 113\end{array}$ 


\section{List of Figures}

2.1 Reuse 1 and other static partition based schemos. . . . . . . . . 12

2.2 Fractional frequency reuse with a rense factor of 3 in the outer zone. . . 14

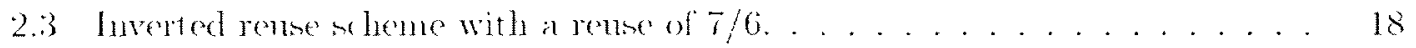

3.1 Notwork latout consisting of 3 -sertor cell siten . . . . . . . . . 32

1.1 Effect of schedulers. . . . . . . . . . . . . . . . . 16

+2 Fffect of interferer restrictions. . . . . . . . . . . . . 47

4.3 Resolures unit restriction recenest for a particular resource unit. . . . . . . . 52

1.1 CDF of UT throughput (Hungarian scheduler): full-huffer. . . . . . . . 58

4.5 CDF of UT throughput (PF schedules): full-buffer. . . . . . . . . . . 59

4.6 CDF of UT throughput (Hungarian scheduler): Poisson arrival. . . . . . 61

1.7 CDF of LT throughput (PF scheduler): Poisson arrival. . . . . . . . . 62

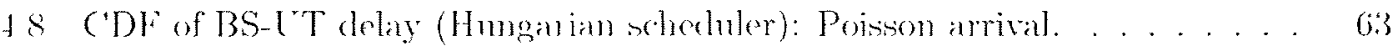

1.9 CDF of BS-UT delay (PF scheduler): Poismon arrival . . . . . . . . 6.1

4.10 simulation layout with hot-spot sectors . . . . . . . . . . . . .5

1.11 CDF of user throughput: iterative Hungarian secheduler (includes hot-spot

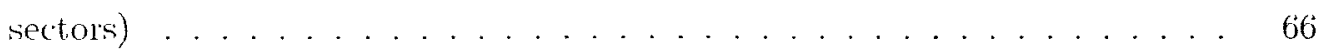

4.12 CDF of user throughput: proportional fair scheduler (includes hot-spot sectors) 67

1.13 CDN of BS-UT delay: iterative Hungarian scheduler (includes hot-spot sectors) 68

4.11 CDF of BS-UT delay: proportional fair selheduler (includes hot-spot sectors) 69 


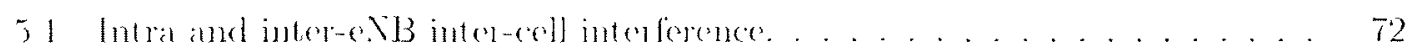

52 Gaphlacal reprementation of inter-e. XB PRB restrietion. . . . . . . . 78

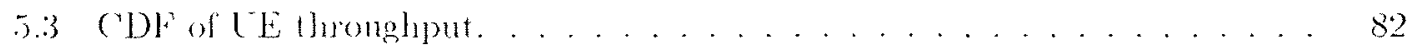

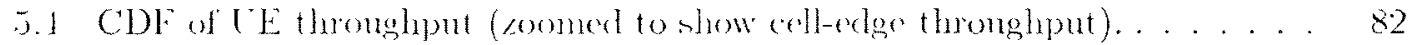

5.5 Cell-edge vis average sector thromghput. . . . . . . . . . . 833

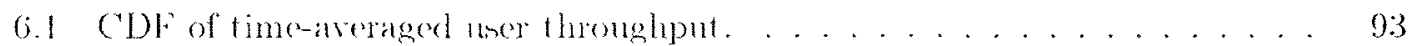

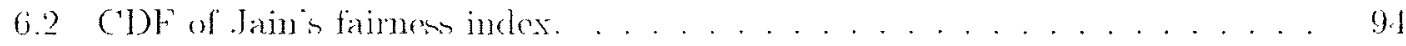




\section{List of Tables}

1.1 Najor pullieations constituting the core chapters ........... 8

4.1 Lint of Symbols Usert . . . . . . . . . . . . . . . . . . . 43

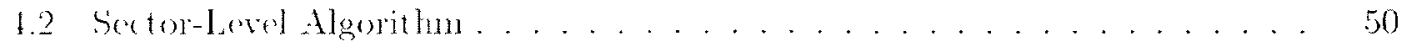

1.3 ('oll-Edge is Secton Throughput: Full-Buffer and Traffic Nodel (in parenthesis) 60

1.1 Cell-Edgre vis Sector Throughput: Traffic Xloded (inchudes hot-spot sectors). 63

5.1 System and Simulation Parameters . . . . . . . . . . . . . 79

5.2 Power Allocation to Phesical Resoure Blocks . . . . . . . . . . . . 80

6.1 List of Srmbols Used . . . . . . . . . . . . . . . . . 86

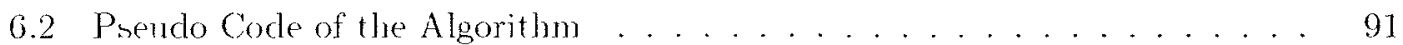

6.3 System and Simulation Parameters . . . . . . . . . . . . . . 92

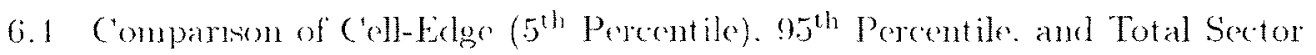

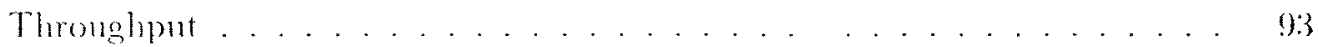

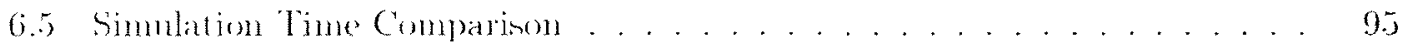




\section{List of Symbols}

a Power amplification factor for the resource blocks in the outer-region in SFR scheme

3 Sistem bendwielth in PFR scheme

3 Bandwidh for the imner region in PFR scheme

$3_{2}$ Bandwistlu for the onter region in PFR sheme

i,j.li Sector inder

4. Dominant interfering sector

$\psi_{1} \quad$ First dominant interfering sector

in Second dombant interfering sector

w Set of dominant interfering sectors that are rentrieted

$n \quad$ Time-fregueney renoures indix

$m$ Liser inclex

$N^{T} \quad$ Naximum total number of resource mits per sector

M Number of user terminals per sector

$\therefore$ Number of eligible resoures mits

$N_{r} \quad$ Number of restricted resoures units 


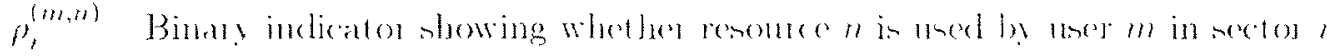

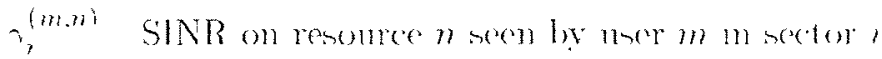

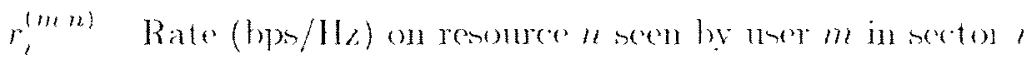

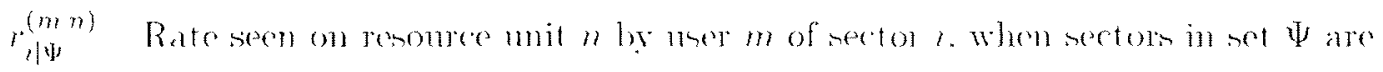
restricted for resource "

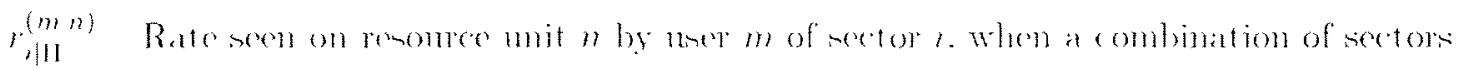
in $I 1$ in restricted for resource $n$

$u_{?}^{(m, n)}$ Utility of resource $n$ if used by user $m$ in sector,

y Litily matix

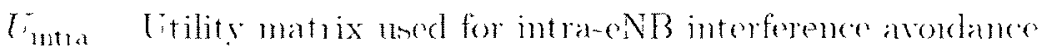

$L_{\text {inter }}$ Lility matrix uned for inter-exB interference aroidance

$\mathcal{H}_{r, r}^{(m, 3)}$ Chamnd from sector $x$ seen by user $m$ in sector 2 on resource $n$ (includes path-losis. antemal gains, shadowing. and fadling)

$d_{z}^{(m)} \quad$ Denand factor of user $m$ of sector $?$

$R_{2}^{(m)} \quad$ Average time-average throughput of user $m$ of sector $i$

$R, \quad$ Average time average throughput across all nser in oretor $;$

$\zeta$ Altemation fartor for atromated and trmented Slammon sates

$1 \quad$ Spectral efficiency

$r_{p} \quad$ Rate penalty used in intra-eNB interference avoidance

$r_{m}^{T H} \quad$ Rate threshold used in heuristics to find resource restrictions

$\Pi$ Combination of dominant interfering sectors that are restricted for a given resource mit

$I_{2}^{(n)}$ Binan indicator showing whether resonere $n$ is restricted for sector $i$ 


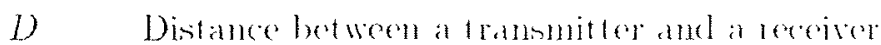

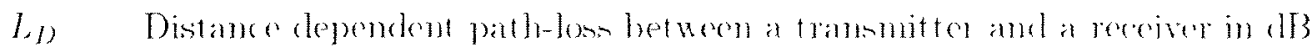

h $\quad$ BSS antematheight in meters

fi carrier frectuency in GH

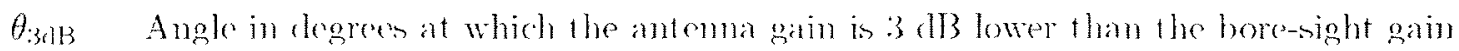

0 Antema pattern azimuth angle in regrers

$A(\theta)$ Antenna gain in dB at an horizontal angle of $\theta$ measured from the bore-sight angle

Pt Transmit power per sector antenna

Pr Transmit power per resonre mit

$P_{7 \times} \quad$ Average thermal noise power

cy,z Cost of assigning job y to machine z

$a_{y, z} \quad$ Assigmment indicator for job y to marhine $z$

1 Time

$r_{m, n}(t)$ User $m$ achievable rate on resource unit $n$ at time $t$

$T_{m}(t)$ User $m$ filtered time-averaged rate at time $t$

$R_{m}(t)$ Liser om total rate achieved for all allocated resoures al time $t$

t. Time constant 


\section{List of Abbreviations}

\begin{tabular}{|c|c|}
\hline $3 G$ & $3^{\text {rd }}$ Generation \\
\hline 3GPP & $3^{r d}$ Gencration Partmerhip Pioject \\
\hline AMC & Adaptive Modulation and Coding \\
\hline ARQ & Automatic Repeat reQuent \\
\hline BER & Bit-Error Rate \\
\hline B-LDPC & Block Low-Demity Parity-Check \\
\hline BLER & Block-Error Rate \\
\hline BPSK & Binary Phase Shift Keying \\
\hline BS & Base-Station \\
\hline BSC & Base-Station C'ooperation \\
\hline CDF & Cumulation Distribution Fun tion \\
\hline CoMP & Coondinated Mult-l'oint Transmission and Reception \\
\hline CQI & Channel Quality Indicator \\
\hline CR & Cognitive Radio \\
\hline CSI & Chammel State Information \\
\hline $\mathrm{E} 2 \mathrm{E}$ & End-to-End \\
\hline
\end{tabular}




\begin{tabular}{|c|c|}
\hline eNB & molved Norleds \\
\hline FDD & Frequencs Drvirion Dnplex \\
\hline FFR & Fuctional Frecuener Reuse \\
\hline FH & Frecpuency loppling \\
\hline GSM & Global Sistem for Wobile commminication \\
\hline ICIC & Inter-Coll Interterence Coorduntion \\
\hline IEEE & Institute of Electrical and Electronics Enginems \\
\hline ILP & Integer Linear Programming \\
\hline IMS & IP Multmodia Suburstem \\
\hline IP & Intemet Protorol \\
\hline IR & Inverted Riense \\
\hline IRC & Interfarence Rejection Combining \\
\hline ISI & Inter-symbol huterference \\
\hline LOS & Line of Sight \\
\hline LP & Linear Programming \\
\hline LTE & Long Tesm Evolution \\
\hline LTE-A & I.TE-Adianced \\
\hline $\mathrm{M} 2 \mathrm{M}$ & Machinesto-Naxdime \\
\hline MCS & Modulation and Codme Scheme \\
\hline MIMO & Multiple-In Multiple-Out \\
\hline MME & Mohility Management Entity \\
\hline MRC & Maximal Ratio Combming \\
\hline
\end{tabular}




\begin{tabular}{|c|c|}
\hline OFDM & Onthogonal Frenuency Dirision Multiplexing \\
\hline OFDMA & Orthegonal Fecpueney Dirinion Nultiple Accesen \\
\hline PF & Proportional latir \\
\hline PFR & Pantial Frepueney Reuse \\
\hline PHY & Physical \\
\hline PRB & Phymical Romourec Block \\
\hline QAM & Quadrature Amplitude Modulation \\
\hline QoS & Quality of Service \\
\hline QPSK & Quadrature Phatse Shift Keying \\
\hline RAN & Raulio Acrens Network \\
\hline RNC & Raclio Network Controller \\
\hline RRM & Radio Resource Management \\
\hline SDR & Software Defined Raclio \\
\hline SFR & Soft Frequency Rense \\
\hline SINR & Signal-to-Interference plus Noise Ratio \\
\hline SISO & Single-In Single-Ont \\
\hline SNR & Signal-to-Noine Ratio \\
\hline SON & Solf Organized Vetwork \\
\hline TDMA & Time Divasion Multiple Access \\
\hline UE & User Equipment \\
\hline UMTS & Universal Mobile Telecommunications System \\
\hline UT & User Torminal \\
\hline
\end{tabular}


UTRAN UNITS Terential Radio Acerom Network

WFQ Weighted Fatir Qnening

WiFi Wireless Ficklit!

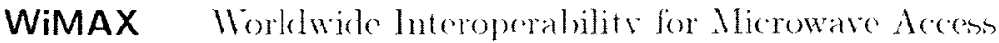

WINNER Wireless Morld INitiative NEw Radio

WINNER+ WINVER Plus

WLAN Wireless Local Area Network 


\section{Chapter 1}

\section{Introduction}

\subsection{Introduction}

In this chapter. the driving factous that motivated the research conducted in this thesion ane presented first in Section 1.2. The statement of the problem is ontlined briefly in Section 1.3 followed br the contributions of this thesis in Section 1.4. The overview of the obtained results and the organization of this thesis are given in Sections 1.5 and 1.6 , respectively.

\subsection{Motivation}

The pace at which the cellulat wielese technology bas been ovolving is probably the fantest compared to any other techologs esolution ft is maring to wituesis all these crolution and revolutions. with respert to hata speed. service type applications. harrware, ete. starting from cauly malog systems to present day digital all-Intermet Protocol (IP) nystems. As the face of the cellular techmology changes. so does its challenges. In the early days. wireless research mainly concentrated on cell capacity, scheduling. antemna design. etc.., on which sescarch hats matured and we have overeome the underlyng issues and challenges orer the years. The challenges of cellular technology has now shifted. as we realize that Radio 


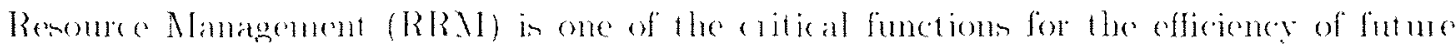
worelens ststems. Based on the realizatom that Radio Acress Notwork (RAN) architecture

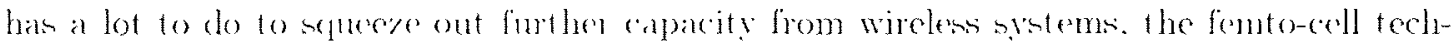
nology has bern invented. State-of-art tedmologies like Cognitive Radio (C'R). Software Defined Radio (SDR). Nachine-to-Nathine (N2N). Self Organized Network (SON) and so on. are emerging with great ponsibilities and opportmities. Howerer. these opportunities accompany comomons chatlengen. expecially, with respect to interference and related RRM aspects. This thesis foc uns on on of snch challenges- inter-cell interference.

Orthogonal Frequency Division Multiplexing (OFDA $[1]$ is being welcomed as a promising air-interface technology for the next generation wireless standards such as for lexal area Wireles Fidelity (WiFi) [2] notworks to wide-anen cellular systems like Worldwide Interopcrability for Nicroway Access (MiNAX) [3]. 3'd Generation Partnership Project (3GPP) Long Term Exolution (ITE) of V'niversal Nobile Telecommunications System (ITMTS) [4] and LTE-Aranced (LTE-A) [5]. and in the form activitios such as WINNER [G] and WTNNER Plus (WINEER+) [7] systems. Equipped with OFDM's inferent robustnens against frequency selective fading. Orthogonal Frequency Division Multiple Access (OFDMA) offers flexibility for radio resource allocation [8]. The finer resource granularity of the OFDMA allows each resoure mit ${ }^{1} 10$ be allecated and modulated adaptively to obtain frecuency as well as multinser diversily.

In order to mest the high harget data-rates in these besond $3^{\text {rd }}$ Gencration (3G) and

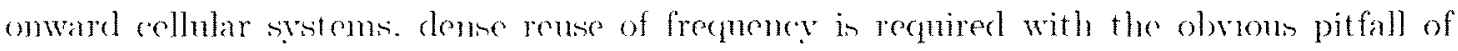
high inter-ell intelference. (lissical approach of interference avoidane through clustering approach may have been good enough for voice services. but it is highly inefficient for systems requiring high data rate for services such as streaming video, video conferenc-

\footnotetext{
1 A collection of comecutive sub-arriers ower a defincel time period. which is regarded an the minimm

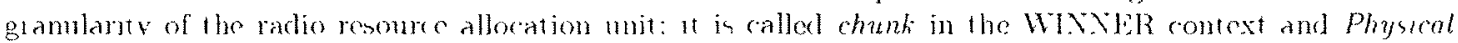
Resounce Block (PRB) in 3C:PP LTE and LTE-A studies.
} 


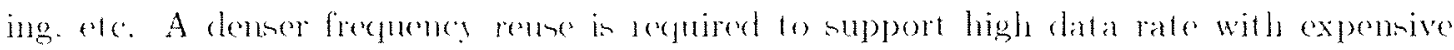
and limited speetrmu. Therefore. fo obtain the full potential of the OFDALA an a demese

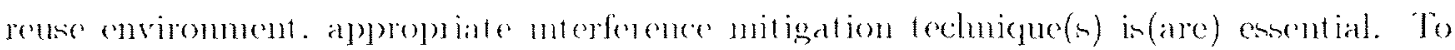
that end. interference mitigation haw hern identified as one of the major insues currently being investigated by different standardization bodies and forms focmsing on forthoming cellular systems. Inter fesence mutigation tedniguen are categorized into three major classess such an interference cancellation through phrsical hyes processing. interference averaging or randomization using freculency hopping. and intorference aroidance throngh network level transmission coordination. The for us of this thesis has been on dynamic inter-cell interference coortination nivg network laner resourec coordination.

\subsection{Problem Statement}

Inter-ell interference avoidate without imparting cell throughput is a chatlenging task. In this thesis. inter-cell interforence problem is adrlonsed using a mumber of novel dynamic Lnter-Cell Interference Coordination (ICIC) schemes.

Interference is an inevitable by product of wireless transmissions and it is inherent to any wireless technology. The issue of ICIC using preplanned resource partitioning in a static mamere can be traced back to the time when the cellular techology was first juvented.

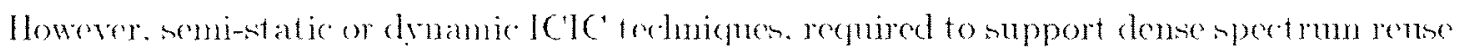
required for comrent and future high data-rate wireless systems. are fairly reent reneard interest. The prinary objective of such ICIC algorithus is to hoost cell-edge performaner with a minimal impact on nefwork throughput. To that end. a number of proposals are available through standardization campaigns and scholarly articles. However, most studies consider either static or semi-static approarhes. such as the variants of Fractional Frequency Rense (FFR) schemes. where cell-edge performance can only be enhanced through significant penalty to network throughput. Additionally. such schemest recuiring frequency 


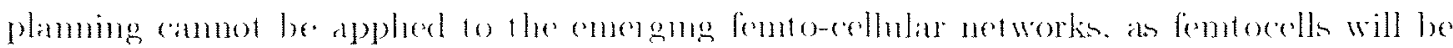

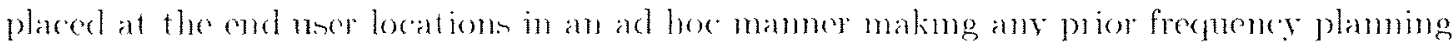

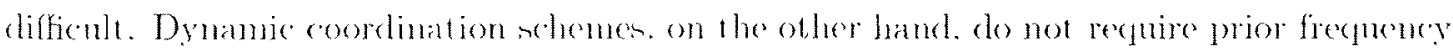
plaming and operate hased on dyamicalls obtained mutual interference information tron surromalng tromsmiters. Therefore, dymanic schemes are not only effective to aroid interference in matrocell-macrecell seconario. they are alio capable of handling interference fiom macrocells if applied to fentorell or ofher piosedl Base-Station (BS)s. These fomto deployments rely on signaling over IP hackbone. Futue IP communications are expected to be on fast IP Multimedia Subsystem (IMS) core, which will support fast information processing reguired for dynanic interference coordination schemes. Dynamic inter-cell coordination

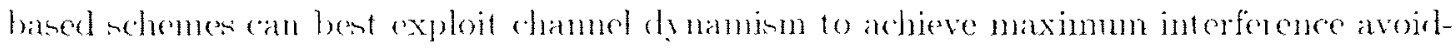
ance gain: however, only a few such studies can be found in the literature.

In this thesis. the interference coordination problem is first formulated using lnteger linfar Programming (LLP) approade and then different viable sub-optimal solutions and/or heuristice are explored. The primary focus of these studies is to provide enhanced performance to cell-edge user terminals while keeping the system throughput minimally affected. not affected at all. or even improved. The formulation takes user's achieved throughput status and interference condition inte account and finds a set of resoure units that are to be rentricted in each tramsmitter in a denamic mamer. Three major different approatedes toward the sulpoptinality of the solutions are investigated and presented in three main subsecpunt chaptern of the thesis.

\subsection{Thesis Contributions}

A number of low-complexity, viable dynanic ICIC schemes, that show significant gain in coll-edge thronghyut without impacting coll throughput. have been designed and evaluated in this thesis. The contributions can be summarized ats follows: 
- The IClC poblem har been fommlated uning a general optimization famework consiclering the fact that only neighloring dominant interferers affect tramsmiston chalits. Wo use our previously adopted ideat of inlerferer group to form merference cluster and model such interedependent interference entitich. I doned form optimal solution of interference coordination problem that combiclers a large mumber of mutnally interfering colls is a complex pothem the to its large problem size. Therefore. an optimil

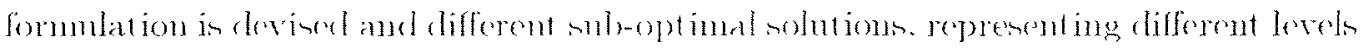
of optimality. complexity. and network anchitectures, are explored.

- A mique, two-level sub-optinal scheme has been developed. where user-centrir re-

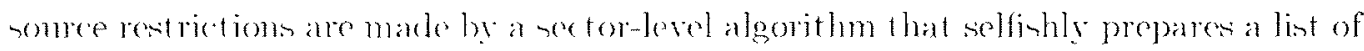
resources to be gestricted in each nemghboring dominant interferer sector. She intercependency of resource restriction is handled by mother algorithen that resides as at cental entity. As the contrat algorithm only deals with resource restriction contlicts. the overall eomplexity of the seheme is redued significantly: He utilize the flumgarian algorithm [9] that works on utility measures (comsidering users achieved thromghput status) of the resources to prepare the resource restriction request.

- The ahove scheme has been tailored to a distributed algorithm for the system in which a central entity is not avalable in the ardutecture. such as the 3GPP L.TE. Interferers

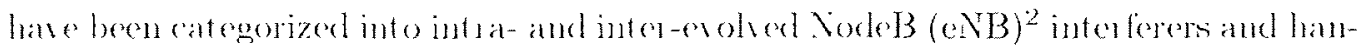
dled differently che to their signalling and condination recpuirements. In particulas. as intra-eNJ interference mitigation dees not reguire inter-cell signaling. arojalance can be done in each eNB considering mutual interference among its sectors. We devise a novel method for intra-eNB interference avoidance. where Hungarian algorithm has been used in a multi-sector context. To the best of our knowledge. Hungarian algorithm has never been applied to resource scheduling among multipte cells (or sectors).

\footnotetext{
$2 \mathrm{ABS}$ is called as aXP on LIt tormulolog:
} 


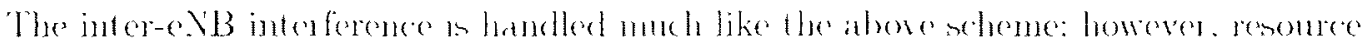
restriction contlieds are handled be inter-ectl signaling using the $X 2$ interface of the LTE strtem.

- Anovel chuter-based sub-eptimal sedeme has bermstudied in this thesis. where interdependency of resoure restriction has been modeled using an HLP approach. Different utility functions have been enusidered to moked different levelo of user fainuess and the trarde-off with system thoughput. Also. diflerent chuster sizes representing different computational complexity have ben muratigated.

- In all investigated solutioms. emplatsis has heen on oflledge user performane which is a function of chammel conditions. muthal juterforence it nation. and users achieved throughput status.

Some of the researde presented in this thesis were conducted under the WINNER project durmg 2004-2007. In the initial phase of this thesis. an interference avoidance scheme in a relay-based network using Time Division Nultiple Aceess (TDMA) air-interface had been studied. The ideas and/or results of this research were included in WINNER Phase 1 deliverables $[10-13]$ and presented in [14]. As conld be seen from [14] that the initial work on the ICIC problem was done quite early on. mulh betore Ie "IC became a hot researeh topic. ICIC sehemes considering OFDMA r rstems that form Chapter 4 of this thesis wan firmt

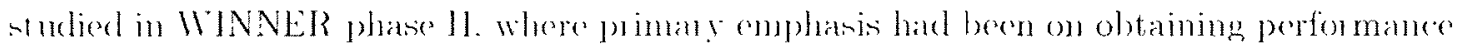
gain the to dymamare merference eordmatom. Results were comt ributed to WINNER Phase II deliverable [15] and in [16. 17]. An extenderl wersion of the work presented in [17] also appeared in [18]. The ideas presented in [16] has been enhanced in [19] in various aspects and a further extended work [20] has been submitted for possible publication.

Beside WINNER, some research were done under industry collaborated research projects in Canada and internationally such as with Communications Research Centre (C'RC). Re- 


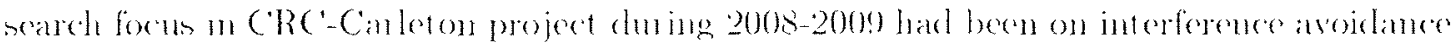
for the 3GPP LTE sistem. Contribution were made to two CRC-Carleton Year I project deliverables. two Year 11 deliverables. and presented in [21]. Some ideas of dymanie interforence avoidance formed part of a patem [22] filed by Samsung Korea. Contributions were also mads 10 other research projects in the form of in-homse research collahorations. which are exchuted from this thesin $[2328]$.

\subsection{Overview of Results}

Cell-edge performance. which is defined as the $5^{\text {th }}$ percentile point of the C'mmulative Distribution Finnetion (CDF) of the time-average user thremghpul is observed. Also. sector throughput for the proposed seluemen an well as for the reference schemen is determined. For each investigated seheme. a corresponding reference scheme has ben considered for comparison. in which coordination is either not used or used in a stat ie manner. The faimess of the proposed schenes has aloo been determined uning Jains faimesm index [29].

It is ohserved that the proposed dynamic interference avoilance schemes always provide enhanced performance, with respect to cell-edge throughput and fairness with a minimum impact to sector throughput, compared to that in the reference schemes.

\subsection{Organization of the Thesis}

The remainder of this thesis is organized as follows. A hrief literature review in given in Chapter 2. Chapter 3 describes a gemeral optimization framowork for the interference coordination problem and gives overview of the three approaches of sub-optimal solutions. Chapters 4, 5. and 6 present details on these approaches along with respective results and discussions. Table 1.1 stmmarizes major publications that comtitute these core chapters of this thesis. 
Table 1.1: Najor public at iom comstunting the core chaptere

\begin{tabular}{|c|c|}
\hline$\left(h_{1}, p\right) t e r$ & Publeatum \\
\hline$\left(h_{1 \times l]}\right.$ & 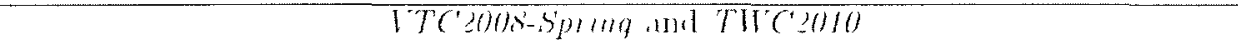 \\
\hline 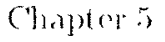 & $\mathrm{WC}$ \\
\hline (hat) 6 & 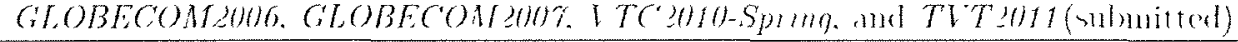 \\
\hline
\end{tabular}

It hould be mentioned that diflerent proposed dymamic ICIC ochemen have been studied in diffesent contexts depending on the recuirement of the underly ing propects. For example.

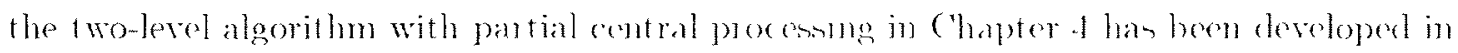
the context of the WTNNER project. On the other hand, the distributerl scheme. presented in Chapter 5, considers LTE system due to the requirements of the project. Therefore. the system and simulation pardmotes of the proposed a hemes are different and hence they ane describer separately in the respective chapters.

Chapter 7 conchudes thes thesis and outhes a few joleas by which the reseanch presented in this thesis can be extended. Fmally. Appendix A prements a list of publications of the anthor.

\subsection{Summary}

In this chapter, motivation. problem statement, and highlights of the contributions this themis. a synopsis of the observed results and the organgation of this these have beon

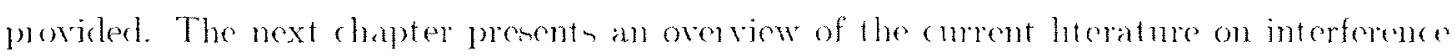
aroidance. 


\section{Chapter 2}

\section{Literature Review}

\section{$2.1 \quad$ Introduction}

An overvies of the current literature on interference coordination latis heen proveled in this chapter. Nulti-cell resource allox ation and schechuling techmieques are clonely related to interference aroidance Therefore. some notable litenatum on multi-cell resource allocation along with brief descruptions of the Hungarian algorithm and proportional faur scheduler, that are used in this thesis. have also been inclucled in this chapter.

\subsection{Inter-Cell Interference Avoidance}

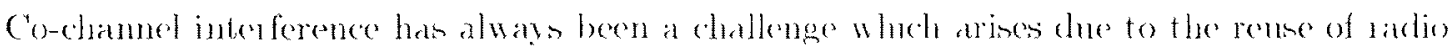

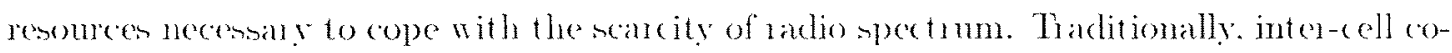

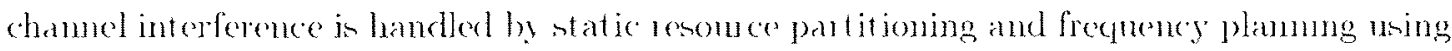
the classical chustering technique. first proposed in [30] at the time when the cellular technology was invented. The reuse distance, locations of the BSs in the cell-sites and antemna directivity have been studied rigorously at that time. see [31, 32]. for example. In this approach. the higher the duster size. the lower the interferene due to a larger reuse distance. 


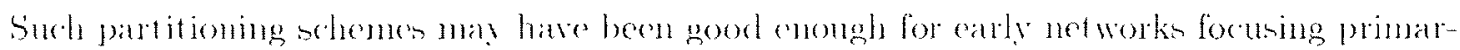

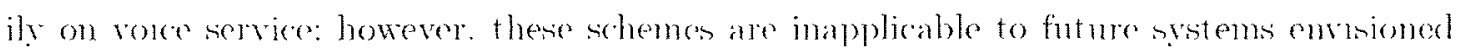
to support ranges of high chata-rate applications such as veleo conference streaning vider.

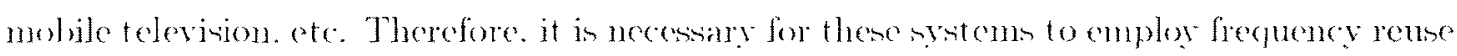
as dense as possible with necrssury protertion against inter-coll interference.

Interference mitigation is one of the key ismes currently being ins estigated by reseanders in industry and a arlemia of different standardization bodies. formms. and rescarch groups. The technignes nsed for interference mitigation are generally classified into three ma jor categories such as interference cuncellation through receiver processing, interference random-

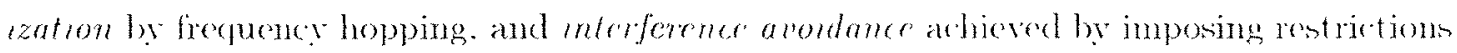
in resoure nage in terms of resource partitioning and power allocation [3. 15. 33. The basic principle of interference cancellation techniques is the receiver signal processing to istimate interforence and subtracting it from the desired signal component. Tuterference averaging fedmiques nuch as frequency Hopping (FII) that emsures User Equipment (LE) to accesis a range of chamels rather than a narrow set in a specific pattern so that interference effect is averaged out for all UEs in the long term. Finally, the interference avoidance technique focuses on finding an efficient reuse factor often achieved through restrictions on frequency and power allocations that meets network performance goals. The benefits of these teetmiques are mutually exchusive and hence. a combination of these approaches is likely to be emploged in the system.

ItE at the cell border experience high interference from neighboring transmilters in axklition to their high distance dependent attenuation. Scheduling sehemes targeting maximized network throughput, such as a maximum-Signal-to-Interference plus Noise Ratio (SINR) type scheduler. will find these ULs with poor channel conditions less at tractive as they are not likely to contribute mude to the total throughput. Strictly speaking. "ven a fair scheduler such as a Weighted Fair Queuing (WFQ) scheduler [31]. will have a linut to 


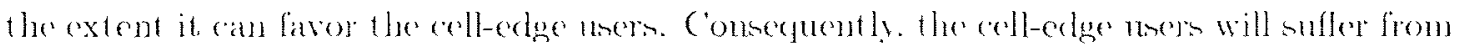
poor thronghput. A hlunt approarh to improve cell-edge UEs rates combl be to ansign more renoures (e.g. an egual rate sharing approach): howerer. it would jeopardize the rates of

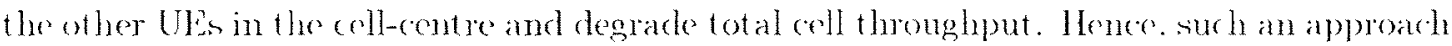
is highty undesirable. The ohjective of interference noidance is therefore. 10 improve SINR and provite botter servicen fo cell-edge LEs without sacrifuing coll-centre throughput. The foc us of this thesis is on interference avoidane nuing dronamic IC'IC'.

For the sake of organization. the techniques for interference avoidance found in the literature are categorized as follows:

- Interference avoidance nsing resource partitioning

- Factional frequency reuse (FIR)

* Soft frecutucy rense (SFR)

* Partial frequency reuse (PFR)

- Imerted renses (IR)

- Interference avoidance by resource allocation and scheduling

- Interference avoidance uning inter-eell handeres

- Dynamir inter-cell interference coorclination

\subsubsection{Interference Avoidance using Resource Partitioning}

If the available frequency spectrum is reused in rach sector without any restriction to frequency resource usage or power allocation. it arhieves a reuse factor of 1 (also termed as unversal reuse), which is the worst inter-cell ${ }^{1}$ interference situation.

\footnotetext{
"The temm "sectur" and "cell" ate used interchangeably in this thesis, and thesefore. inter-cell interference

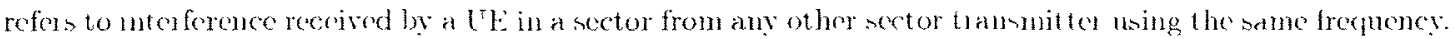




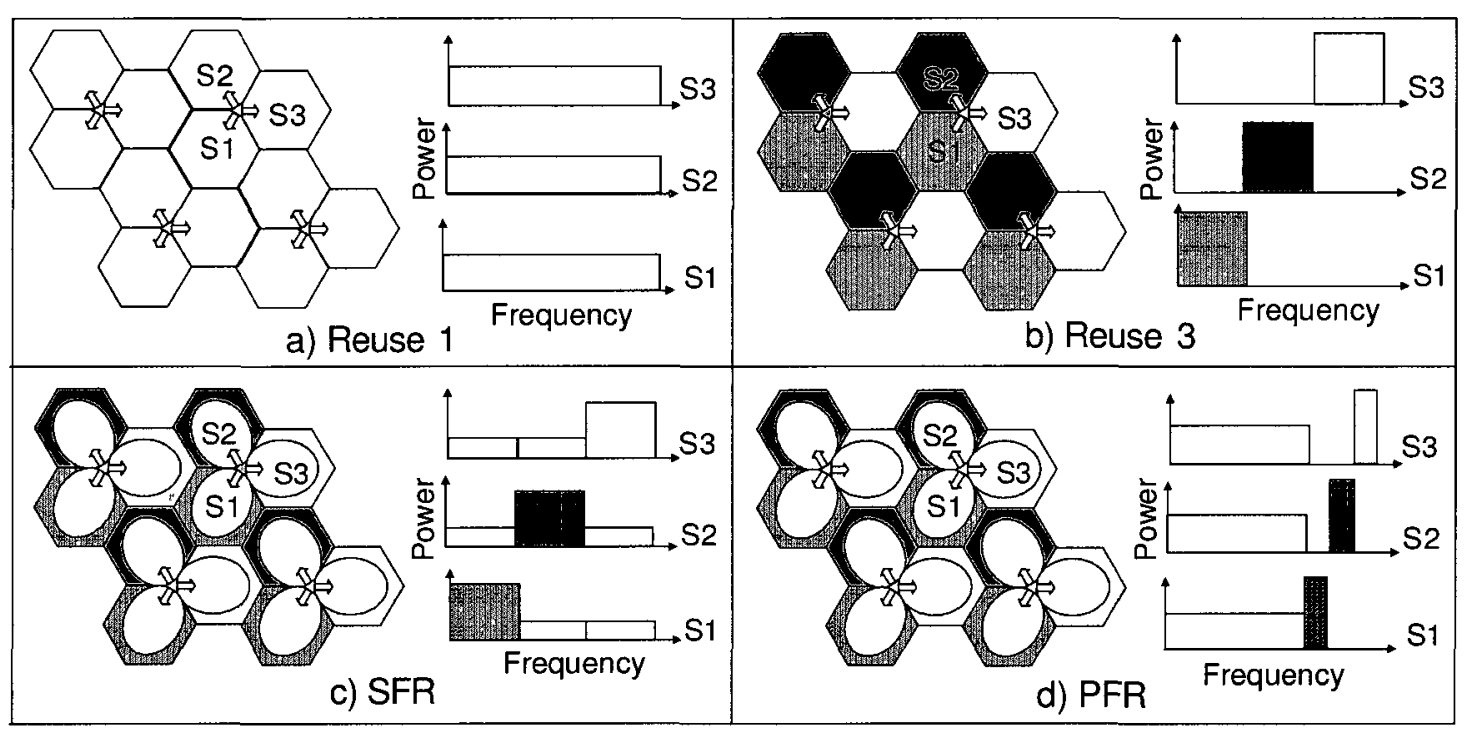

Figure 2.1: Reuse 1 and other static partition based schemes.

On the other hand, if the available frequency spectrum is divided into three sub-bands and each sector is given an orthogonal sub-band among neighboring sectors, then a reuse of 3 can be achieved [30]. This clustering obviously provides improved inter-cell interference, however, it results in a significant resource loss due to partitioning. Figures 2.1.a \& 2.1.b show reuse 1 and 3 schemes, respectively, where total transmit power per sector transmitter remains constant in both cases. While reuse 1 does not employ any interference coordination, reuse 3 can be regarded as an extreme case of partition-based static interference coordination. The FFR schemes achieve an effective reuse factor between 1 and 3 . Two variations of FFR schemes, namely Soft Frequency Reuse (SFR) and Partial Frequency Reuse (PFR), are shown in Figures 2.1.c \& 2.1.d. These schemes are used as some of the reference schemes in this thesis and therefore, are elaborated further in the subsequent sections. 


\section{Fractional Frequency Reuse (FFR)}

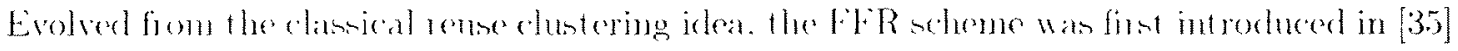
for the Global Sratem for Mobile communication (GSM) yotems. In the recent gears. the FFR sedene has attraeted the atention of the researchers in different atandardization bodien and formus. It is alopted by the WiMAX form [3] and 3GPP LTE [3:3] in the form of clifferent variants. This idea in also explored extensively in the HTNNER [15] project. The motivation for proposing the FIR lien in the fact that usem in the central area of a cell are robust against interference due to likely weak interference and strong desired signals, and hence the'y can tolerate reuse of 1 compared to the users at the cell border suffering from high interferene as well an high distance dependent attenuations (in desired links). Therefore, it in more effective to use mixed reuse factors, ie.. a higher reuse factor for the ULis in the coll-ertge compared to that for the cell-centre areis where reuse of 1 can be supported. A common example of an FFR for a network with trisector BSs is a blend of rense factor of 1 and 3 in the cell-centro and cell-edge areas. respectively. A simple FFR scheme in shown in ling. 2.2. Genemally. users are classified into cell-edge and cell-centre groups based on the user geometry. Resource is partitioned into inner- and outer-bands (also called minor and major bands). and are allocated to cell-centre and cell-edge users, respectively. Pat ition of resoureses inte the cell-edge and coll-centre bands detemines the cffective reuse factor. In mont achemes. higher power in allocated to the resources uned for the cell-erlge IF. In [36]. the effect of power coordination in FFR selheme has been investigated. In that study a pretefined power and freguency plaming is applied to show that the power coordinated FFR scheme ontperforms a pure FFR wheme where an equal power is applied across the whole band (both the inner and outer sub-bands). PFR [37] and SFR [38] are two variants of the FFR scheme, which are discussed below with a greater details. 


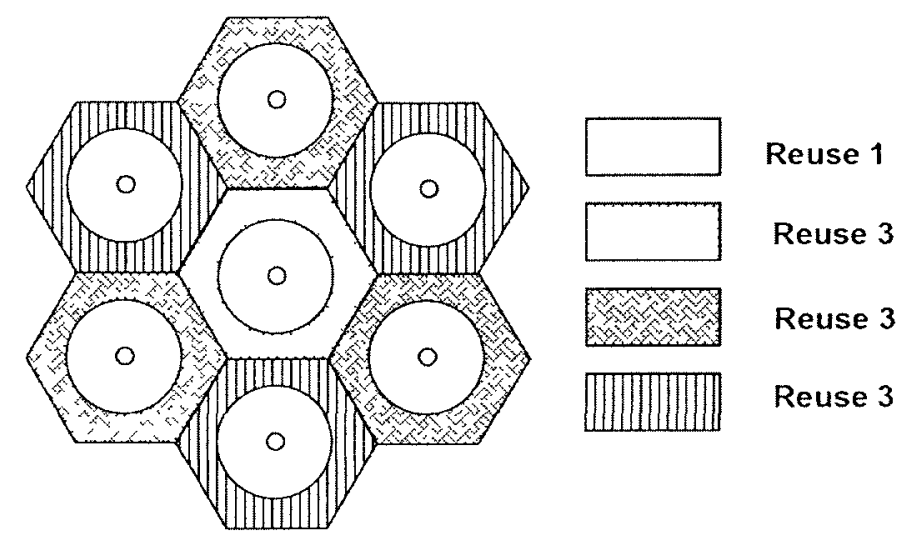

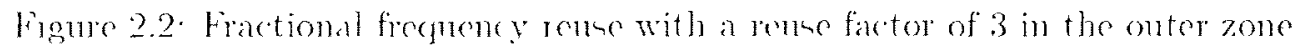

Soft Frequency Reuse: Soff frepuency retuse schene is a variation of FFR in which a reuse faxtor of 1 mel a factor expal to or greater than 1 are applied in the cell-centre and cell-edge areas. mopectively. It was proposed in [38] and [39] moler 3GPP LTE framework to provide a highes me to doriduntaged LEs such as those nean the coll boundary.

Fig. 2.1.c show an example of an SFR scheme for cell sites with sectorization. For 3sector cell sites, the cell-edge band is usually $1 / 3$ of the available spectrum and is orthogonal to those in the neighborng cells. The cell-edge subcarriers are called major subcarrier

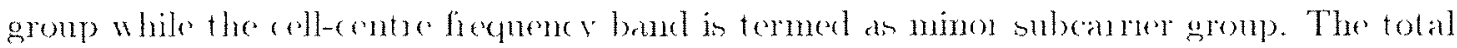
transmit power is wet fexed and ach group is ansigned transmusion power dependng on desired effective erme fantor. Which is determined bs the sato of the allorated powers of coll-centie to cell-adge group

Transmishions use higher power on the major band as shown in the right side of Fig. 2.1.c. Let us consider that the power per PRB (i.e., time-frequency resource unit) is 1 in the case of reuse of 1 and power per PRB for the cell-edge (major) band is a for the SFR scheme. Then power per PRB in the minor band would be $(3-a) / 2$ giring a pow ratio of $(3-a) / 2 a$ 


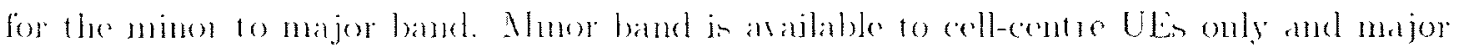
band cim also be used for cell coutre areas. Arljusting power ratio from 0 to 1 effectively

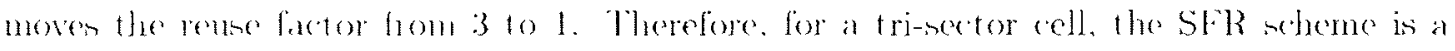
tumable compunomise betwern reuse 1 and 3.

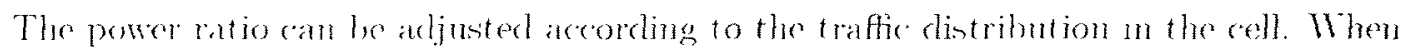

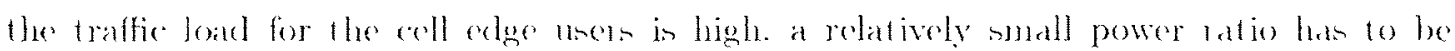

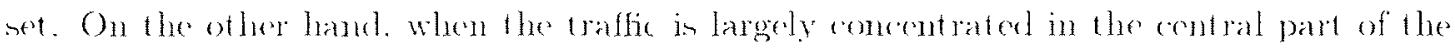
coll. a relatively high power ratio is suggested. In that sense. the effective rense factor of SFR can be arlapted in a static. semi-static, or dynamic depending on the time-scale of the adaptation. In [39]. "ith cell hasout without aretorization. simulations are performed for different power mation in a satic mamer. Results show that decreasing power matio provides higher cell-edge throughput with the decrease in throughput for the cell-centre IFs and the oell in general. In [37]. simulations are performed witly different antema configurations and recoiver combining methods. While the result follow the general trend of increasing cell edge thromghput with the decrase in total cell thronghput for all simulation combinations, dual antenna Interference Rejection Combining (IRC) receiver provides higher netrork throughput compared to the single antenna and dual antenna receivers with Maximal Ratio Combining (ARC).

The perfomanes of the erm-static SFR is compared with that of a static in [40] in a

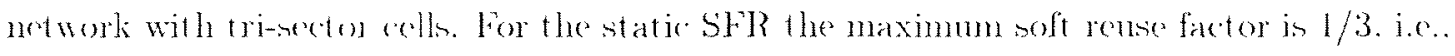
the sub-hand allocated to coll-edge usern can be up to $1 / 3$ of the fotid frecunemey band. Howerer, in semuistatic Str. the percentage of freguency resources allocated to cell edge users is comsidered to be equal to the percentage of cell-edge terminals relative to the total number of users which may become larger than 1/3. A single antenna transmitter and dual antenna receiver have been assumed for simulations. It has been shown that the semi-static SFR outperforms the static SHR by providing up to $50 \%$ higher cell-edge throughput while 
kerping the cell-conte throughyul sighly better.

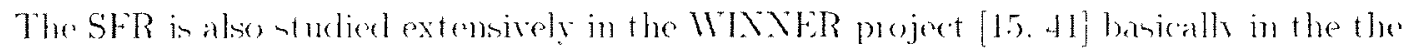
rontext of static pantitoming into sub-bands and power allocation. This allocation can be done orer the time-scale of days thromgh network plamming. The criteria for this allowation could be the aroge SIXR over whole bombidth. The SFR in evaluated with different

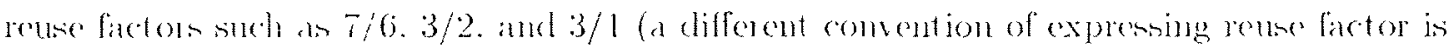

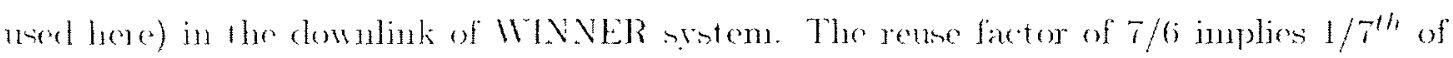
the resource will have to une reduced power. for example $10 \mathrm{~dB}$ lower an considered here. in each cell. Also. different user speed scenarios have been considered in the simulations. As

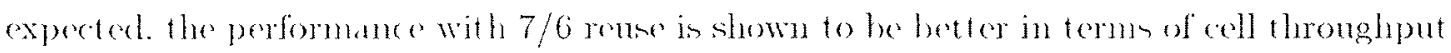

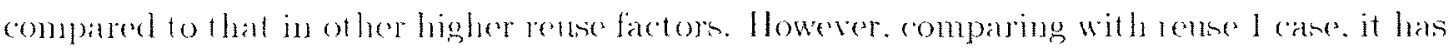
been shown that only manginal coll-edge thoughput performance is obscreed compared with a large reduction in overall sector throughput. Study also investigates perfomance with and without recoiver diversity. MRC: scheme. The LEs are ategorized into coll-erdge and cell-entre based on user geometry determined by the received signal power (averaged over multi-path fading) taking into account the large-scale path-Joss, shatowing, and antenna gains.

Partial Frequency Rouse: Contrary to the Sl'R. the idea of at PlR sheme is to restrict some resenures no that some frecpuencies are mot used in some sectors at all. This rencept was first presented in [-12]. The effective reuse factor of thin sedene depemels on the fraction of umber fregueney. The PFR and some of its variants ane studied in the 3 GPP and MINNER projects (see. for example. [37] and [1.5]). An example of PFR for cell sites with 3 sectors is shown in Fig. 2.1.d. Let us assume that the available system bandwidth is $\beta$ which is divided into immer and outer zones with $\beta_{1}$ and $\beta_{2}$. respectively. Usually. $\beta_{1}$ is used with a rense factor of 1 and for the tri-sector BSs. the rense factor for, 32 is 3 in 


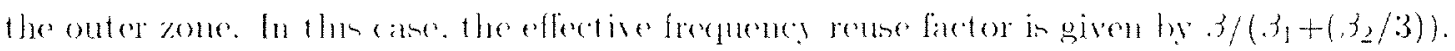
Therefore. the effection renose of PFR sheme is always greater than 1. Like SFR sheme.

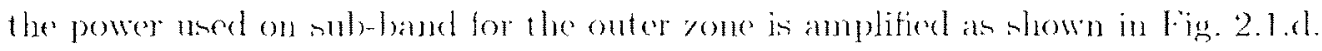

In [15]. the FFR is imestigated in the contrxt of WINNER system for various power control and wherluling wenarres. Benides interference avodances throngh partitioning and power contus several scheduling appondes have been considered that priositize the allo-

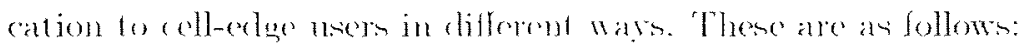

- Cell-edge ULis are cherduled first, hence. it can take sub-chammels from cell-rentre band

- Coll-crlge Utes an ouly use coll-edge band

- Cell-fedge LE are scheduled en enll relge band. however. if they recpuire more they take from coll-centre band

The reuse of 3 has been emplored for the celledge band. Two cases have been considered. In one cast. a full-power inolation (defined FFla Fil) has been considered. whese cells are not. permitted to use the cell-edge hand of neighbors. In the other case. cells are allowed these bands but only with reduced power (partial power isolation. FFR PI). For FFR PI scheme,

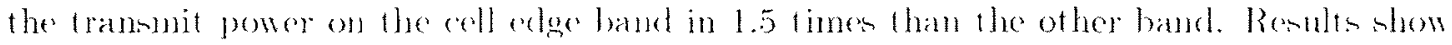
that FFR PI dow not bring signific ant benefit to the cell-edge thonghput while kexping

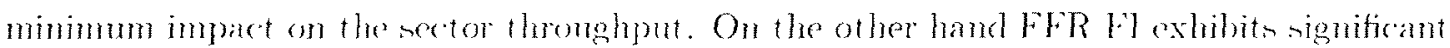
gain in coll-eelge throughput (15.5\%). howeres. with a significant reduction (up to $15 \%$ ) in sector throughput.

\section{Inverted Reuse (IR) Scheme}

The so called inverted reuse scheme was proposed within the 3GPP framewonk for the UNTS Terentrial Radio Accens Network (UTRAN) downlink in [43]. and analyzed in [44] 


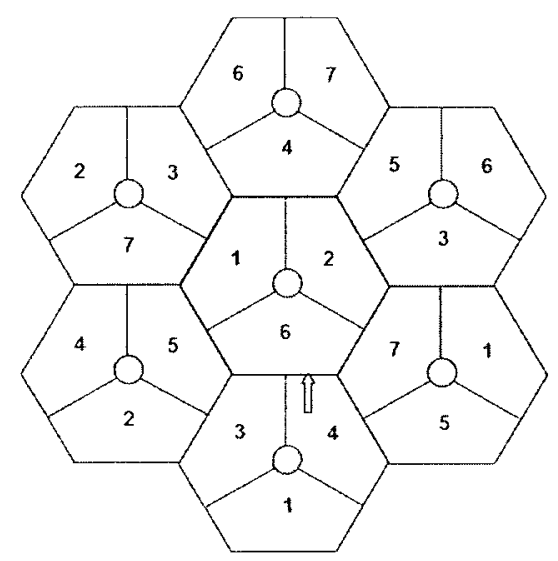

Figure 2.3: huverted rouse scheme with at reune of $7 / 6$.

and [45]. The hasie wea of this sheme wan 10 divide cach sector into zones and ardiable frecheney baudwidth into different frecueney pattems. For each cell some frecuency patterm coukt only be used with a redned power. This scheme is very similar to SFR in that the whole frequency band an be used in each sector. Two ponsibilities were diecunsed. where one required network power planing and the other did not. The number of nubsets the frequency band partitioned to was $T$ or 9.

Figure 2.3 shows the basic concept of this scheme for a reuse factor of $7 / 6$. Here. available frequency band is partitioned into 7 sub-hands. In sector $n$, the $n^{\text {th }}$ sub-band can only be need with rechuced power. A IVE moving from a sector to the direction of another will be

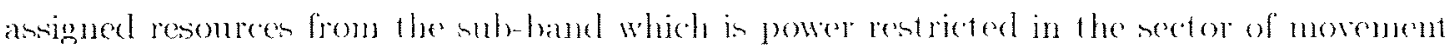
direction. For example. as shown by the arrou in the figure. a le currenty serred by sector tin botton cell in mering toward sector 6 of the cell. In this case. thes user will be allecated resources from sub-band 6. As this sub-band is used in sector 6 with reduced power, this cell-edge user in sector 4 will experience reduced interference power from neighboring sector 6. 


\subsubsection{Comparison Among Partition-based Schemes}

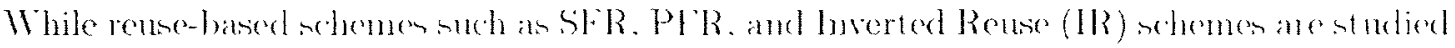
extensively within the 3C.PP L.TE project. much of the initiative was in an arl-hoc manner:

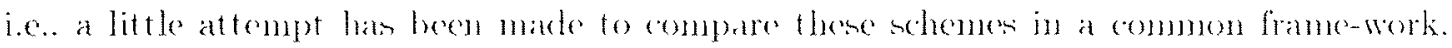
Also, as static coordination schemes show little to no significant gain in perfommanee [16].

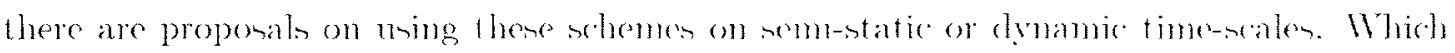
means, the partition of fiequency and/or allocation of power should be aclapted based on traffic load and/or user terminals data rate requirements.

In [40], a semi-static SFR scheme is evaluated against static SFR. In the scmi-static

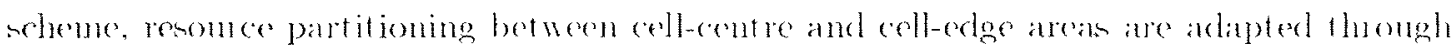
semi-static network coordination in cesperation with the Radio Network Controllere (RNC) ronsidering the traffic loat and dala mate requirements of LEs near the edge of each eell. The simulation result in terms of the total. cell interior. and cell-edge throughput are compared with those for the static SFR. Where cell-edge partitioning is $1 / 3$ of the arailable resources. Simulation show that the cell-edge thronghput in the semi-static SFR is 10 to $50 \%$ higher compared to the static SFR while the cell throughput is marginally better.

Instead of using a fixed power profile in SFR, a dynamically changing power profile has been studied in [-17]. The ('Es are arouped into high-Signal-to-Noiso Ratio (SNR) and odlalge terminals. This categoriration in dome based on the observation of long tom (hammet

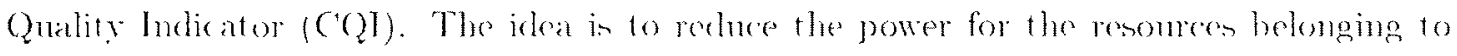
high-SNR UEs dynamically to obtain a dynamic frequency-power pattern. The algorithm works in followi:

- perform frequency-domain scheduling and initial link adaptation

- for each high-SNR LE. reduce power on a subset of scheduled UL based on a certain criteria. for example. Bit-Error Rate (BER) 
- redistribute saved power acrose renounces belonging to the cell-edge lite

- estimate interference and chamel gualits of the cell-extge l'E

- update link arlaptation and nen rate for the cell-edge l'En

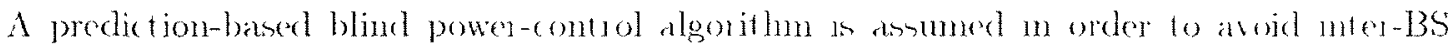

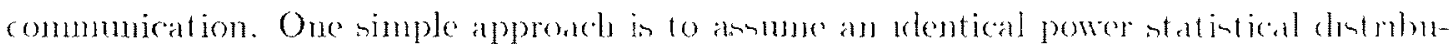

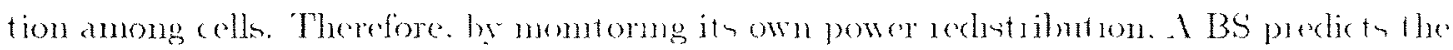
interference distribution and adjust the CQI values for UEs by moniton ing its on n power redistribution (assuming identical tatintical power distribution in the cell). An rn example. an exponential-window average of powe allocations is suggented to be used to whate the

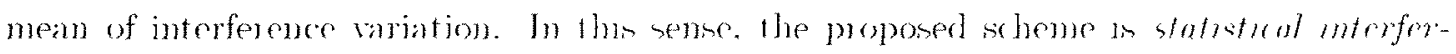

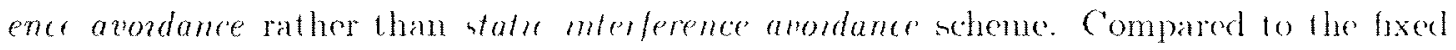
power profile adaptive power profile (power control) providen no lons to $2 \%$ gain in swatem throughput while improving the cell-fige thronghput by 1.5 to $25 \%$.

SFR and PFR have been compand in termm of theoretical capacity as woll an simmlations for cell-edge and sector throughput in [48]. It has been shown that SFR is a better cancliclate than the PFR to enhance cell-edge performance without sacrificing the sector throughput.

\subsubsection{Interference Avoidance by Fast Cell Selection}

In [49]. interference aroidance through the use of fint coll selection is imentignted the idea is that each cell-celge LE monitors th interferess as possible candiclaten for a tuture handover. By switching to a BS frem where it receives the stomgent interferemes. it not only avoids interference but also ensures a strong link for future services. A UE preparen a set of active BSs though measurement to which it can potentially switch to according to certain ritera. for example. instantaneous SINR or achievable rate. The terminal then reguests for admission to eade of the these cells in the artive cell. If the cell cammot afford 


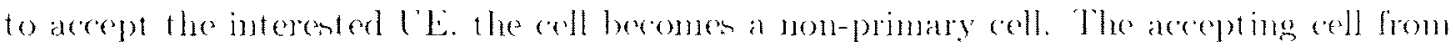
the active cells is termed as the primary cell to which a hanclover taken place. Sote that

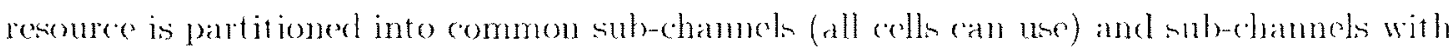
restriction determined during artive set preparations. The sub-channeds in the latter group (au be restricted at the non-primary colls. Rents atre compared with these for comentional handorer with and without interference aroidance. and are shown to be better in terms of achiowed spectral efficioncy.

A similar sturly is investigated in [50]. where the optimal inter-and intra-cell association is discussed considering the network loal and inter-cell interference. The PFR has been used

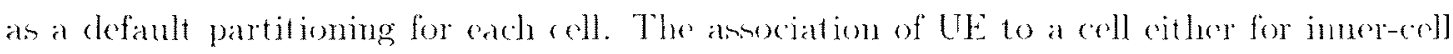
or for onter-eell resoures ane detemined thromgh a network-wide utility maximization problem.

\subsubsection{Dynamic Inter-Cell Interference Coordination}

Most available proposals on FFR rely on stativ or semi-static coordination among BSs; it is seen in the literature that FFR schemes that use interference coordination in a static or semi-static manner do not provide much overall gain as cell-edge throughput can only be improved with a significant penalty to the sfstem throughput [1.0]. This is due to the fact that static resoure partitioning and/or powed allowation on a harger time acale in mable to exploit channel dynamism. An optimal partitioning depends on the distribution of the UEs. arrived traffic. and chamel dymamism. Therefore. my static rense partitioning solheme would be a highly sub-optimal solution. A dymamie partitioning based on CE traffic loat an well as mutual interference situation may provide balanced improvements for both the celledge and cell-centre UEs' rates. Such a dynamic reuse adaptation requires dynamic inter-cell coordination. In addition. seleness recuiring freguency plamming cammot be applied to the cmerging fento-cellular networks [51]. an fento-cells will be placed at the end user locations 


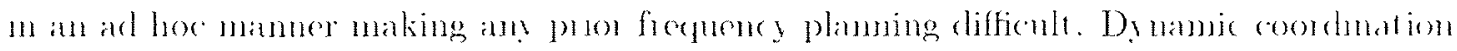
schemes. on the other hand. do not recume prior frecunency plamming and openate baned on dynamic interforese information from sumomding tamsmitters. Thenefore. dyume

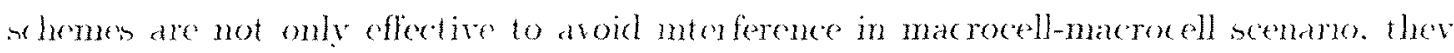
are capable of handling interference from macrocells if applied to fentocell or pucocell IBSs. There ane a few studien in the literatue that adelyes interference avoidanee betwern macesand fentocell deploy ments [52 51$]$.

Dynamic inter-cell coordination based schemes can best exploit chanuel dynamism to achieve maximum interference avoidance gain: however, only a fow such studies can be

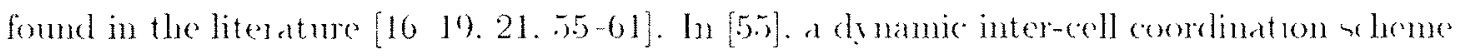
in studied $n$ a simplistic scenario and asmumptions. Where scheme dhoosen a reuse pattern from four defined patterns with varying degrees of partitioning (e.g.. reuse of 1 to reuse of 3). The dynama FFR scheme. studied in [56], partitions resomece dynamically into super-group and regular-group which are allocated to cells and sectors. respectively. The sheme achieves highen svotem throughput. however. the cell-edge performaner clegrades an compared to a static FFR scheme.

In $[17,18]$, a 2-level algorithm has been used to formulate the interference coortination problem. Each sector applien the sector-level algerithen to find a lists of sesource mute to the restrieted in the surounding dominant interfering rectors as the form of recuests $A$ central optimal algorithm. that maximizes the uthet for restrictons. at a entral controllen han been ned 10 process all recuosti from all involved sectors. A distributed dy namic interference coomlination scheme in the context of LTL system is studied in [2]]. Here. interferme has heen categorized into intra- and inter-eNB interference. Different treatments have been applied to intra- and inter-eNB inter-cell mterference. As the central processing is not encouraged in LTE systom due to its flat network arehitecture. inter-cell coos dination for inter-eNB interference has been pelformed over X2 interface (eNB to eNB) [1] through 
negotiation

A solf organiring drmamic fill scheme in stuclied in [57]. Where each sector applies selfish optumazan to reach to the Nash Equhbrum point. The algorithun in tented in a simple scenario to thow the puof of concept. The basic idea of the algorithm is that

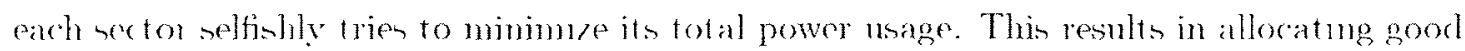
sub-bands to cell-edge users with higher powet. thereby making these sub-band poor to

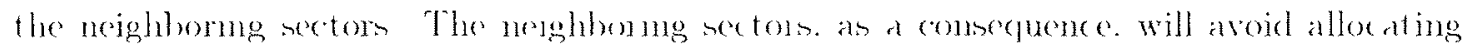
these sul-bands to their coll-edge users: allocation of these sub-bands to their cell-contur usels with possibly lower power makes these sulb-bands even better for the former sector. The algonthm works iteratively and sottes 10 an equilibrium. This algon ithm mminizes sector transmit powers.

Interference coordination in studied using interforence graph approach in [58] and |.59]. Interference graph is created in [58] based on a predefined SINR. For each node, interfering signak are removed starting from the highent interference unt the SINR is ahove a defined throhold. The interfering nodes that are removed in thin process are said to be comnected with the node of interest in the interference graph. Resources are allocated in such a way that connected nodes are given orthogonal resource units. The Tabu Search algorithm is uscet in the gaph coloning approdeh in order to allocate renources. In the graph theoretic

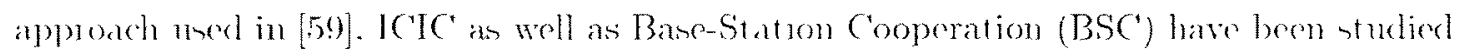
The latter is defined as a system architertue. where same data is temsmitted from muliple base stations to a partienlar noer on a same time-frecpency resource mit.

A joint pattern-bared inter-coll interference management and user scheduling schene. suited for time-division multiple acceso (TDMA) systems. has been investigated in [60]. where a pattern determines whether a particular base station should be turned off at a particular time. Interference coordnation using power control has been studied in [61]. where power adaptation is performed in an iteration manner by cxchanging information 
mong neightom base stations

\subsection{Multi-Cell OFDMA Resource Allocation using Optimiza- tion Framework}

A lage mumber of arailable literature on sesonre allocation in OFDNA concentrate pri-

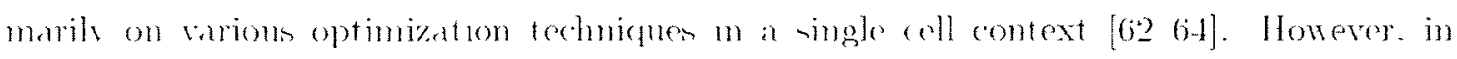
designung practical networks, optimization should be performed in a multi-cell em ironment takmg into accomit one of the most mportant performance lmiting factors. inter-cell $2 n$ terferene To the authors howledge. resource optimiation in a multi-cell enveromment han mot yet beon imestigated well and only a fen reseanch norke on multi-cell allocation (an be found in the literatue [59.65-67].

In [65]. a Linear Programming (LP) formulation is proposed. where sub-chamels are partitioned and assigned fixed 1ense factors suele that LEs at the (ell-edge (an only use subchamnels with higher rense factors. The scheme based on non-lnear integer programming. presented in [66] is interesting from an optimization point, where algorithms residing at the $\mathrm{BNC}$ and $\mathrm{BS}$ s aim to optimize the total network throughput. However, since the UEs' rate reguirements are not comsidered in the formulation. the sebeme is expected to fasor lies

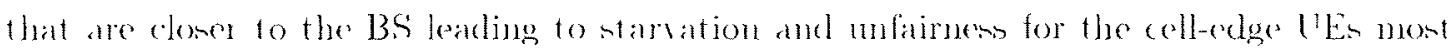
alfertal by interforence

An optmization study that provides optmal resource division between the cell-centre and coll-edge users as well as the optimal distance fiom the BS beyond which unet ane defined as cell-edge users has been investigated in [68]. It has been shown that the boundary on cell-centre region is $0.63 \mathrm{Km}$ away from the BS for a coll radius of $1 \mathrm{Km}$. For the total of 50 resource blocks (in LTE context). the optimal division is as follows: 32 for the cell-centre and 18 for the cell-edge users. 


\subsection{Resource Scheduling Algorithms}

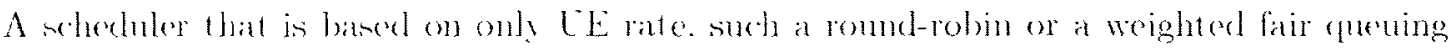
(TIFQ) [34] would be able to provide a good lowel faimen but woukd result in poor system thomghput. On the other hand. an opportunistie scheduler. such as a maximum SINR setheduler. wondd mliane the cell throughput. hemerer. would sererely penalize LEs with poor chamnel cuality resulting a pose level of famesh. Radio resources can be utilized efficiently by using scheduler that takes into account both channel variations and users" achieved data-rate. A comprehensive overview of wireless scheduling along with comparison can be found in [69]. In this thesis, two different scherhling algorithms are used, namely, Hunganian ${ }^{2}$ s(heduler [9](aho known as kilm-Mhukres algorithm) and proportional fair shednler [70. 71]. These chammel- and faimessi- aware schedulers are elaborated an follows.

\subsubsection{Hungarian Scheduler}

Hungarian scheduler is optimal for one-to-one resource allocation: it has heen used in wireless communications in a number of studies $[64,7274]$. Hungarian method solves a typical assignment problen as follows:

menumze

$$
\sum_{i t} \sum_{i} r_{\mu \ldots} a_{1,:}:
$$

subjert lo

$$
\begin{aligned}
& \sum_{y} a_{y, z}=1 . \\
& \sum_{z} a_{y, z}=1 . \\
& a_{y, z}=0 \text { or } 1
\end{aligned}
$$

\footnotetext{
${ }^{2}$ II II Kuhn proposed the Hungarian algorithm an "9]. The work in based on two Hungarian mathematicians. D. König and E Egervary. and therefore. nelmed an Humgaman to aknowledge then contributions.
} 


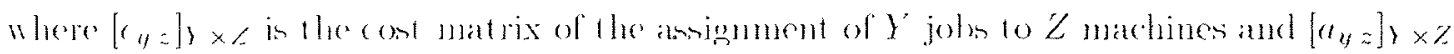
in the assigmment matrix Vote that the above minimistion fonmulation ran be comverted

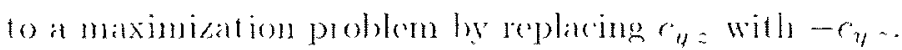

The Hungarian algorithm work for both balamerd $(Y=Z)$ or mbalanced $(Y \neq Z)$

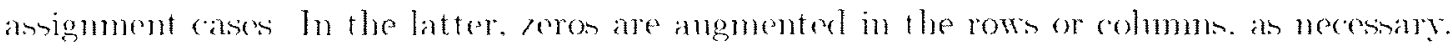

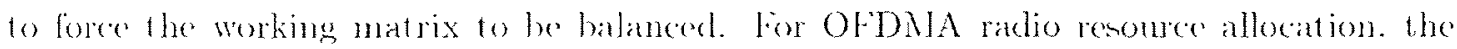

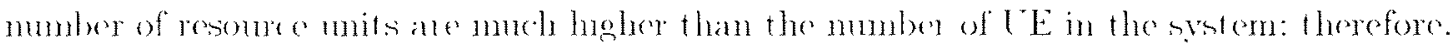
the utility matrix (negative of cost matrix) is unbalanced. lterative Hungarian algorithm works in a repetitive mamner. where in rach iteration each IE is assigned one rosource unit and the process repeats mutil all resoureson are exhanked.

An example of a halaned $\left(Y^{\circ}=Z=4\right)$ Hunganian asigmment is given as follows. Let us consuler a cost matrix als

$$
C_{1 \times 1}=\left(\begin{array}{cccc}
1+ & 5 & 8 & 7 \\
2 & 12 & 6 & 5 \\
7 & 8 & 3 & 9 \\
2 & 4 & 6 & 10
\end{array}\right) .
$$

The stope of the Homgarian algorithm can be descriled as follows.

- Siej 1: Find the minimm value in each row of he cost matrix:

$$
\begin{aligned}
& \text { RIT mm } \\
& 5 \\
& 3 \\
& 2
\end{aligned} \quad\left(\begin{array}{cccc}
14 & 5 & 8 & 7 \\
2 & 12 & 6 & 5 \\
7 & 8 & 3 & 9 \\
2 & 4 & 6 & 10
\end{array}\right) .
$$




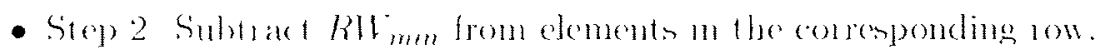

$$
\left(\begin{array}{llll}
9 & 0 & 3 & 2 \\
0 & 10 & 1 & 3 \\
4 & 5 & 0 & 6 \\
0 & 2 & 4 & 8
\end{array}\right) .
$$

- Step 3: Find the mummm value me each columm of the above modified matrax

$$
\begin{aligned}
& C L_{m m} \quad 0 \quad 0 \quad 0 \quad 2 \\
& \left(\begin{array}{cccc}
9 & 0 & 3 & 2 \\
0 & 10 & 1 & 3 \\
4 & 5 & 0 & 6 \\
0 & 2 & 4 & 8
\end{array}\right)
\end{aligned}
$$

- Step 1. Subtract CLmm from elements in the comesponding columm:

$$
\left(\begin{array}{cccc}
0 & 0 & 3 & 0 \\
0 & 10 & 4 & 1 \\
4 & 5 & 0 & 1 \\
0 & 2 & 1 & 0
\end{array}\right) .
$$

- Step 5: Lae the muimmun munher of lines to cover all the zeros in the mat rix:

$$
\left(\begin{array}{cccc}
4 & 0 & 3 & 0 \\
0 & 10 & 4 & 1 \\
-4 & 5 & 0 & 4 \\
9 & 2 & 4 & 6
\end{array}\right) .
$$




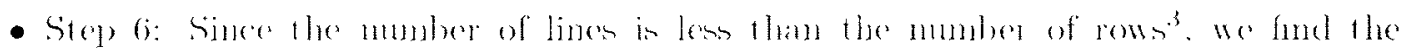
minimum value of mowered mmbers whe he 1 for thin example. Me subtract 1 from erery menesered smmber and add 1 to every number covered with two lines and the nordified matrix brecomm

$$
\left(\begin{array}{cccc}
10 & 0 & 3 & 0 \\
0 & 9 & 3 & 0 \\
5 & 5 & 0 & 1 \\
0 & 1 & 3 & 3
\end{array}\right) .
$$

- Step T: Use the ninimum number of lines to cover all the zeros in the matrix again:

$$
\left(\begin{array}{cccc}
-10 & 0 & 3 & -4 \\
0 & 9 & 3 & \phi \\
7 & 5 & 0 \\
\phi & 1 & 3 & \phi
\end{array}\right)
$$

- Step 8: In the above. the number of lines to cover all the zeros is equal to the number of rows. Therefore. the aswignment ('an be determined by inspecting the rows as follows. An assignment can be made uniquely when there is only one zero in a row. For exarnple. the third job to the third inachine and the fourth joly to the first machine. Correnponding rown and columm cau be marked an follows:

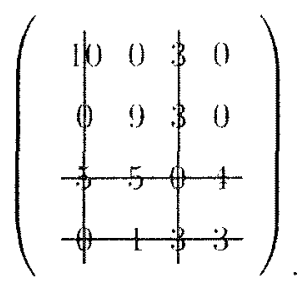

Inspecting the unassigned rows. it is seen that the second job can be assigned to the the mathine leaving the first joh for the second machine. Therefore. the complete

\footnotetext{
'(ie) to Step 8 if the number of lines to cover all zaros is expal to the number of rown.
} 
assigmuent wall be $a_{1.2}=1 . a_{2.1}=1 . a ; 3=1$. and $a_{11}=1$. an follows:

$$
\left(\begin{array}{cccc}
10 & 0 & 3 & 0 \\
0 & 9 & 3 & 0 \\
5 & 5 & 0 & 1 \\
0 & 1 & 3 & 3
\end{array}\right) .
$$

\subsubsection{Proportional Fair Scheduler}

The proportional fair schechuer (PFS) was first presented in the context of code-division

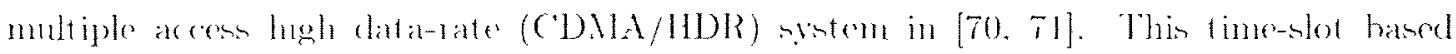
scheduling. in it original form in not directly applicable to OFI) MA mistem as radio res-

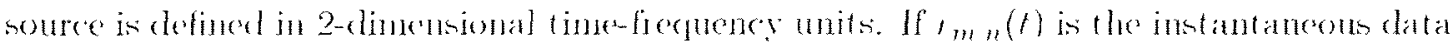
rate for user $m$ and resoure unit $n$ at time $t$. Hhen user $m$ will be given trammission opportumity besed on the following:

$$
\underset{m}{\operatorname{argmax}}=\frac{r_{m, n}(t)}{T_{m}(t)}
$$

where $T_{m}(1)$ is the filtred average throughput for uner $m$ (alculated over a time-window of 1. This average thomghput is updated after eath scheduling interval an follows:

$$
T_{m}(t+1)= \begin{cases}\left(1-\frac{1}{t_{1}}\right) T_{m}(t)+\frac{1}{t_{1}} h_{m}(t) . & \text { if uner } m \text { is assigned resoures in time } t: \\ \left(1-\frac{1}{t_{c}}\right) T_{m}(1) . & \text { if user } m \text { is not ansigned resourees. }\end{cases}
$$

Here, $R_{m}(t)=\sum r_{m}(t)$ for all resonces that are assigned to user $m$ at time $t$. Clearly, time window size $t_{c}$ has a prominent effect on the trade-off between system throughput and user fainess. and it is the dremining fartor for the time-scale of the desired famess which in application -perific. 


\subsection{Summary}

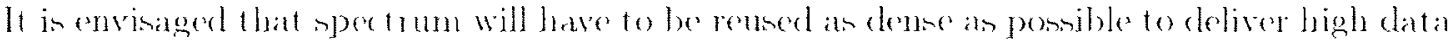

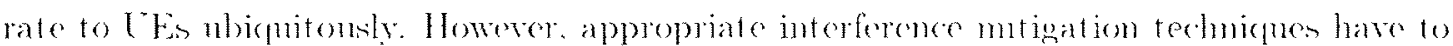

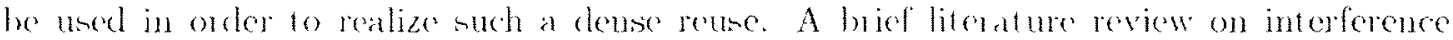
coordination studies. for OFDXMA systems arailable in the litemature and standardization communtios. in proviled in thin chapter.

Nost of the proposed schemes use static resource partitioning and/or power allocation to improve coll-erlge UE data rates. However. these schemes cost orerall sector throughput dhe to partitioning. A dynamic seheme can exploit dhannel dyuamism as well as traffic

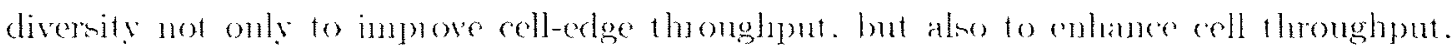
Howerer. the benefit of such drmanic adaptation comes with the cost of overhead signaling and computational complexity. Cument literature does not pay much attention to this overhead and benetit trarle-oll. 


\section{Chapter 3}

\section{A General Optimization Framework for Interference Coordination}

\subsection{Introduction}

A general optimization framework for a sum-utility optimization formulation for dynamic interference coordination problem and its suboptimal solutions are deseribed briefly in this chapter. These sub-optimal approaches are based on different assumpt ions repententing different system configurations. complexities. and interference avoilanes gains. which emerge from the common optimization framenork.

\subsection{Common Optimization Framework}

Let us consider a network layout which consists of 19 cell-sites as shown in Fjg. 3.1. In this lavout, each BS has 3 hexagonal sectors ench of which is ecpuipped with $120^{\circ}$ elirec- 


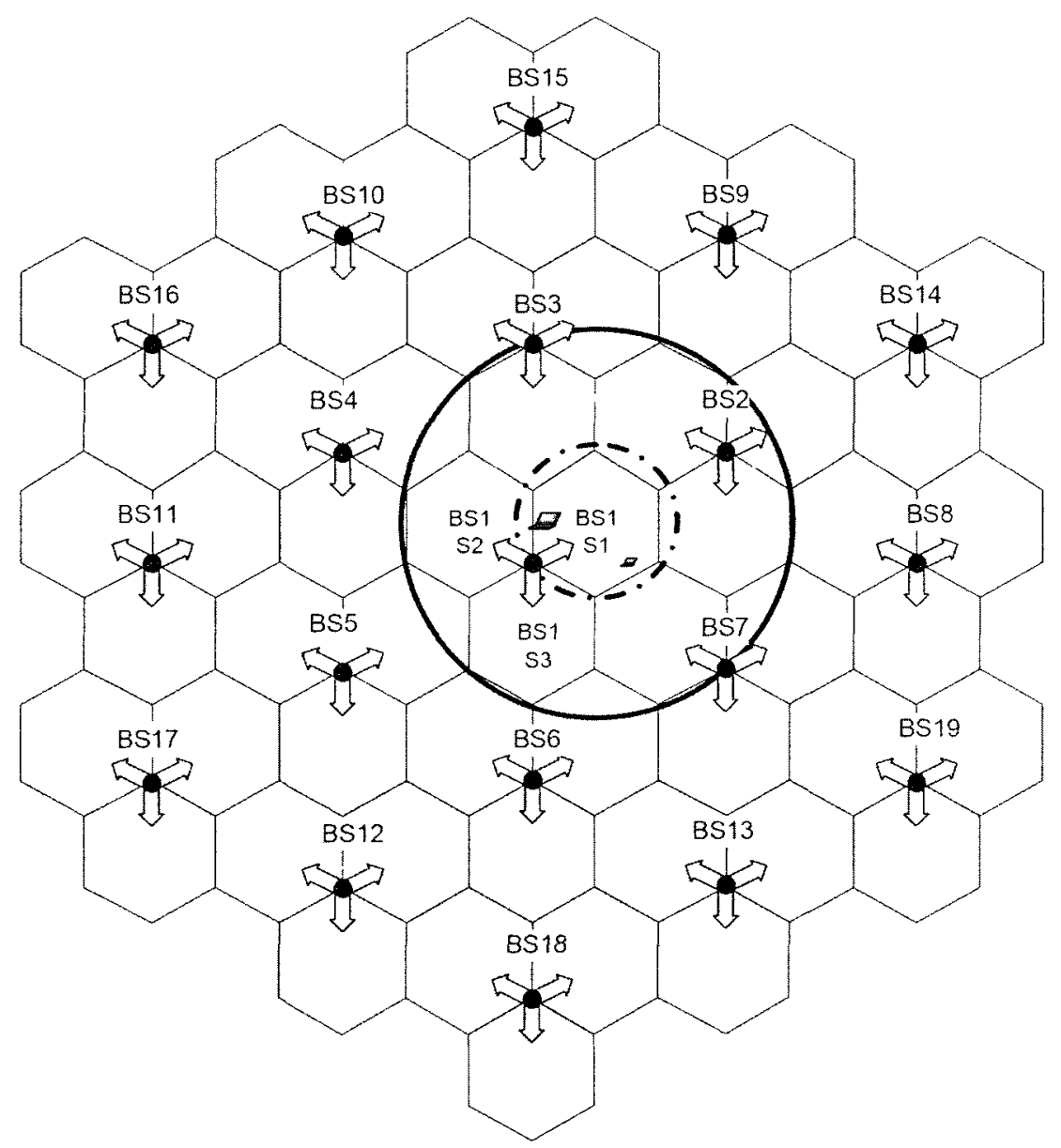

Figure 3.3: Network layout consisting of 3-sector cell sites.

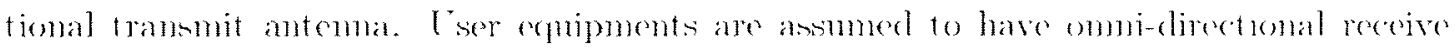

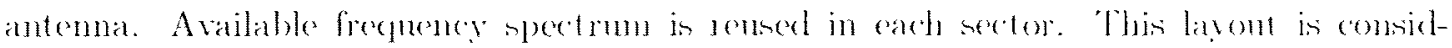
ored in bascline simulations for performance exaluation in the standardization activitios in beyond $3 G$ systens such as in LTE [33] and LTE-A [75] from 3GPP. and 802.16j/m [76] standards from Institute of Electrical and Electronics Engineers (IEEE), and form activities in WINNER [77]. Only downlink interference coordination in this high interference condition, where each sector transmitter is a potential interferer to UEs in other sector. is considered. The smm-ulility maximization problem. in which utility is a function of usere 
throughput and taimens. (aul be exprested in follows:

maxmize

$$
\sum_{i}\left[\sum_{m=1}^{M} \sum_{n=1}^{\lambda} u_{1}^{(m, n)} \rho_{i}^{(m . n)}\right] .
$$

subjert to

$$
\rho_{r}^{(m . n)} \in\{0.1\} ; \forall m \text { and } \forall n
$$

where ${ }^{(m, n)}$ is the achicrable utility of remource ${ }^{2}{ }^{1} n$ for user $m$ in secton 2 . Which only adds up in (3.1) if $f_{\imath}^{(m . n)}=1$, is expressed in (3.2) implying sector $z$ assigns resulurce $n$ to user $m$. Parameters $M$ and $N$ denote the number of usern in each sector and the mumber of available resoure units. respertively. Comstraints in (3.2) inclicales that the problem is of a binary integer trype.

If all available resourcesis are potentially used in all seetors. i.e. reuse of 1 (also callect universal rense), high mutual interferene will likely degrade the performance of edl-erge users that are not only prone to high inter-cell interference but also to high distance dependent attenuations in the clesired links. If the utility dopend only on user rate. i.e. $u_{\imath}^{(m, n)}=f\left(r_{i}^{(m, n)}\right)$, where $r_{i}^{(m, n)}$ is the achieved rate on resource $n$ when allocater to user $m$ in sector $i$, the optimization formulation expressed by (3.1)-(3.2) results in rate maximization problem. This rate maximization is only meaningful for clatic traffic [78]. Resource allocation schemes often have to balance bet ween two competing oljectives- sytem thronghput and uner faimesn [79, 80)]. However. sehechling alome may not be sufficient to boost the cell-erder performance or efficient from the system perfomance point of view. For example. a blunt approach conld be to allocate a large mumber of renoure units to each cell-edge user in order to enhance their throughput, which can only be possible with the cost of system throughput as the cell centre UE will be deprived from resources: thus this approach will be highly inefficient. Interference coordination. on the other hand. can

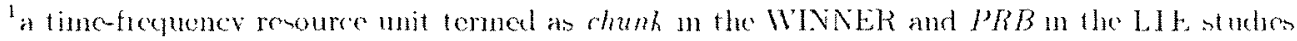




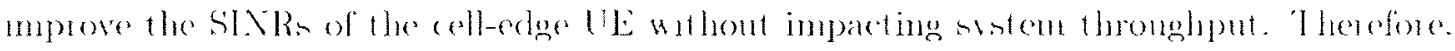
interference coosdination in the fom of resource iestrietion has been artopted an one of the key featum in the future aeneration system.

In the presented solutions in this thesin. do clescribed in detail in the subsecuent a hapters. scheduling constraints have been combielered: therefore, solutions do not aim to maxmise netwolk throughput Rather. green some seheduling criteria. the proponed schemes dim to

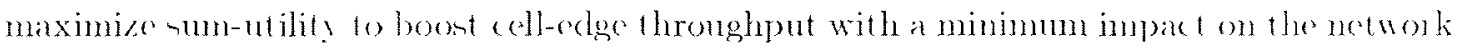
thronghput. It should he not ed that all proposed schemes and their corresponding reference schemes use the same schedulung principle and constraints. Therefore, ohscrual porfor mauce

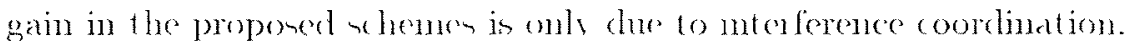

The interterence coordination prohlem is formulated with the following constant to the abore problen.

$$
I_{r}^{(n)}=\sum_{m=1}^{M} \rho_{l}^{(m, n)}= \begin{cases}0: & \text { resounce mit } n \text { is rest rieted in } \\ 1 ; & \text { other wise. }\end{cases}
$$

The binary indleator $l_{2}^{(n)}$ in constraint (3.3) indicates whether a resource unit is restricted in sector 1 or not: it also implies that if a resource unit is not rest 1 icted in 2 . it can only be assigned to one l'E. For example. $l_{i}^{(n)}=0$ expresen that resounce $n$ is restruted in sector 1. i.e. it would not be used. Note that in one proposed scheme ne asume that the resticted resoures ane uned but onl? with lower power: howeven. discumion ase limited only to the fermer cane in this chapter.

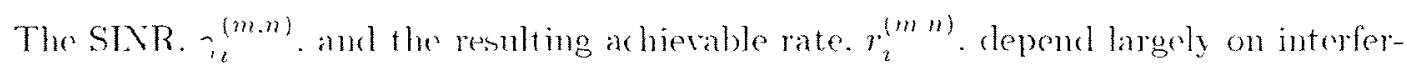
ence received from the neighboring first-tier sectors. Let us denote $\psi$ and $x$ as the indicen of the first-tier dominant and other non-dominant distant inter-cell interferers. respectively, for the LEs in sector 1. For any icsource unit $n$, resonce restriction in a sector affects the SINR seen by user $m$ in wector 2 as follow: 


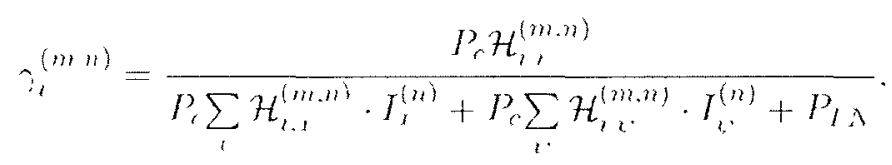

where $P_{r}$ in the transmit power applied to each resource unit derived from anual power distribution: that is, $P_{r}=P_{1} / \mathrm{X}$. Where $P_{t}$ is the total tratsmit power per sertor and $\mathrm{I}^{2}$ is the number of avaibble resources. The parameter $P_{I x}$ is the thermal noine power over

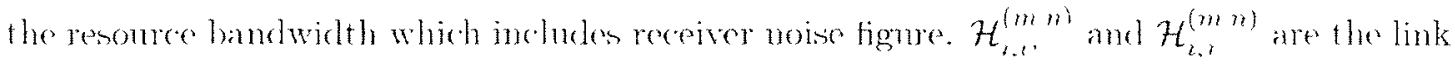
gaims to the first-tier dommant and other non-dominant interferer sectors. The parameter $\mathcal{H}$ includes large scale path-loss ${ }^{2}$. antenna gains and fading. The indicators $I_{\eta}^{(n)}=\sum_{m=1}^{M} \rho_{2}^{(m, n)}$

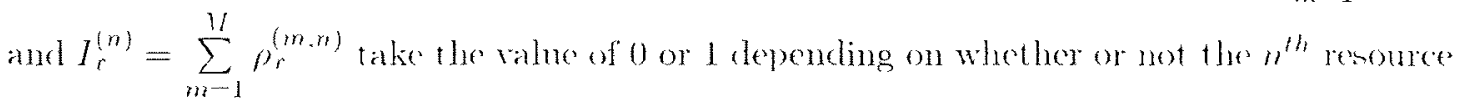
unit is restricted in the dominant secter $u$ and nom-dominant sector $x$, respectivels:

Equations (3.1) to (3.4) describe a combinatorial optimizat ion problem which is comput tationally prohibitive. To illustrate the problem size. let us consider the WINNER yistem. where there are 144 available resource mits. Now, if we consider Fig. 3.1 (i.e. 57 sectors) where ench sector has 12 users. the mumber of 3-dimensional allocation variable. denoted by $\rho$, will be close to 100.000 . An integer optimization problem of this size is difficult to solve in reasonable time. However, the second summation in the denominator of (3.4) has the dominant effect on the guality of a resource. i.e. most interference avoidance gain can be acheved by imposing restrictions on these intefferests. The forms is to apply interference coordination among a small number of mutually interfering sectors (i.e. b) with diflerent approaches as described briefly below and in later chapters in details. In other words. $\gamma^{(m . n)}$ will not be very semitive to non-dominant distant interferern and therefore. $I_{r}^{(n)}$ (an

\footnotetext{
${ }^{2}$ Distance dependent attenuation and hadowing.
} 


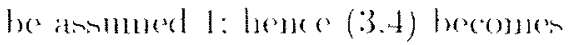

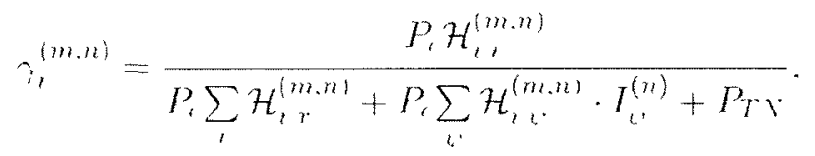

As the mumber of transmitters in the dominant interferer set is not large. it is possible to calculate a finite set of SINRs given different resouree restriction ponsibilitien in the interfering sertorn. This facilitates the use of ILP approarh to solve the coomelination problem.

The utility in (3.1) is defined as a function of rate and user demand. i.e., $u_{2}^{(m, n)}=$ $f\left(r_{r}^{(m n)} \cdot d_{1}^{(m)}\right)$. Where $d_{,}^{(m)}$ is the demand factor that indiates achieced throughput status of a $\mathrm{CE} m$. We defino $d_{1}^{(m)}$ an follows: $d_{1}^{(m)}=R_{1} /\left(R_{2}^{(m)}+\delta\right)$. where $R_{1}^{(m)}$ in the average throughput of $\mathrm{LE} m$ over a certain time-window. and $R$, is the average thronghput acrosis all IFE and is given by $\bar{R}_{z}=\left(\sum_{m=1}^{11} R_{2}^{(m)}\right) / M$. A rate deprived UE, such as one near the cell-elge. will have a higher demand factor. Therefore. the utility will provide uhantages to rate deprived LEs to boost their per fomance. The parameter $\delta$ has a small value that prevents $d_{z}^{(m)}$ from being $\infty$.

\subsection{Overview of the Sub-optimal Solutions}

Solving the optimiation problem defined through (3.1) to (3.1) globally offere a munter of (hallenges- 1) a contralized approath in necossary 2) complete syntem knowledge at the cent ral controller is recunired. 3) The resulting combinatorial integer linear problem is similar to a 3-dimensional assignment problem which is NP-complete [81] for a fairly sized prohlem. In this thesis different sub-optinal solutions are explored in order to mitigate ahove difficulties.

The fact which is ased in the proposed solutions is that only the dominant interfor- 


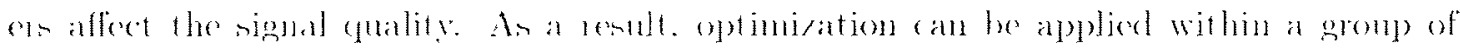
neighboring transmitters forming a dhster and thes geduces the size of the combinatorial problem significantly. However. in a rad network. the mation of interference and its interdependency propagates throughout the whole network. To illnstrate with an example. let In consider four sectors A. B. C. and $D$ : here. let ns assmme that the transmit antemus belonging to sectors $C^{\prime}$ and $D$ are dominant interferers to CEs in sector A. and antentnas in sectors $A$ and $C^{\prime}$ are dominant to theme in seretor $B$. If two chesters are formed an $\{A, C, D\}$ and $\{A, B, C\}$, it woukl be observed that sectors $A$ and $C$ are common in both clusters. Hence, optimizing each cluster imbependently may reduce the overall problem size (compared to optimizing $\{A . B . C . D\}$ in a single shot) but it may provide minleatling result unlese inter-relation among the chuners are captured in the optimization problem. In the solutions. the concept of menferer group [11.16.82] to form a chuster is used. Algorithm aims to maximize sum-ntility within a chuster honoring the intor-chuster dependencios. In partienlar. three different approaches have been investigated as follows.

\subsubsection{A Two-Level Algorithm with Partial Central Processing}

The functionalities of this algorithm resile at two different levels- sector and central. In ensence. the 3-rlimemnional (3-D) assigmment problem defined in Section 3.2 is decomposed to. 2 dimensions.

Earh sector forms a chuter taking all timatien sectors as potential clominant interferers. The sector-terel algorithm finds a set of resource units for each of its first-ticr sectors that are to be restricted from its pesseretive that hembistically maximize its the smm-ntility in a 2-dimensional sense. However, these clusters are very dependent on each other as a particular sector is a member of different clusters. Therefore, the results from cluster-wise heuristic optimization should be processod in a cent ralized mamer. However. the henristie optimization (somewhat in a selfish mamer) reduces the problem size significantly as it 
une-dimensional ansigment problem at the sector-tered itgorithm.

The Hungarian (also know as Khum-Nomkres) algorithm [9] is used at the uector-level in an iterative manner. The llungarian algorithn is a one-to-one optimal solution for an assignment problem. "hich is polymomial time solvable. Howerer. as this algorithm is used in an itontive mamer. the orerall assigmment becones rather a good -ub-optimal solution. The sector-ferel algonithm preparen jenourer pestrictions as a form of requestis from its perspective. To that ond. a contral comtwoller is used to process these restriction requests in an oplimal manner (the $3^{\text {rd }}$ climension is handled here) and produces a fimal set of resource restrictions for all sectors. Note that the problem size at the central controller Is wery tractable as it only works on restriction recpuests rather than looking into a large combinatorial optimization space. The deterils of this approach along with performance results are provided in Chapter 4.

\subsubsection{A Distributed Algorithm with Neighboring Cell Coordination}

This is a distributed algorithm where each sector finds a set of restrictions for each of its neighboring dominant sectors as in the previous approach. However, these resource restrictions are negotiated by inter-BS communications. This scheme was developed to study interference coordination problem in ITE [21]. where cental processing of RRM functionalities is not encommand due to flat notwork architerture. In LTE. neighboring BSs (eVBs) communicate with cach other uning X2 interface [83]. Furthermore. inter-e cell interference as intra-e.NB and inter-oNB interference are treated differently an eVB-e.NB commmnication is not required for int ratexB interference. The Hungarian algorithm is used for intra- and inter-eNB interference avoidance. The scheme is presented elaborately in Chapter 5. 


\subsubsection{A Centralized Approach with Clusters}

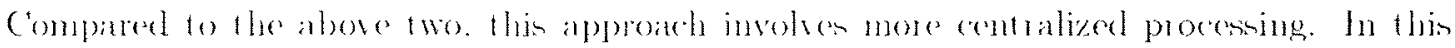
scheme. each user in crery sector finds two mont dominant interferers from the neighboring first-tier sectors with which it forms in merferer group (i.e.. choless). The ULP formulation taken dependencies mong clusters into comsideration by appropriate linfar constraints. The

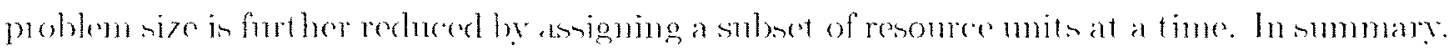
a 3-dmenswonal amignment problem is solved in this schene. however, with reduced size. A fast commercial solver is used to evaluate the performance of this approach. The icheme along with performance results is provided in Chapter 6. A similar approach in lighter

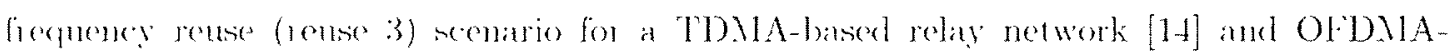
based comventional network [16] is studied ine the early phase of this thesit.

\subsection{Summary}

In this chapter, a general optimization framerven for interference coordination problem as formulated in this thesis has been described. The overview of the sub-optimal approaches to the solutions is given briefly. These approaches along with performance results are provided in the subsecuent chatpters. 


\section{Chapter 4}

\section{A Two-Level Algorithm with Partial Central Processing}

\subsection{Introduction}

In this chapter. a novel dyntmic interference dsoldance scheme is presonted which makes use of inter-cell coordination in order to prevent excessive inter-cell interference, especially for cell or sector edge users that are most afferted by inter-cell interference. with minimal or no impact on the netwolk throughput. The proposed scheme is comprised of a twolesel algorithm - one at the base satson level and the other at a cental controller to

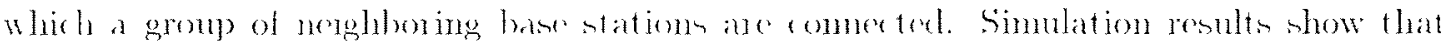

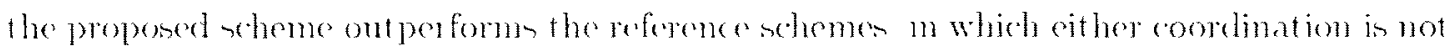

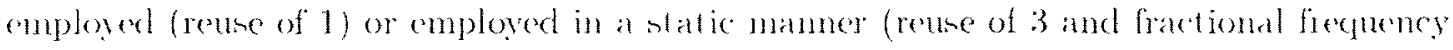
reuse). in terms of cell edge throughput with a minimal impact on the netwolk throughput and with some increase in complexity.

By using inter-cell coordination. the proposed scheme thrives to enhance throughput on allocated resonre unts connidering the throughput status of the coll odge Liser Terminal 


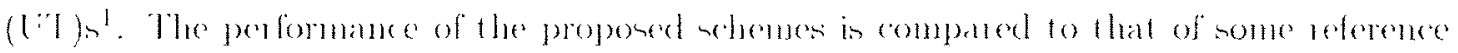
whemes. for example. remse of 1 reme of 3. and the PFR wehemes ats described in ('hapter

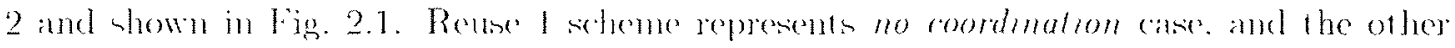
two represent statio cosolination casch.

The work presented in this rhapter is an extended version of anthor's previoun work

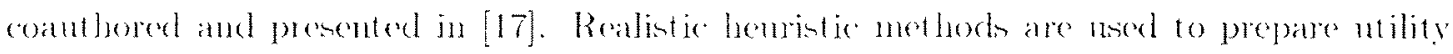

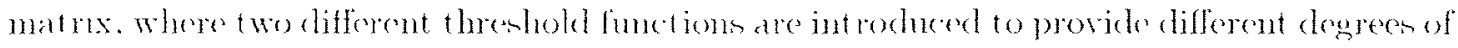
trade-off between throughput and cell-edge performance. An additional bcenario in which restricted resource units can also be used with lower tramsmit power is consiclered. In arklition to the full-buffer traftic assmetion. the algorithm is also tested with a trathe

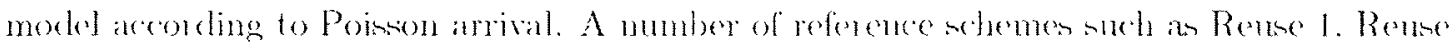
3. and PFR are incheded to which the perfomane of the proposed schemes is compared. Finally a Proportional Fair (PF) scheflner [T] along with an iterative Humgarian (IH) scheduler is used.

The remainder of this chapter is organized as follows. The system model is deseribol in Section 4.2. Details of the proposed scheme are presented in Sections 4.3-4.5. Section 4.6 describes svstem and simulation parameters. Numerical results, ohtained through extemive simulations. are disconsed in Section 1.7. A hot-spet secolatio. where seretors have

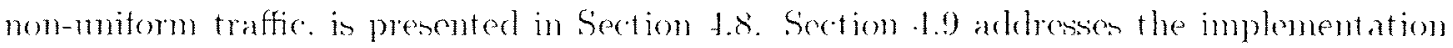

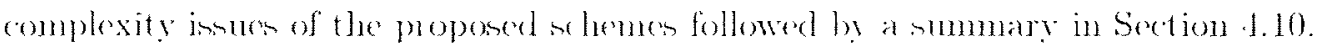

\subsection{System Model}

Let us consider a network layout with 19 BS sites each with 3 hexagonal sectors as shown in Fig. 3.1. Sectors are equipped with $120^{\circ}$ directional transmit antennas. while UTs' receive

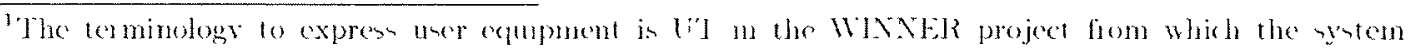
parametes are taken for this chapter.
} 


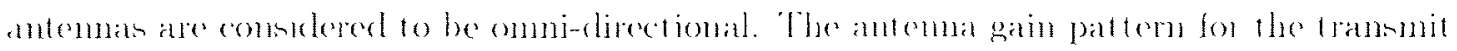

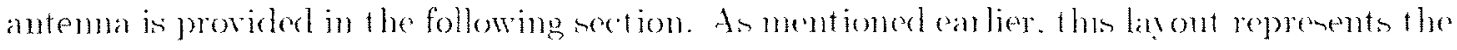

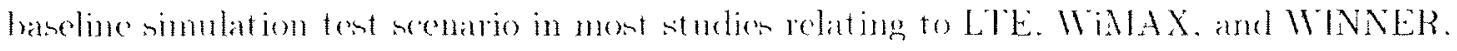

It is assumed that the system uses cell-sperifie orthogomal reference signals [1]: L'T know the reference signal of noghhoring first-tien sectom and are able to cletemine interference repantels. It is evident that for a downluk transmission to a lor in any sector. one of its

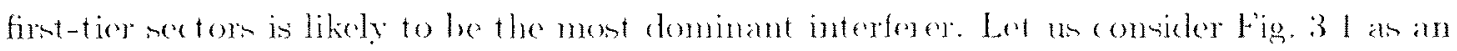
example: due to the relative locations and antenna divectivity, a cell-edge UT in sector 1 of BSI may receive the most clominant interference from sector 2 or 3 of BSI (depencling on the I"T loration). of from sector 2 or 3 of 1352 . on from sector 3 of BS3. on from sector 2 of BSi7.

\subsection{Description of the Proposed Scheme}

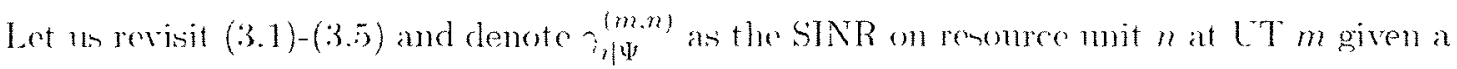
set of sorted dominant interfereis. $\Psi$. are not allowed to uhe ronourer unit $n$ (for convenicuce, the symbols used in this section and onward are listed in Table 4.1). The rector $\Psi$ is sorted by the descending order of interference powers which varies from $\Psi=\{\}$ to $\Psi=$ $\{1 \cdot 12 . \cdots .6 h\}$. reprenenting no interferer restrietion to all first-tier interforer restriction.

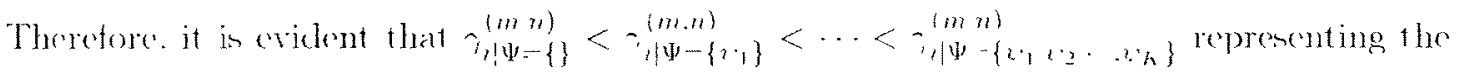

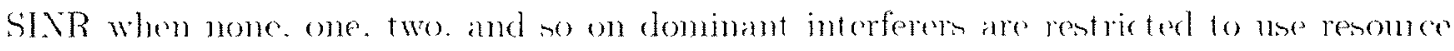
mit $n$ in their sector $(s)$. The restriction can be either in the form that restricted resouree mits are not used at all (as in (3.1)-(3.5)) or used only with redured transmit power.

For a target BER, modulation and coding scheme. the above SINRs can be mapped to achievable rates as $r_{l \mid \Psi=\{\}}^{(m, n)}<r_{l \mid \Psi=\left\{w_{1}\right\}}^{(m, n)}<\cdots<r_{, \mid \Psi=\left\{n_{1}, n_{2}, \cdots, b_{k}\right\}}^{(m, n)}$. Clearly. the minimum and maximm rates can be achieved as $\gamma_{i \mid \psi=\{\}}^{(m n)}$ and $r_{\mid \psi=\{1,2, \cdots, k}^{(m n)}$. respectively: however. the increnental gain from interferer restrietions diminishes as more and more interferem are 
Tablo 1.1: List of Symbols Lined

\begin{tabular}{|c|c|}
\hline 1 & 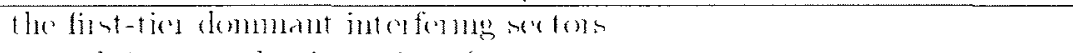 \\
\hline $1: 2$ & 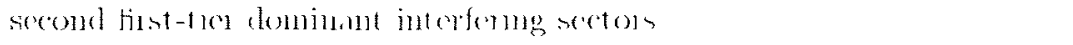 \\
\hline$m$ & IT imtrex \\
\hline$n$ & resonnce muit index \\
\hline M & numbley of U'Ts per sector \\
\hline$\lambda^{2}$ & number of ariblablo esomeremits per seetor \\
\hline$P_{l}$ & total power per seetor \\
\hline$P^{3}$ & powes per resonere muit \\
\hline$P_{l}$ & average themal noise power \\
\hline $\mathcal{H}^{(m \cdots)}$ & 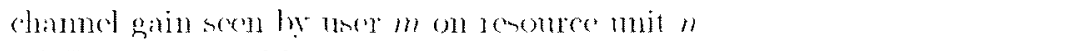 \\
\hline$\left.\eta^{(n} \quad \cdots\right)$ & 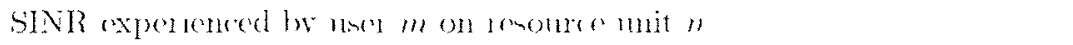 \\
\hline$r^{(m n)}$ & achievable rate on resonre nuit $n$ for user $m$ \\
\hline$\Psi$ & set of sorted dominant interferens in dencending onder that ne resticted \\
\hline$d^{(m r)}$ & UT demind factor \\
\hline$I^{(n)}$ & indicaton to show whesher resounce mit $n$ is resticted on not \\
\hline$R^{(m)}$ & time average thronghput achioved he Tre $m$ \\
\hline $\bar{R}$ & avorge thromplynt arams all $\mathrm{CT}_{\mathrm{S}}$ \\
\hline$r_{1}^{(1, \prime)}$ & $m^{H}$ UT's rate theshold \\
\hline
\end{tabular}

restricted. becanne $\Psi$ is arranged according to the descending order of interference powers.

As stated in Chapter 3. solving the interference coordination problem network-wide by (3.1) (3.1) is computationally prohibitive. Therefore. a hemistic approadh is resorted to. where each sector locally finds a set of resource units to be restricted, in the form of wish-list, in each surrounding first-tier dominant interferer sector. In other words. each sector solfinhly finds resoure mits for which it prefers $I_{?}^{(n)}=0$ for all $2 \cdot($ as in $(3.3))$. This list is prepared based on the inter-eell interforence and l'Ts clemand factoms. A utility

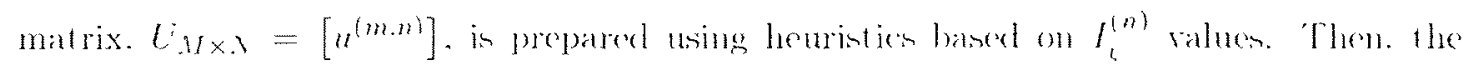

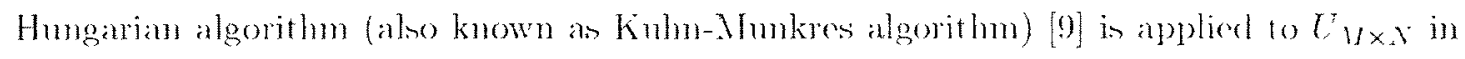
order to find Iontative resource mit-to-UT preferences and resulting restriction wish-lint. However. as every sector is a dominant interferer to UTs in some other sector's, it is likely that there will be conflicts in restriction requests. Therefore, a physical or a logical central entity is reguired to resolve the conflicting reguest optimatly. This central for localized central) cont roller can be a node functionally similar to a RNC in 3G sistems or a Nohility 


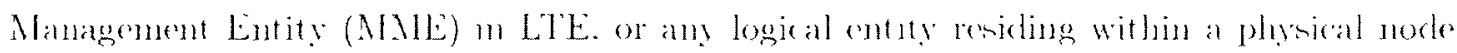
such as an eNB with recpured comectivity and procensing capability. The eNBo having central processing capahility can be strategically and sparoly placed in the corerage area. These cNBs can communicate with of her regular eNBos using $\mathrm{X} 2$ interface.

The proposed inter-cell interference coortination wheme is comprised of two separate algorithms: one is located at the BS level that prepares the penoures unit restriction repuest and the other resides at the enutral controlley that resolves restrietion reguest conflie to. The working principle of the scheme can be summarized an below:

- UTs send Channel State Information (CSI) including information on two most dominant interference received from their firttien sectom. to the sorving sector.

- Each sector prepares a utility matrix baned on the chammel states ame UTb demand factors.

- Each sector iteratively applies Hungarian algorithm to the utility matrix to find resource unit restriction recuests for each of its dominant interferer neighlors.

- Each sector forwards restriction request list to the central entity.

- The central entity processes recpuests from all involved sectors and resolve conflecting recuests baned on the ntility values in an optimal manner.

- The central contily then forwards each neetor a decided set of renonere units that ane to be restricted by its scheduler.

The list of restricted resource units remains valid over a long enongh time-period but shorter than the channel coherence time. In the following section. the effects of scheduling and dominant interference on throughput and faimess are first discussed. Then investigated algorithms are presented elaborately in the subsequent section. 


\subsection{Effects of Scheduling and Dominant Interference on Through- put and Fairness}

Sehedulug has a profound effect on the throughput and fanness that can be ardieved with a given amomit of exources. To show the effeet of scheduling on "T thenghput. Fig. \& 1 in provided. where different sheduless such do maximum SINR. omul-sobin. Herative Hun-

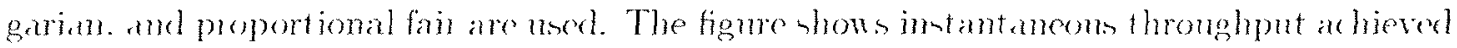
at each scheduling instant (not averaged over time cluration). For the sake of organization, the retails of the simulation parameters are deferred until Section 1.6. While maximum SINR shedulng an achiese the highest seetor throughput. it sevelels puninhes the rellalge CTs (lower tail of the CDF) Romd-robin scheduler an provide betwerestice to edge ITTs. however. it may result in poor sector thronghput. The iteratwe Hunganan and proportional fair scheduless can be seen as schemes that exhibit good complomise between

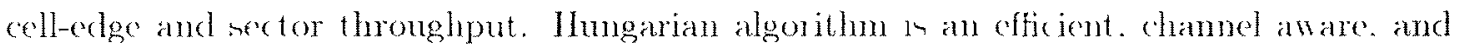
low complexity solution to integer linear programmm for one-to-one anignmont problen. However, if a UT needs multiple resource units in order for it to achieve the required rate, the iterative Hungarian method rather becomes a good sub-optimal solution. The proportional fair is also a channel aware scheduler. where sheduling prioritios are determined by the filtered avesage (IT horoughput updated oves a certain time window.

In older to have a glimpse of the effect of dominant miteferemee simmlations are ured to obsere the UT throughput in a sector with different munber of interferes restricted. Fig. 1.2 shows the CDF of $\mathrm{CT}$ theughput when none. one. two. and three dominant interferers are restricted. Here, full-buffer traffic model and iterative Humgarian scheduler have been considered. It is seen from the figure that most avoidance gain can he achieved by restricting the most dominant interferer and the gain is insignificant beyond $\Psi=\left\{a_{1}^{\prime}{ }_{1} \cdot l_{2}^{\prime}{ }_{2}\right\}$ $\left(\Psi=\left\{1^{1}, 1,2,13\right\}\right.$ and onward are not shown in the figne). The mset of Fig. 42 shows the 


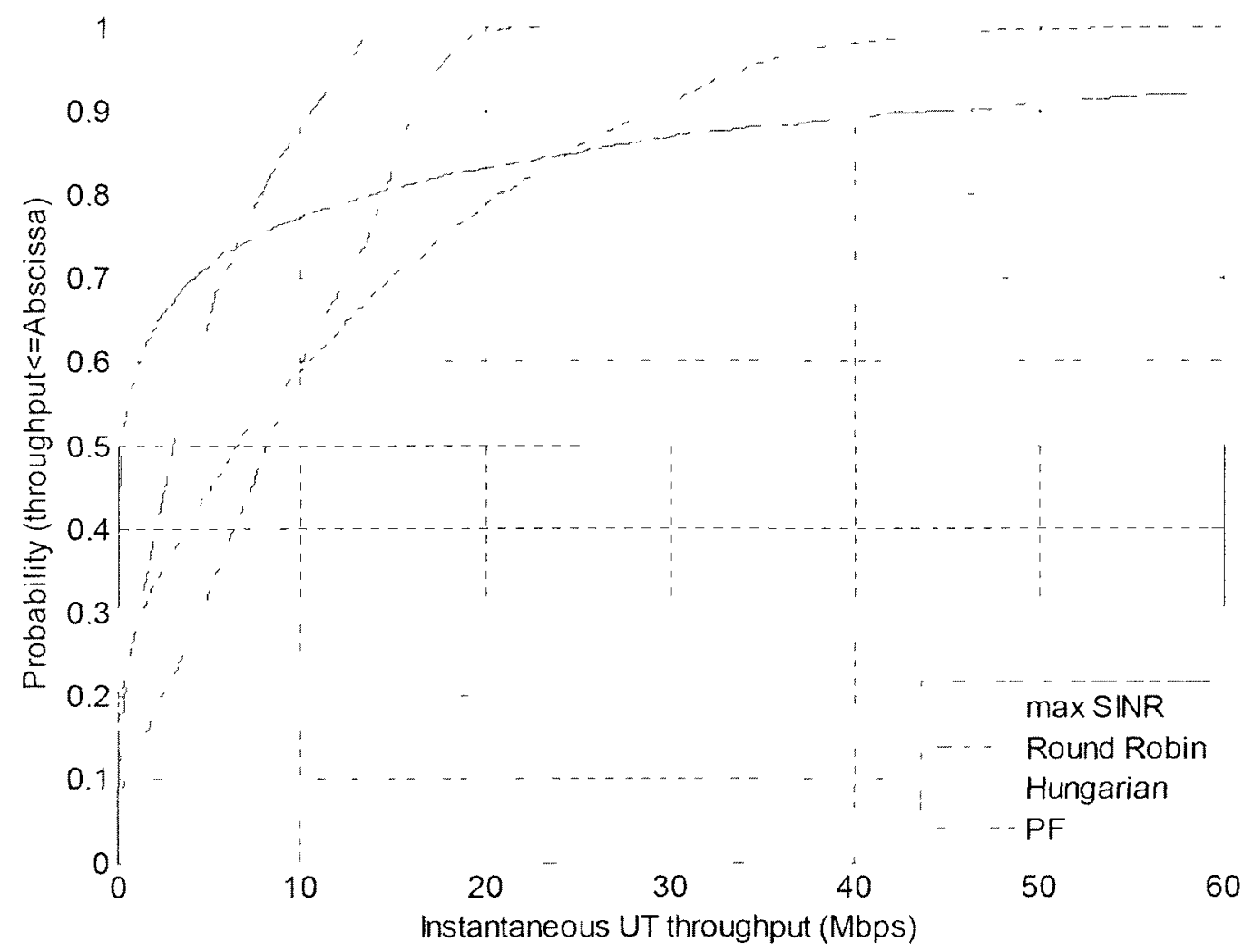

Figure 4.1: Effect of schedulers.

percentage of resource units restricted for $\Psi=\left\{w_{1}\right\}$ and $\Psi=\left\{v_{1}, v_{2}\right\}$. Note that for each resoure unit. interferess are restristed only when there is a rate gan from restrietion. For

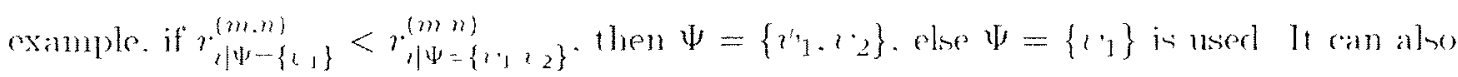
be observed fom the figme that on avelage around $12.5 \%$ and $20 \%$ of resonere muts ane to be rostruterl in each surennding sector in order to obtain the threnghput gain observed in the figure. If a sector sestrict these many renoure units in its surrounding sector. it will also receive similar resource unit restrictions on average from each of its neighbors causing a large number of resource unit restrictions in each sector and resource loss as a consequence. For simplicity. Fig. 4.2 does not comsider the resource loss due to icstrictions. Detailed results considering resoure losi are presented in Section 1.7. It is evident that in order to 


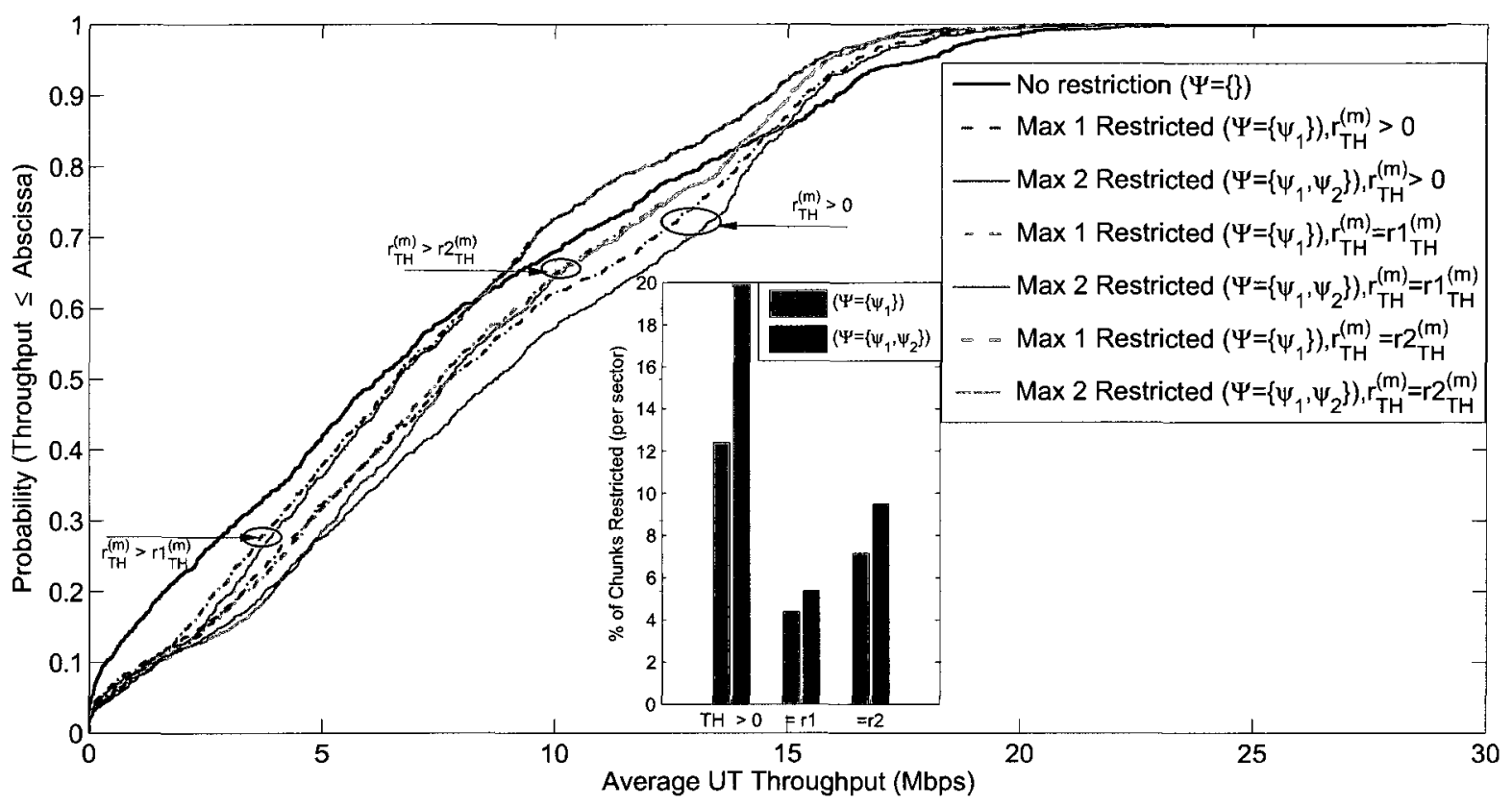

Figure 4.2: Effect of interferer restrictions.

limit the number of restrictions and hence resource loss, only justifiable restrictions should be made. To that end, two cases are presented when resource unit restrictions are made only when significant gains can be obtained considering the service of the UTs. A sector decides on restrictions based on a threshold value $r_{T H}^{(m)}$ given as follows:

$$
r 1_{T H}^{(m)}= \begin{cases}e^{\left(1-d^{(m)}\right)} ; & d^{(m)} \geq 1 \\ \infty ; & d^{(m)}<1\end{cases}
$$

and

$$
r 2_{T H}^{(m)}=e^{\left(1-d^{(m)^{2}}\right)}
$$

In (4.1) and (4.2), restrictions are made considering the UTs' current throughput status. In the former, restrictions are made only in favor of those that have received less than 


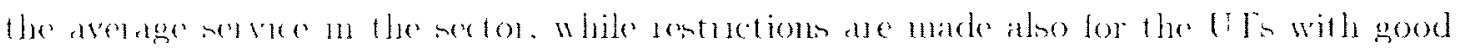
thromghput atam m the later given only when a combiclerable gain an he achieved. That

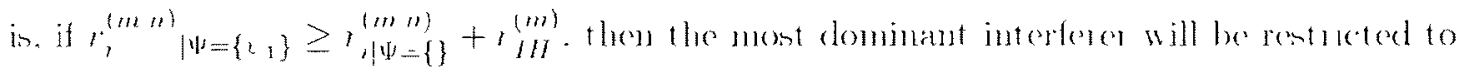

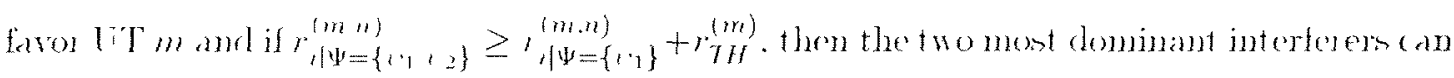
be renticted. In (1.2). the threshold function in consdered steeper moder to impone the

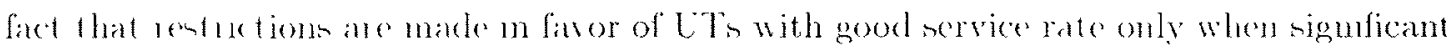

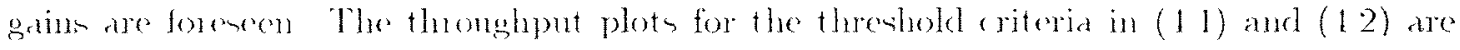
shown in Fig. 4 2. The following important observations an be drawn by analyzing Fig. 4.2 .

- Higher throughput can be achieved by restricting more and more resounce units which implicis more penaltien to noighboring sectors.

- Substantal gain can be achieved by restricting only the most dominam interferer. Attempts shomld be made to restrict only this interferes. with the exception for severely rate deprived ITs for which the two most dominant interferess can be restricted.

- The number of nentricted resouree units and performane em be tuned by choosing an appropriate gain threshold value

- The performance using the threshold function given by (4.2) is superior compared to that in (1.1) with slight increase in the mmber of rentricted fenomere unts. Both

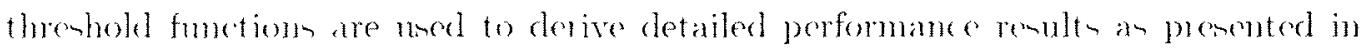
Sextion 1.7.

\subsection{Interference Avoidance Algorithms}

In this section, the sector-level and the central algorithms me described as follows. Sectorlevel algorithm prepales utility matrix and prepares renource unit restriction recpuests for each of its fint-ties interferess. The central algorithm resolves any conflicting restriction 


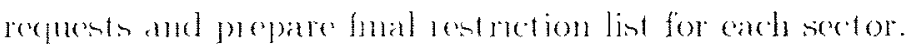

\subsubsection{Sector-Level Algorithm}

Two major functions are assoriated with the sector-level algorithm-namely. 1) preparation of a ntilit matm ung the throbold-based restrictions derived from the dhamel conditions

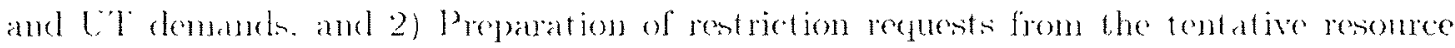

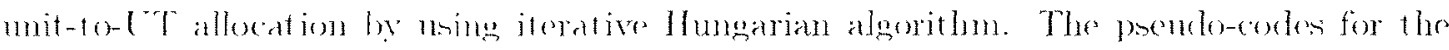
sector level algorithm are presented in 'Table 4.2 .

\section{Preparation of the Utility Matrix}

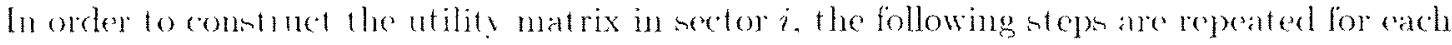
UT $m$ and each resource mit $n$.

- Dominant interfores anc sorted in desconding order of interference powers into a dominam interforer set.

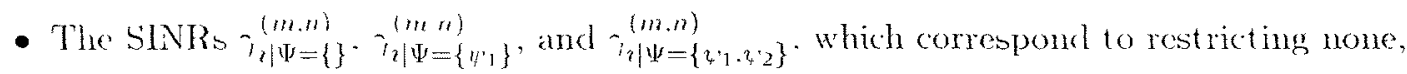
one, and two most dominant interferers, are calculated from the SINR expression in

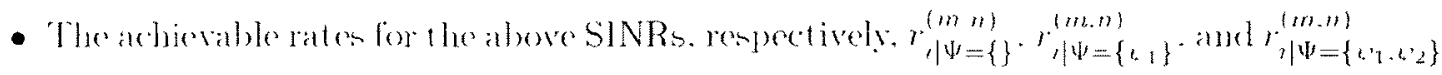
are deternined.

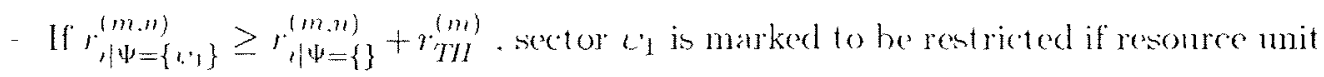
$\prime \prime$ is to be asigned to UT $m$.

- If $r_{\left.2 \mid \Psi=\left\{\imath_{1},\right\}_{2}\right\}}^{(m . n)} \geq r_{i \mid \Psi=\left\{\nu_{1}\right\}}^{(m . n)}+r_{T H}^{(m)}$. sector $\psi_{2}$ is also marked to be restricted for lesource unit $n$.

After finding the inter-cell dominant interferer(s) to be restricted on each resomer unit and anch UT, achievable rates $r_{t}^{(m, m)}$ are calculated. Vow. the utility of resouree unit $n$ for UT 
Table 12 Sector-Lenel Algerilhm

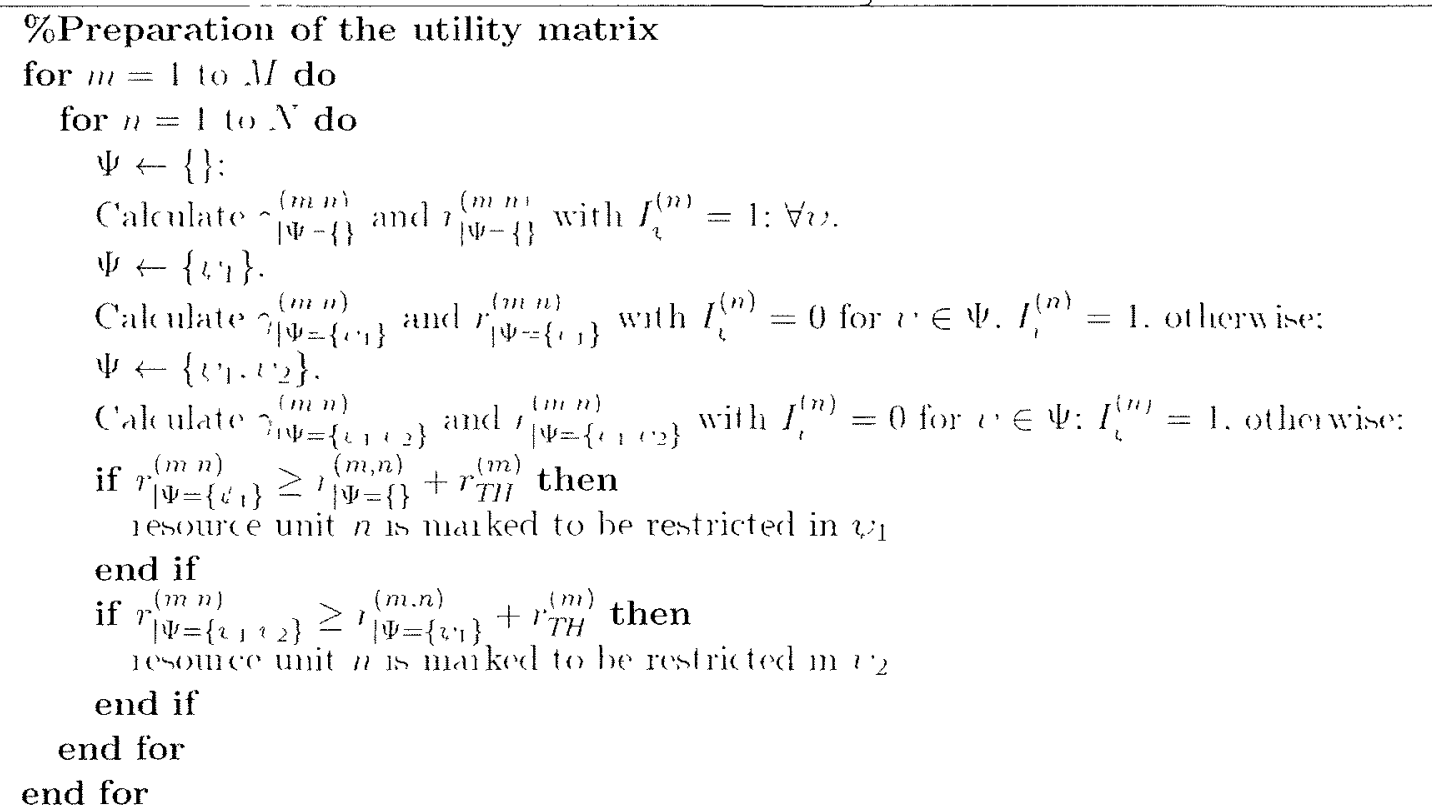

Fill in con roponding entry of uthlut matrix $U_{M \times x^{\prime}}$ with $u^{(m n)}=r^{(m, n)} \cdot d^{(m)}$. comsidering above restictions

\% Preparation of resource unit restriction requests

Initialize $\mathcal{R}_{t}=\{\}: \forall \imath:$

Jnitialize $\mathcal{U}=1 \cdots N$

while $\mathcal{U} \neq\{\}$ do

Apply Hungarian algonthm to $U$

if Allocated $n^{\text {th }}$ resource unit has a mark for $2^{\text {th }}$ sector interferer restriction then

Update corresponding entry of restriction recpuest $\mathcal{R}_{r}$.

end if

Remove colmums of $l$ 'omesponding to allocated resource units end while

m can be expresed an

$$
u_{2}^{(m n)}=r_{1}^{(m n)} d_{1}^{(m)}
$$

Earch entry of $\left[U_{\imath}\right]_{I I \times . V}=\left[u_{t}^{(n, n)}\right]$ is associated with the corresponding interferer(s) to be restricted along with the achieved utility when the resource unit is used by the respective UT. 


\section{Applying Hungarian Algorithm and Finding Restriction Requests}

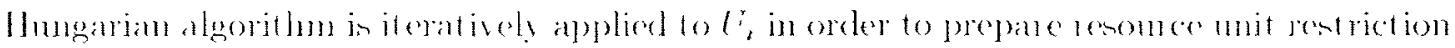

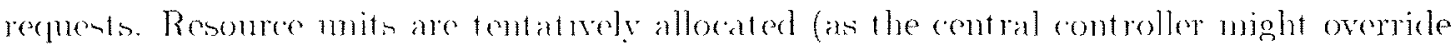

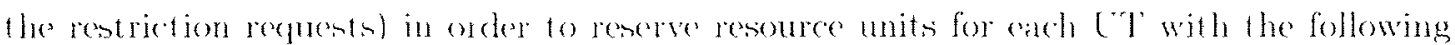
scips.

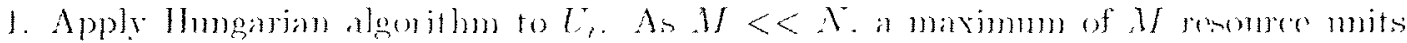
that visk the maximum sum utility will he allocater to the corresponding $M$ UTs.

2. If any of the above $M$ dhosen entries has restriction marked, the corresponding resemere unit will be placed in the entrietion list for the corresponding interferer.

3. The columus belonging to the desen cutries are deleted from li, The Hungarian algorithm in applied to the updated $b_{\text {, }}$.

1. Stepe 2 and 3 are repeated until all resoures units ane tentatively allocated to L'Ts.

Now. earh sector has a wish-list of resource mits to be restric ted for each of its neighhoring sectors. These lists are forwarded to the central controller.

\subsubsection{Central-Level Algorithm}

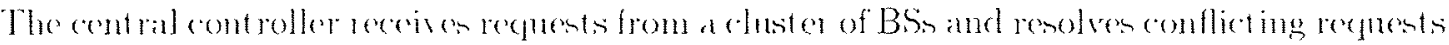
in an optimal manuer. For a pertu ular resonere unit. Fig. 4.3 show an example problem to be solved at the central contuller using its algorithm. In this figure. arrous with the solicl and dashed lines inclicate that interferene seceived at the arrow-originating-sertor from the arrowhead-sector is acceptable and unacreptable (requested to be restricted), respectively. For example, for a resource unit of interest. sector $B$ can tolerate interference from sector A. but the opposite is not true as there is a red (dashed) arrow from sector $A$ toward sector $B$. In this asce either acetor $A$ or $B$ has to be restricted for this resource mit. For any 


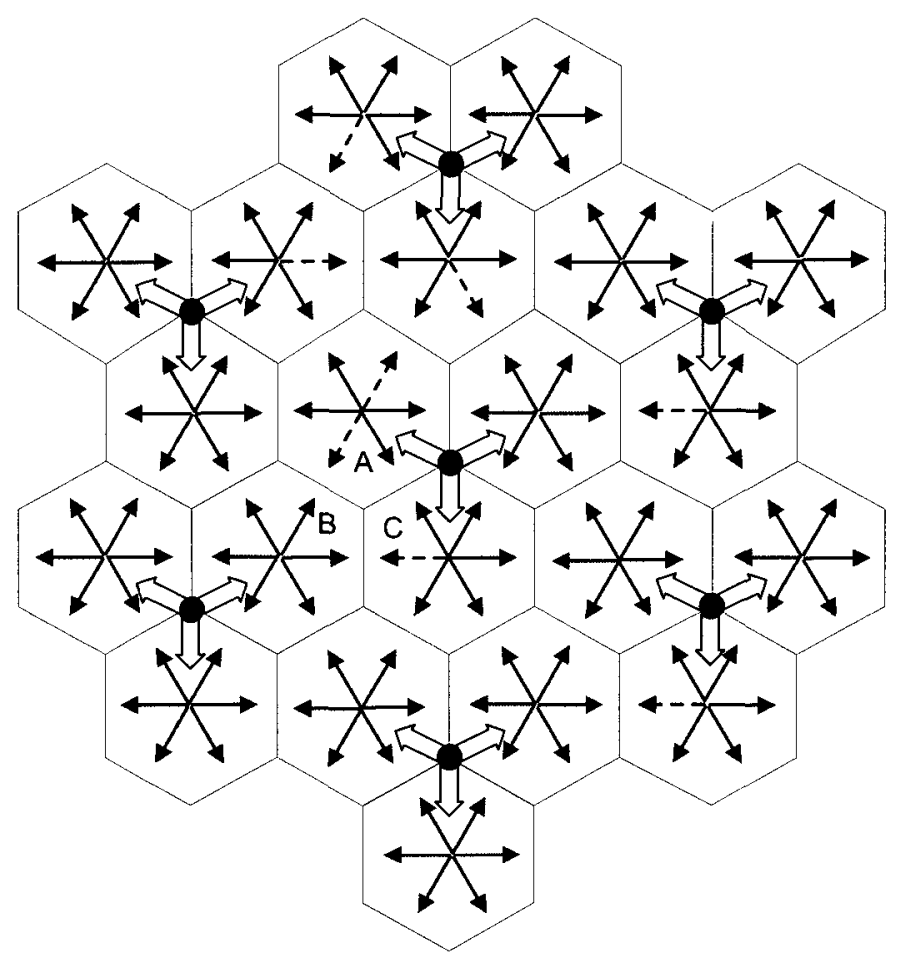

Figure 4.3: Resource unit restriction request for a particular resource unit.

resource unit $n$, the problem at the central controller can be formulated formally as follows: maxımıze

$$
Z=\sum_{\imath, \jmath \in \Phi} u_{\imath}^{\left(m_{\imath}, n\right)}\left(1-x_{\imath}^{(n)}\right)+u_{\jmath}^{\left(m_{\jmath}, n\right)}\left(1-x_{\jmath}^{(n)}\right)
$$

subject to

$$
x_{\imath}^{(n)}+x_{\jmath}^{(n)} \leq 1
$$

where $\Phi$ is the set of sectors in which each sector either requests or is requested for restriction to use resource unit $n$; i.e., $i$ has restriction request to sector $j$ or vice versa or both have restriction requests to each other. $m_{\imath}$ and $m_{\jmath}$ are the candidate UTs for resource unit $n$ in sector $i$ and $j$, respectively. The variables $x_{\imath}^{(n)}$ and $x_{j}^{(n)}$ are binary which represent resource unit restrictions. $x_{\imath}^{(n)}$ (or $x_{\jmath}^{(n)}$ ) takes the value of 1 if the resource unit is restricted in sector 


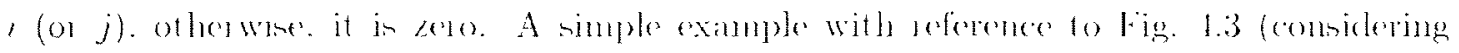

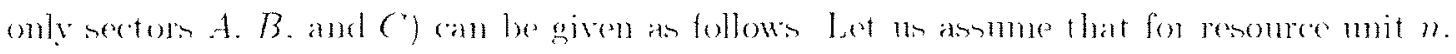

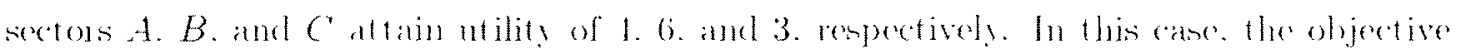
function is $Z=1\left(1-x_{1}^{(m)}\right)+6\left(1-x_{n}^{(m)}\right)+3\left(1-x_{c}^{(n)}\right)$. and the constraints are $x_{1}^{(n)}+x_{l 3}^{(n)} \leq 1$ and $r_{B}^{(n)}+r_{c}^{(n)} \leq 1$. (learly $x_{1}^{(n)}=0 . r_{13}^{(n)}=1$. and $x_{c}^{(n)}=0$ provide maximised $Z$. and therefore sector $B$ has to be menticted for resomere unit 12 .

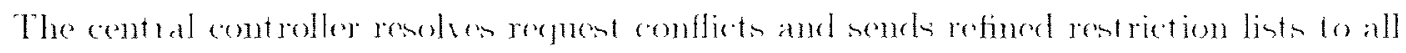
involved BSs.

The propused restriction procensing a an be clone from time to time an long as the channel

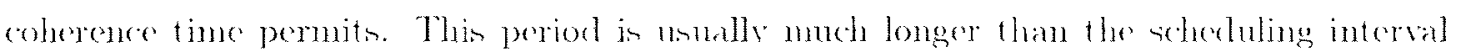
and shorter than the dhanel coherenee time. Once the resomed mit restriction list is available to a sector. the scheduler can perform resource unit scheduling baned on its own criteria. In that sense. the above resoure mit restriction tedmigne can be considered as independent of scheduling. In this study. the itesative Humgarian and proportional fair scheduling principles are uned in bot he the proposed and the reference schemes. Resoures unit restriction processing is performed on 6-resource mit time-interval (i.e.. $\sim 2$ ms which is much lower than the channel coherence time of $\sim 6 \mathrm{~ms}$ considering $20 \mathrm{~km} / \mathrm{hr}$ user speed and

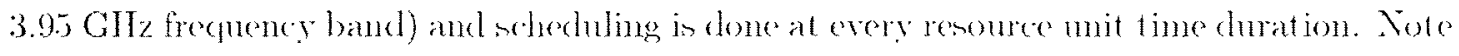
that the orerhead complexity is propertional to the frepueney of the resourer rentrietion

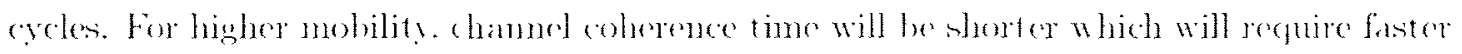
restriction upelates incurring higher signaling orerhead.

It shonk be mentioned that the propened scheme alio work without the ned for a central controller [21]. however. with possible degradation in performance as conflict resolution is expected to be suboptimal. In such case, the scheme can take advantage of the inter-BS communications, for instance. using the $\mathrm{X} 2$ interface as defined in 3GPP LTE [83]. If tno sectors wish to restrict a resource unit to cach other. the decision should result in favor of 


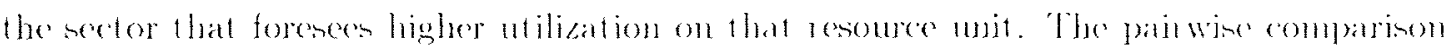
of ntilization result a in sulh-sptimal solution.

Curently. X2 interface supports information exchange between BSin (called arolved NodeB in LTE teminology) primarily for molility mamgement. load managenent. and interference coordination. which is controlled by X2AP protocol [81]. Wuth neresany mod-

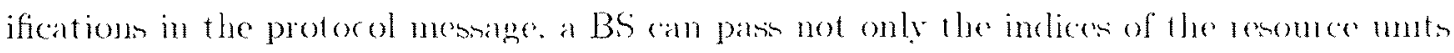
to be restrieted but also the utiliation seen on llese resoure mits.

\subsection{Simulation Models and Parameters}

A total of 19 cell sites (i.e. 57 lexagonal sectoms are comidered in the simulations. an shown in Fig. 3.1. The inter-site distanes is $1 \mathrm{~km}$. CTh are randomly distributed [8.5] in the centre 21 shaded sectors within a mininnm and maxinum radius in each sector. While the sector algorithm is exeruted in these 21 sectors. other sectorn remain as interference contributors only. Performance statistics are collected from the 3 central sectors (i.e. BSI as marked by the circle in lig. 3.1).

The available spectrum of $45 \mathrm{NHz}$ in the $3.95 \mathrm{GHz}$ frequency hand in available to each sector giving a total of 1152 sub-carriers each of which has a bandwidtl of $39.0625 \mathrm{kHz}$. A resoure mit (sub-chamel) combints of 8 comeculive sub-carliess. It is a time-frectuency

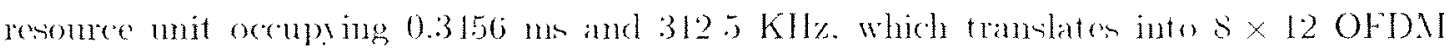
symbols $[77]$.

All UTs are ansumed to fall in the same service class. Both full-buffer and Poison traffic models have been considered in this investigation. For the simplicity of simulations. a simple queuing morlel with Poisson arrival has been assumed for the downlink traffic. The arrival data rate and packet size are considered to be $5 \mathrm{Mbps}$ and 96 bytes, respectively.

Time-frequency-correlated Rayleigh chamel samples are generated from the power delay profile for 17 INNER wide area scenario [ 85$]$. The usere mobility is ansumed to be $20 \mathrm{~km} / \mathrm{hr}$. 
The following exponential path-low $\left.\left(L_{l}\right)\right)$ model has been waed [8.5].

$$
\left.L_{l)}=\left(44.9-6.5 .5 \log _{10}(h)\right) \log _{10}(D)+34.16+5.83 \log _{10}(h)+23 \log _{10}(f . j 5.0)[d] 3\right] .
$$

where $h$ and $D$ are the BS height and transmitter-receiver separat ion in meters. respectively and $f_{c}$ is the carrier frecuency in GH\%.

The l'T receive antemas are asumed to he ommi-directional. while the gain pattern for $120^{\circ}$ directional sector transmit antemas is considered to be as follows [77]:

$$
A(\theta)=-\min \left[12\left(\frac{\theta}{\theta_{\text {sil } 13}}\right)^{2}, 20\right] .
$$

where the value of $\theta_{3 \mathrm{~d}}$ is $70^{\prime \prime}$ and $\theta$ varies from $-180^{\circ}$ to $180^{\prime \prime}$. A Single-1n Single-Out (SISO) antenna configuration than been userl.

The average thermal noise power in calculated with a noise figure of $7 \mathrm{~dB}$. Inderpendent lognormal random variables with a stanclard deviation of $8 \mathrm{~dB}$ are consiclered for shadowing: Sector transmit power is assumed to be 39.81 Watts and resouree mits are ansigned powers so that the total used power is constant in all schemes. Retransmission for erroncous data is considered only in simulations with traffic model.

Arlaptive modulation with a Block Low-Donsity Parity-('hork (B-LDPC) corde in noed. The throwolds for Adaptive Nodnlation and Coding (ANC) mokes are dotemined from a sot of water-fall curves produced by the link level simulations [77] and considering $10 \%$ Block-Error Rate (BLER). From Binary Phase Shift keying (BPSK) to 61- Quatrature Amplitude Modulation (OA.I) modulation have been used with warying rode rates. Fight OFDN symbols (out of 96) distributed within each resource unit are considered to be occupied by the reference signals and control signaling. Therefore, a resource unit using Qnadrature Plase Shift Keying (QPSK) with a codling rate of $1 / 2$ can cary 88 information bits. 


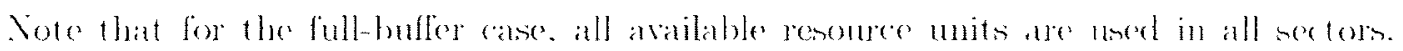
Therefore there is wo interfereme uncertainty due to the umused residnal rosonces. However. in the sinulations with traffic moklel, it is posibible that some renourees may not be used in some sectors due to empty quenes and/or poos channels which may result interference fluctuations: i.e. cliscrepancies between predicted and act nal interference. An approach hats been taken in order to minimize the effect of such fluctuations. Interferenee is estimated based on a probabilistic model. If a mosource unit is used at least ones in the puevious thrce scheduling instances in an interfering sector, then it is assumed that this particular interfering sector will use that particular resource unit in the upcoming instant. This approath captures the dynamice of a multi-eell simulation more aremately than assmming a fixed allocation in the interfering colls. The statistice are collecterl based on are ual SINR on the scheduled resource mits. In this case. if the actual recoived SINR is less than the predicted me which is used at the transmitter to determine the A.CO mode. then the preket is considered to be compted. Such retransmissions are seheduled in the next opportmity and given higher priority compared to the new packets.

BS-UT delay performance is observed in the cases with traffic model. This delay is defined as the time difference of the packet arrival at the transmitter queue of the BS and the succesuful reception of the last byte of the packet at the UT.

In order to solve the hinary integer optimiation problem at the central centroller. YALNIP [86] and LPSOLVE (an ILP solwe) [ST] have ben used along with MITLLAB.

\subsection{Simulation Results}

Performance results have been observed for a user density of 12 UTs per sector. Performance of the proposed scheme is compared with that of a mmber of reference schemes such as reuse 1. rense 3. and PFR schemes. where the reuse 1 represents a scheme with no condination and the latter two are the examples of static iuterference coordination schemes. The rouse 1 


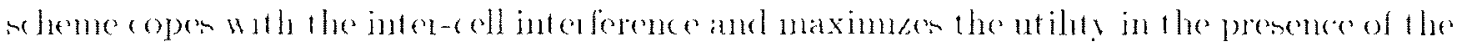
wort-cane mterference. The reme 3 and PFR schemes show henehte of static comdination over acuse 1 scheme. While all schemen achiese multuser diversity the gain in the propored wheme is solely due to dymanic interference coordmat on.

The CDF of the average UT throughput is observed and compared with the $3^{\prime \prime \prime}$ percentile

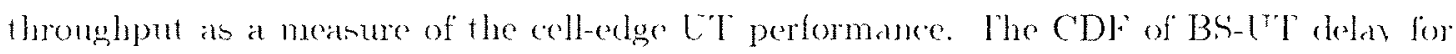

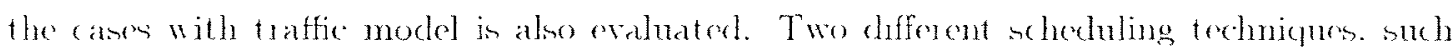
as the iterative Hungarian and proportional fair scheduling plinciples are used. Statustics are collected in the rentral 3 sectors and from 150 simulation drops, where each clrop is simulated ores a time chuation of 100 resource units. In cach drop. the thronghput of the UT is aterigerl over this time duation.

The CDFs of UT thoughput for the full-buffer ase are shown mig. 1.1 and Fig. 1.j when iterative Hungarian and proportional fair schedulers are used, respectively. The lower tail of the CDF in zoomed for the clarity to show the $5^{\text {th }}$-percentile points. As expected. reuse 1 scheme performs very poorly with regard to the cell-edge throughput as there is no interference coordination. On the other hand. being a static interference coordination scheme. reuse 3 scheme provides enhanced cell-edge throughput, however, with a significant loss in sector thronghput (i.e.. around 5.1\%). The PFR scheme attains around 12 times gain in cellerge throughput companed to the rense 1 scheme. but with aromed 30 a low

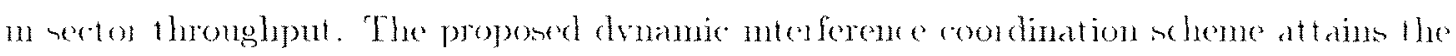
mont gan in coll-edge performance when the restucted resoure units are not used at all It is also otmerved that threshold criteria expremserl in (4.2) provides a coll-edge thoughput equivalent to that of the reuse 3 scheme whle keeping sector throughput greater than that in PFR. Also, when restricted resource units are used with 10 dB lower power and the threshold is set to $r 2^{7 H}$. proposed scheme achieves significantly higher cell-edge thronghput withont any inpact on the sector thronghput companed to the PFR seheme. Table 4.3 


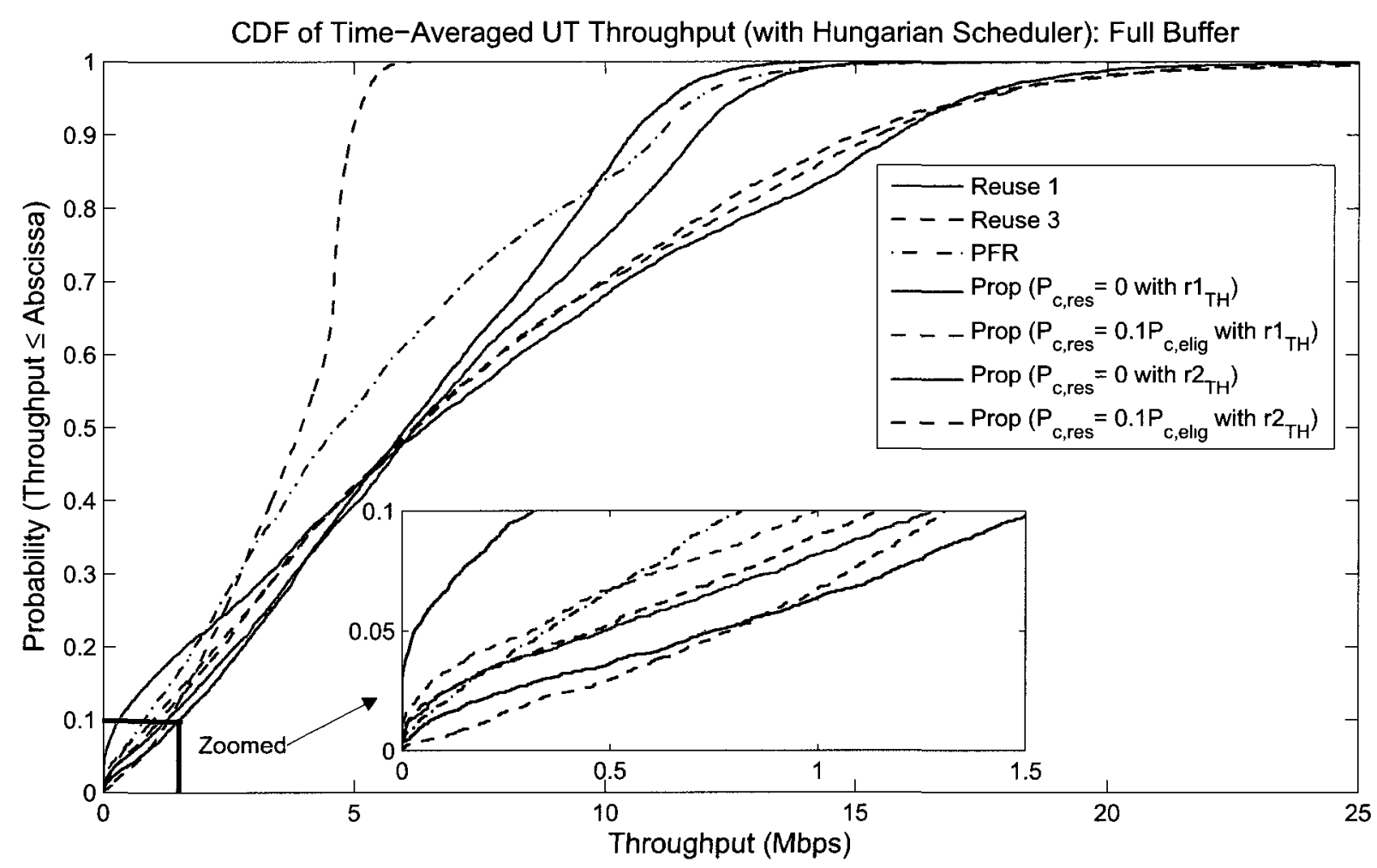

Figure 4.4: CDF of UT throughput (Hungarian scheduler): full-buffer.

summarizes results for the full-buffer and with traffic model (in parenthesis), and compares cell-edge and sector throughputs for the reference and proposed schemes. Prop. 1 and Prop. 2 in the table refer to the scenarios when restricted resource units are not used and used with $10 \mathrm{~dB}$ lower power, respectively.

For simulations considering traffic model with Poisson arrival, the CDFs of average UT throughput for the iterative Hungarian and proportional fair schedulers have been illustrated in Fig. 4.6 and Fig. 4.7, respectively. Corresponding BS-UT delay performances are presented in Fig. 4.8 and Fig. 4.9, respectively. Similar to the full-buffer scenario, it is seen that reuse 3 scheme achieves significant gain in cell-edge throughput, but with loss in sector throughput and degraded delay performance compared to the reuse 1 scheme. 


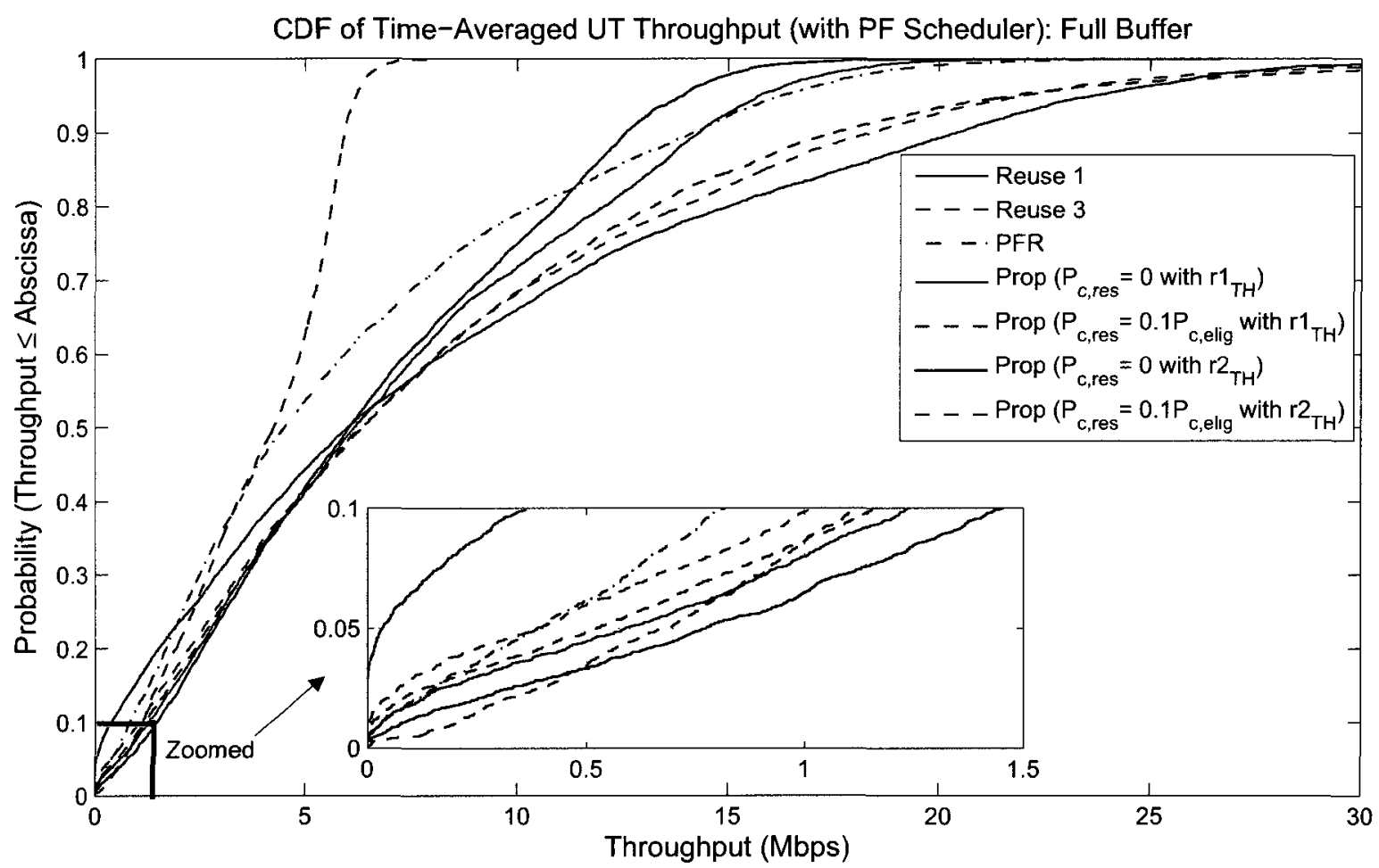

Figure 4.5: CDF of UT throughput (PF scheduler): full-buffer.

The performance of PFR falls between reuse 1 and reuse 3 schemes in terms of cell-edge and sector throughputs, and packet delay. Proposed scheme with $r 2^{T H}$ that does not use restricted resource units achieves cell-edge performance comparable to reuse 3 scheme while maintaining the sector throughput and delay performance comparable to reuse 1 scheme. It should be noted that the proposed schemes which use restricted resource units with 10 $\mathrm{dB}$ lower power do not bring any additional benefit in the cases with a traffic model as the packet arrival is limited. The numbers in the parenthesis of Table 4.3 compares cell-edge and sector throughputs for all simulated schemes when a traffic model is used. 


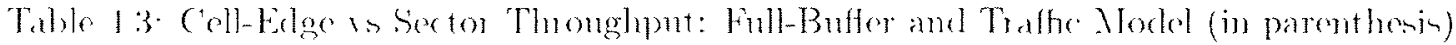

\begin{tabular}{|c|c|c|c|c|c|c|c|}
\hline & & \multicolumn{3}{|c|}{ Itratios Ifung a ian } & \multicolumn{3}{|c|}{ Popostional Fair } \\
\hline & schex & $\begin{array}{c}5,-P(n e \\
(k+p) s)\end{array}$ & 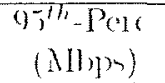 & $\begin{array}{l}\text { Sertor lT } \\
(\text { Allops) }\end{array}$ & $\begin{array}{c}3^{-1}-P \mathrm{Qg} \\
(\mathrm{kl}) \mathrm{m})\end{array}$ & $\begin{array}{c}95^{\prime \prime}-\mathrm{Pele} \\
(\mathrm{Al}) \mathrm{ps})\end{array}$ & $\begin{array}{l}\text { Secton TP } \\
\text { (Mbpu) }\end{array}$ \\
\hline & & .20317211 & & & 33 & & \\
\hline & & & & & 11 & & \\
\hline & & ) & $10()$, & & 80,4 & & \\
\hline $1 \%$ & & $j 8(105.3)$ & 12.6 & $i \pi$ & $3 \times 64$ & 15 & 7.4) \\
\hline Prop & $2 w$ & $10.9(317.7)$ & $17 \pi(\pi$. & 88.6 & $3915(357.1)$ & 21.9 & 7.1) \\
\hline l'op & $1 w$ & $70.3(511.9)$ & 113 & -3.3.1 & $7.3+(605.4)$ & 1.3 .9 & $(6.3)$ \\
\hline P(o) & 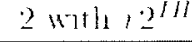 & $1617(1196)$ & $17.2(5: 39)$ & $\sin (171)$ & $5201(1723)$ & $21 \&(5.39)$ & $9+1(16,3)$ \\
\hline
\end{tabular}

\subsection{Results for Scenario with Sectors Having Non-uniform Traffic}

In this se tions. the result of 2-level algorithm are premented when there are nom-unifom traffic in different sectors: this resembles today is real-world real-tme traffic. where some sectors mas appede to be in the hot-spot areas The Poison arrisal procens is still used. howerer. with highes generation rates (1.5 times) in thene hot-upot sectors.

A lavout similar to Fig. 3.1 is considered but identifying the hot-spot sectors (sharled) as shown in Fig. 4.10. It in assumed that the packet size is 96 bytes and average data generation rates for users in the hot-spot sectors are $7.5 \mathrm{Mlhps}$, while the rates for users in the regular

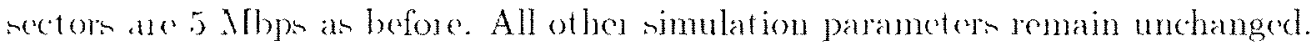

The ('DF of arerge noce throughput with iterative Humgarian and proportional fall whedules have been shown in Fig. 4.11 and Fig 4.12. respectively The mrogularition in the (DF plots arise from the fanet that $1 / 3$ of ueserse hat ing 1.5 times genesation mates. In Table 1.1. the coll-cdge and sector thoughputs for simulations with hot-spot sectorn are compared It is observed that the cell-edge performance for all reference schemes degrade due tu the inclusion of hot-spot sectors. while in proposed schemes with threshold function in (1.1). the cell-edge performance is enhanced. However. in preposed shemes with threshold function (4.2). the cell-edge performanee slightly degrades. BS-UT delay performanee is 


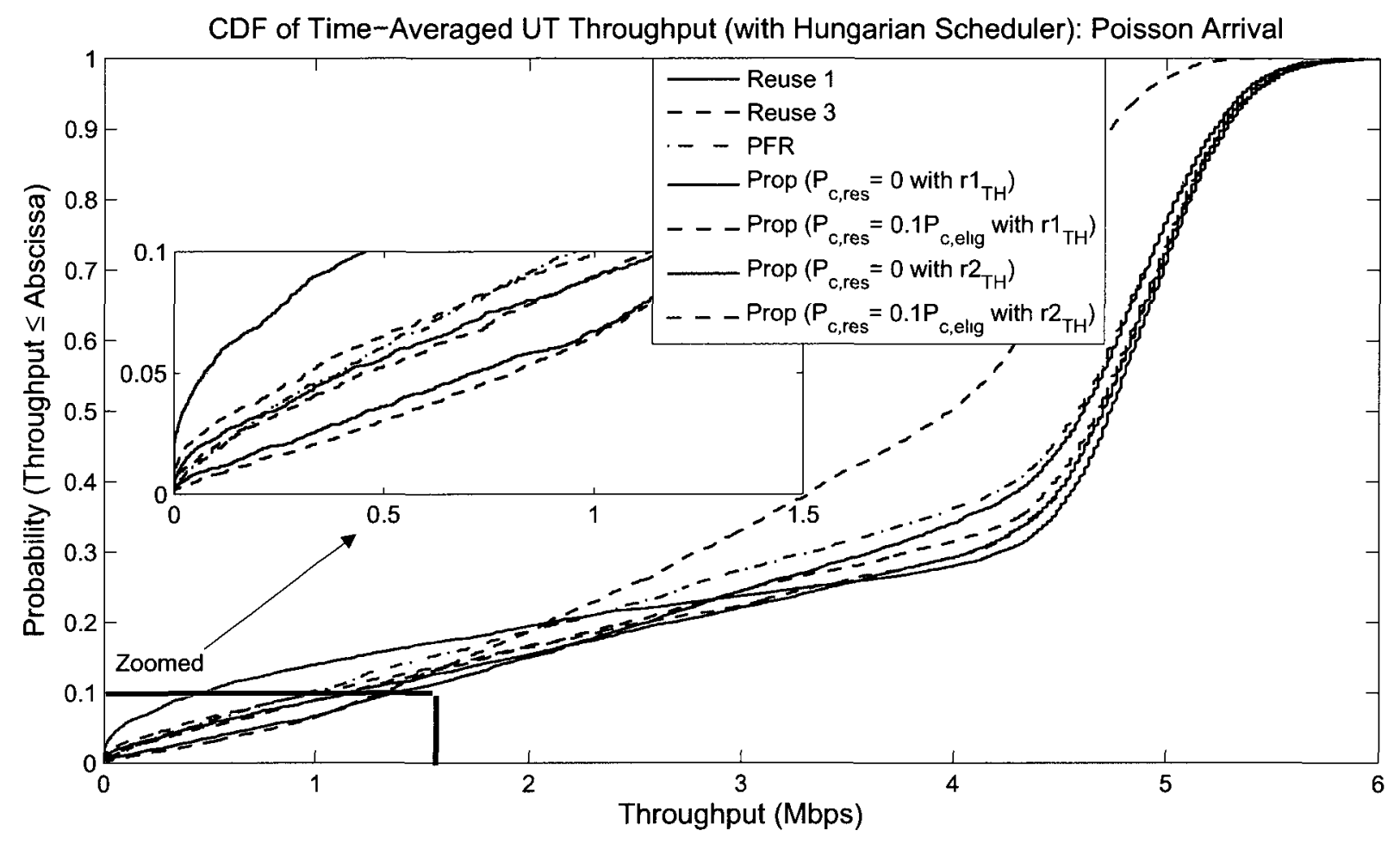

Figure 4.6: CDF of UT throughput (Hungarian scheduler): Poisson arrival.

shown in Fig. 4.13 and Fig. 4.14 for the iterative Hungarian and PF schedulers, respectively. As expected, delay increases for all schemes, however, the relative delay performance remains unchanged.

\subsection{Implementation Complexity Issues}

Two different kinds of complexities are associated with the proposed schemes; the computational complexities of the algorithms and the signaling overhead.

The overall complexity of the sector-level algorithm is dominated by the complexity of the Hungarian algorithm which is upper-bounded by $O\left(\min ^{2}(M, N) \cdot \max (M, N)\right)[88]$, where $M$ and $N$ are the number of UTs and resource units, respectively. The complexity of 


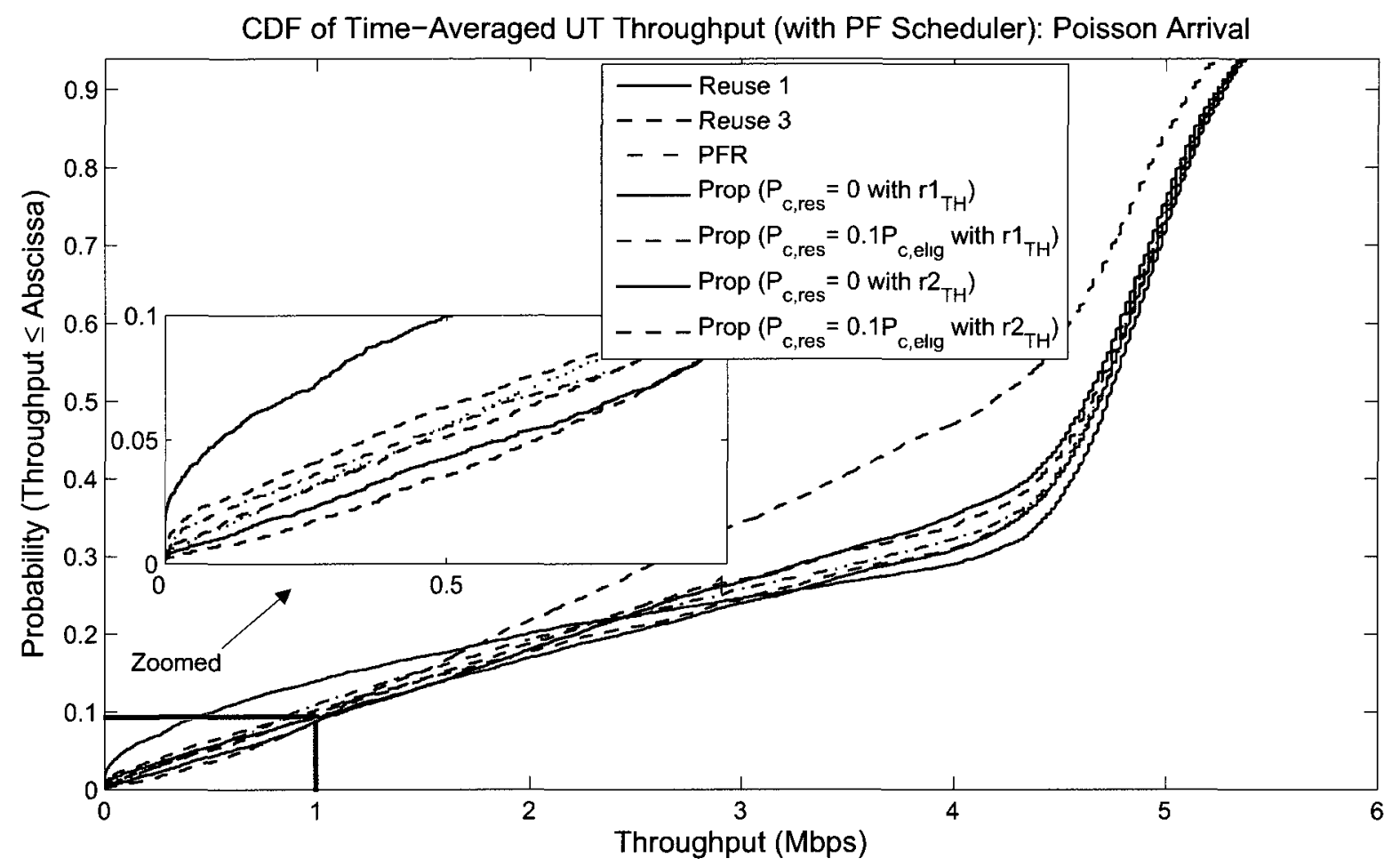

Figure 4.7: CDF of UT throughput (PF scheduler): Poisson arrival.

the algorithm at the central controller depends on the number of sectors that have conflicting restriction requests. This determines the number of variables and constraints in the binary integer problem. For example, if there are 3 pair-wise conflicting requests for a particular resource unit, then the number of binary variables to solve is 6 and the number of constrains is 9 .

Systems employing AMC are required to facilitate CSI feedback and are subjected to associated signaling overhead. In the proposed schemes that use threshold function (4.1), only rate deprived UTs are required to send information of two most dominant interference to the serving BS causing additional signaling overhead. All UTs in the proposed schemes with threshold function (4.2) are required to forward such information. Threshold functions 


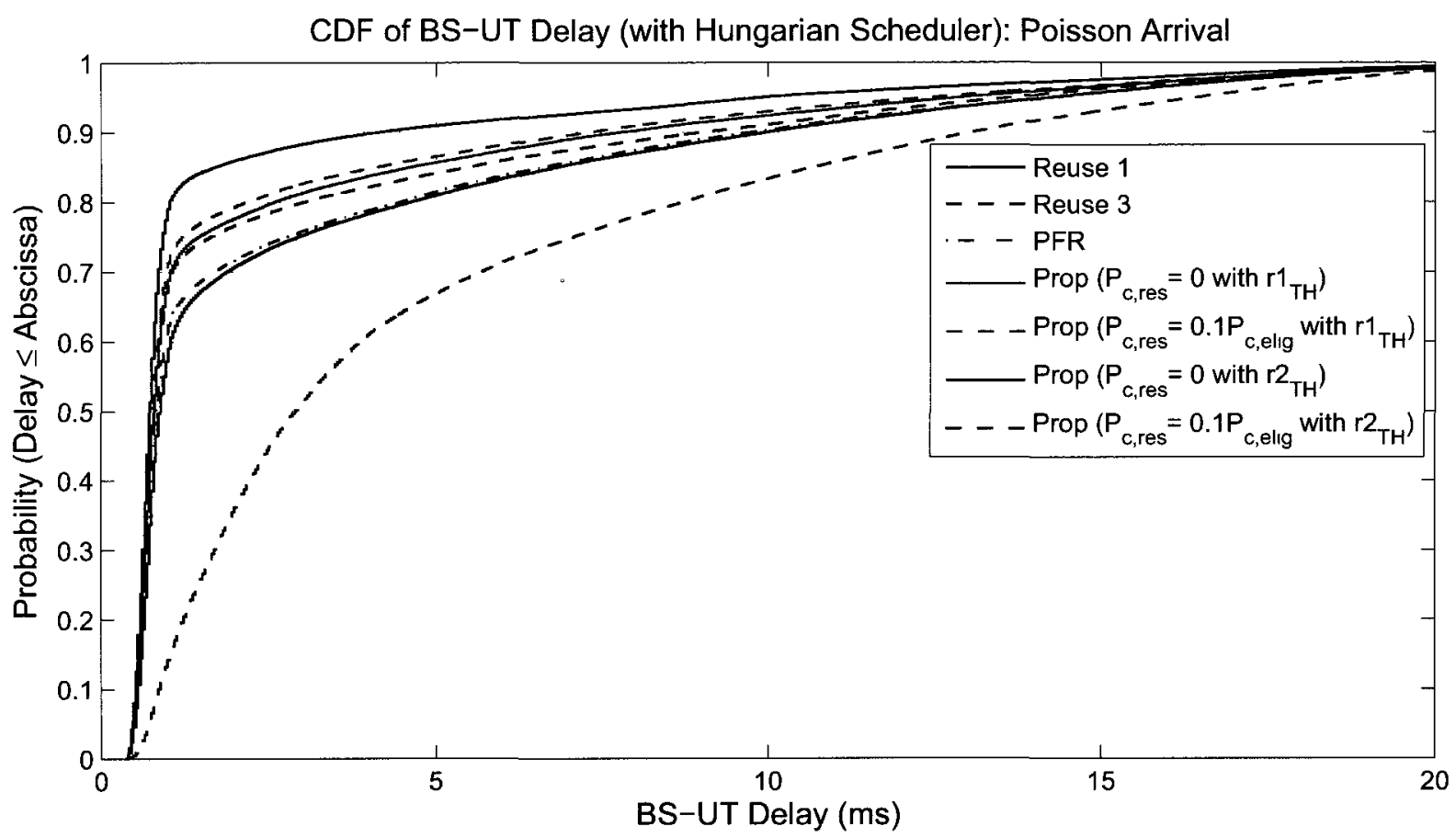

Figure 4.8: CDF of BS-UT delay (Hungarian scheduler): Poisson arrival.

Table 4.4: Cell-Edge vs Sector Throughput: Traffic Model (includes hot-spot sectors)

\begin{tabular}{c|c|c|c|c|c|c} 
& \multicolumn{3}{|c|}{ Iterative Hungarian } & \multicolumn{3}{c}{ Proportional Fair } \\
\hline Scheme & $\begin{array}{c}5^{t h} \text {-Perc. } \\
\text { (kbps) }\end{array}$ & $\begin{array}{c}95^{t h} \text {-Perc. } \\
\text { (Mbps) }\end{array}$ & $\begin{array}{c}\text { Sector TP } \\
\text { (Mbps) }\end{array}$ & $\begin{array}{c}5^{\text {th }} \text {-Perc. } \\
\text { (kbps) }\end{array}$ & $\begin{array}{c}95^{t h} \text {-Perc. } \\
\text { (Mbps) }\end{array}$ & $\begin{array}{c}\text { Sector TP } \\
(\mathrm{Mbps})\end{array}$ \\
\hline \hline Reuse-1 & 55.8 & 7.59 & 51.9 & 73.0 & 7.59 & 51.8 \\
Reuse-3 & 802.1 & 4.99 & 41.1 & 648.5 & 5.73 & 43.3 \\
PFR & 389.8 & 7.37 & 48.5 & 454.9 & 7.53 & 50.8 \\
Prop. 1 with $r 1^{T H}$ & 536.6 & 7.53 & 52.9 & 541.9 & 7.55 & 52.1 \\
Prop. 2 with $r 1^{T H}$ & 395.7 & 7.57 & 52.9 & 438.0 & 7.57 & 52.0 \\
Prop. 1 with $r 2^{T H}$ & 697.0 & 7.39 & 50.9 & 578.9 & 7.51 & 50.4 \\
Prop. 2 with $r 2^{T H}$ & 433.1 & 7.57 & 52.2 & 458.5 & 7.55 & 50.9 \\
\hline
\end{tabular}

in (4.1) and (4.2) can be considered as the trade-off between performance and overhead complexity. However, the rate of required overhead is related to the frequency of the channel reporting and resource allocation operations, which essentially depends on the mobility of the UTs and hence on the resulting channel coherence time. Therefore, a higher signaling overhead would have to be supported for higher mobility UTs. UTs in the reference static 


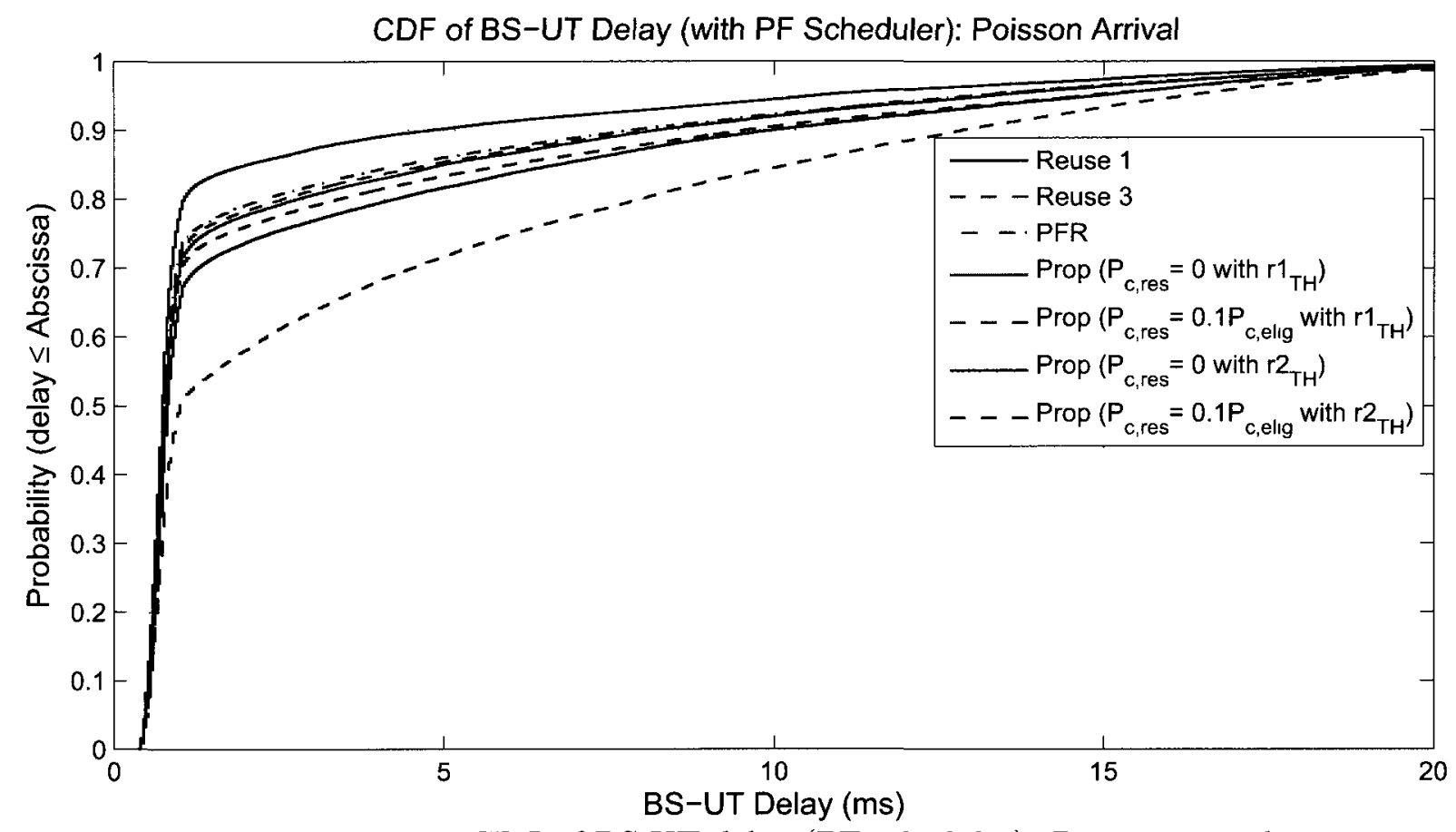

Figure 4.9: CDF of BS-UT delay (PF scheduler): Poisson arrival.

interference coordination schemes do not require to send any additional signaling other than the CSI.

In the proposed schemes, signaling between BS and the central entity is also required which can be performed using high data rate backbone connections such as fiber links and thus it is less of an issue.

\subsection{Summary}

A novel viable interference coordination scheme using downlink multi-cell resource unit allocation with dynamic inter-cell coordination is presented in this chapter. The performance of the proposed schemes is compared with that of a number of static coordination-based reference schemes available in the literature. It is observed from the simulation results that the static coordination schemes achieve enhanced cell-edge throughput only with a significant 


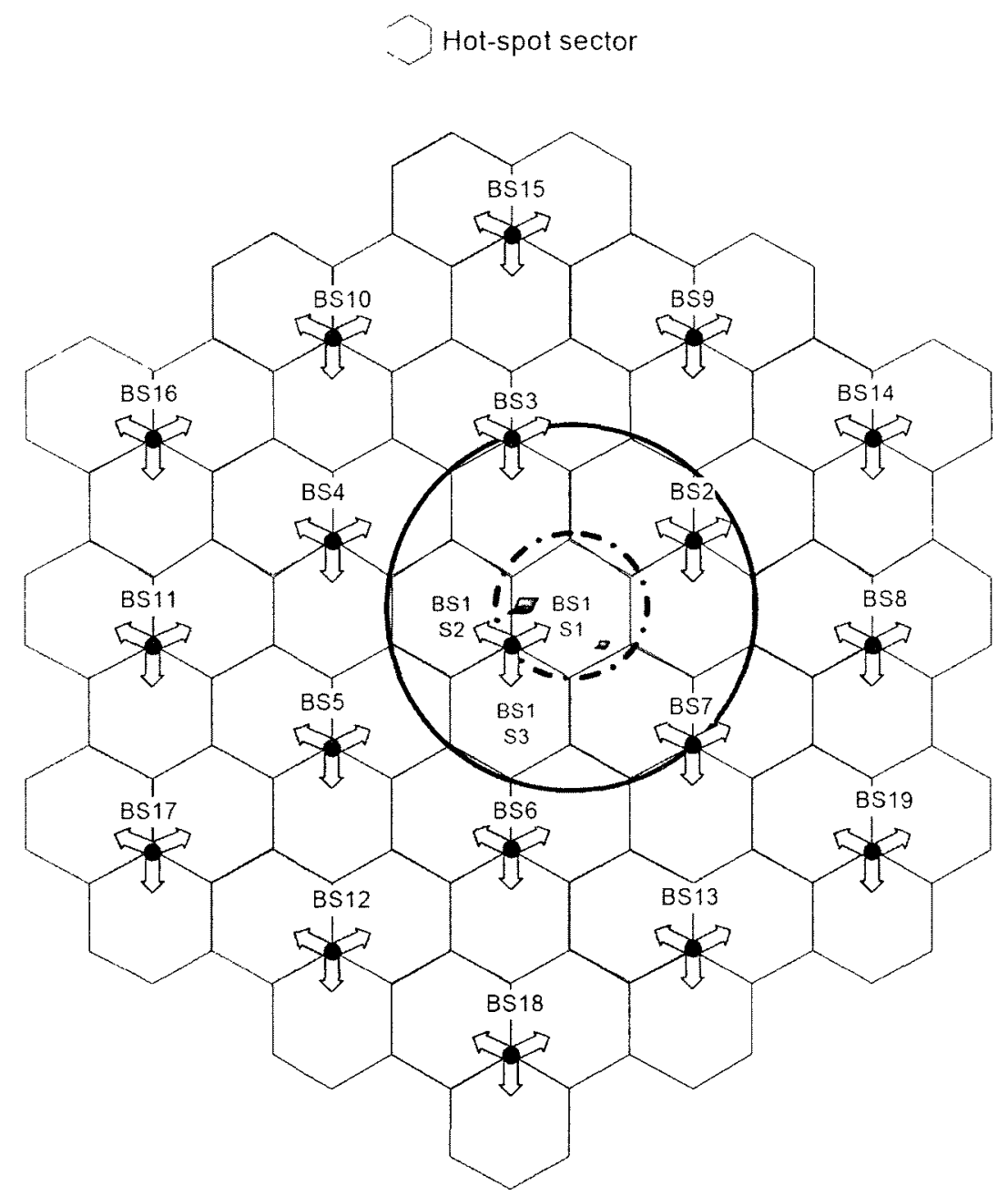

Figure 4.10: Simulation layout with hot-inot rectom

loss in sector thoughum. On the other hand the proposed shemes ahere equivalent or better cell-edge throughput without impacting the sector thronghput. All simulated schemes achieve multi-user diversity through the schedulers. Therefore. the ohserved performance gain in the proposed scheme is solely due to dy namic interference coordination. Enhanced cell edge thronghput in the proposed scheme can potentially allow a smaller mum- 


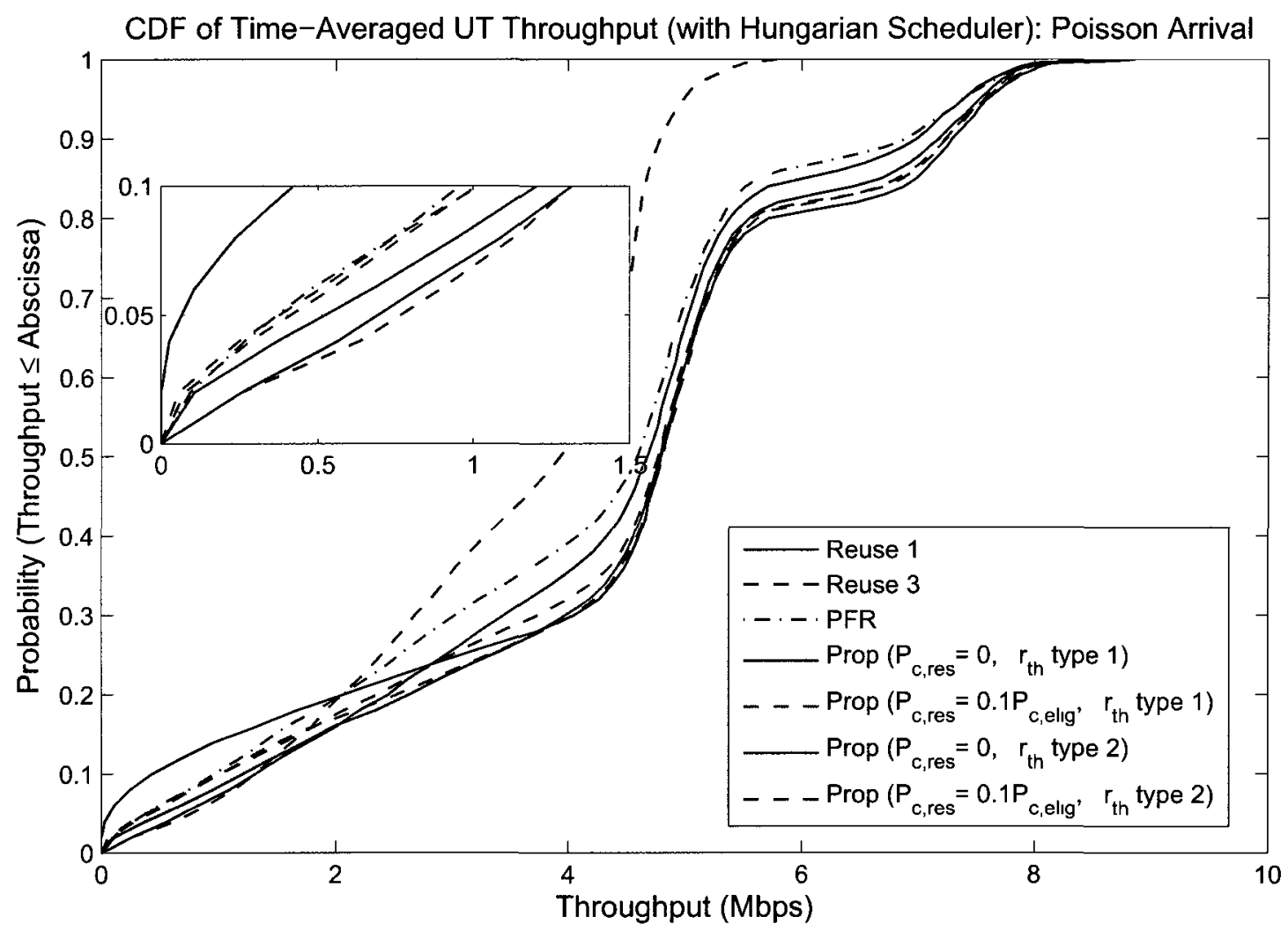

Figure 4.11: CDF of user throughput: iterative Hungarian scheduler (includes hot-spot sectors)

ber of BSs to cover a region yielding substantial savings in the deployment cost. As it does not require any frequency planning, the proposed scheme is not only effective for macrocell environment, it can be applied to future femtocell BSs where user terminals are expected to experience severe interference from neighboring macrocell BSs.

Although a central entity for the resolution of the conflicting requests is used, the algorithm can be applied to radio access networks (RANs) without a central controller, for example, 3GPP LTE and LTE-A networks. In this case, resolutions can be performed among neighboring sectors through negotiations using X2 interface that inter-connects BSs.

In the sector algorithm, a simple utility function has been used, where the considered 


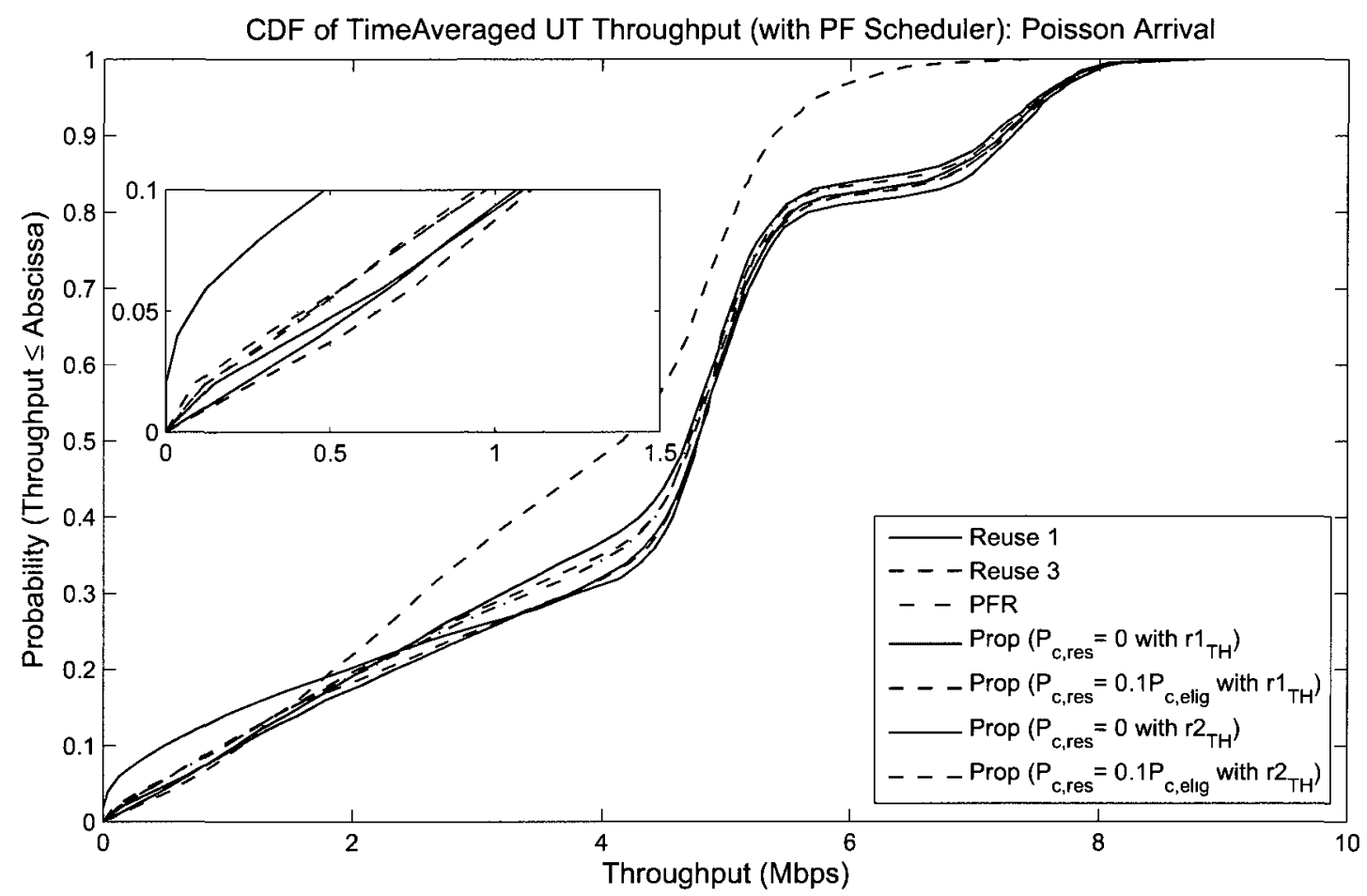

Figure 4.12: CDF of user throughput: proportional fair scheduler (includes hot-spot sectors)

utility is proportional to the achieved rate on the resource unit of interest and UT resource demand at the allocation instant. However, it may be possible to devise a more comprehensive utility function that may consider other critical factors necessary for improved network performance. The presented schemes have, nevertheless, shown the potential of dynamic interference avoidance and highlighted its trade-off between the performance and complexity adjusted through the tunable threshold function. 


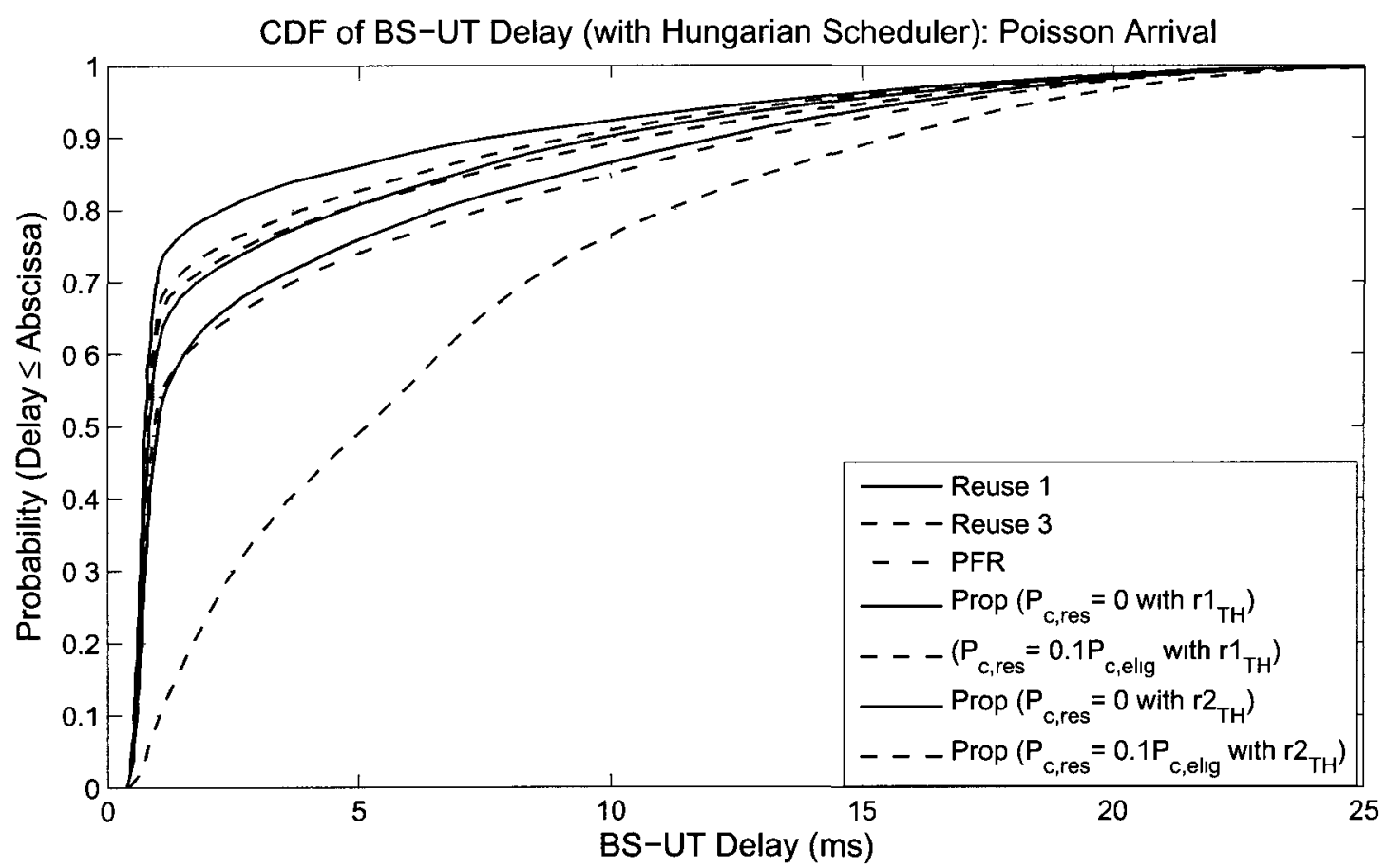

Figure 4.13: CDF of BS-UT delay: iterative Hungarian scheduler (includes hot-spot sectors) 


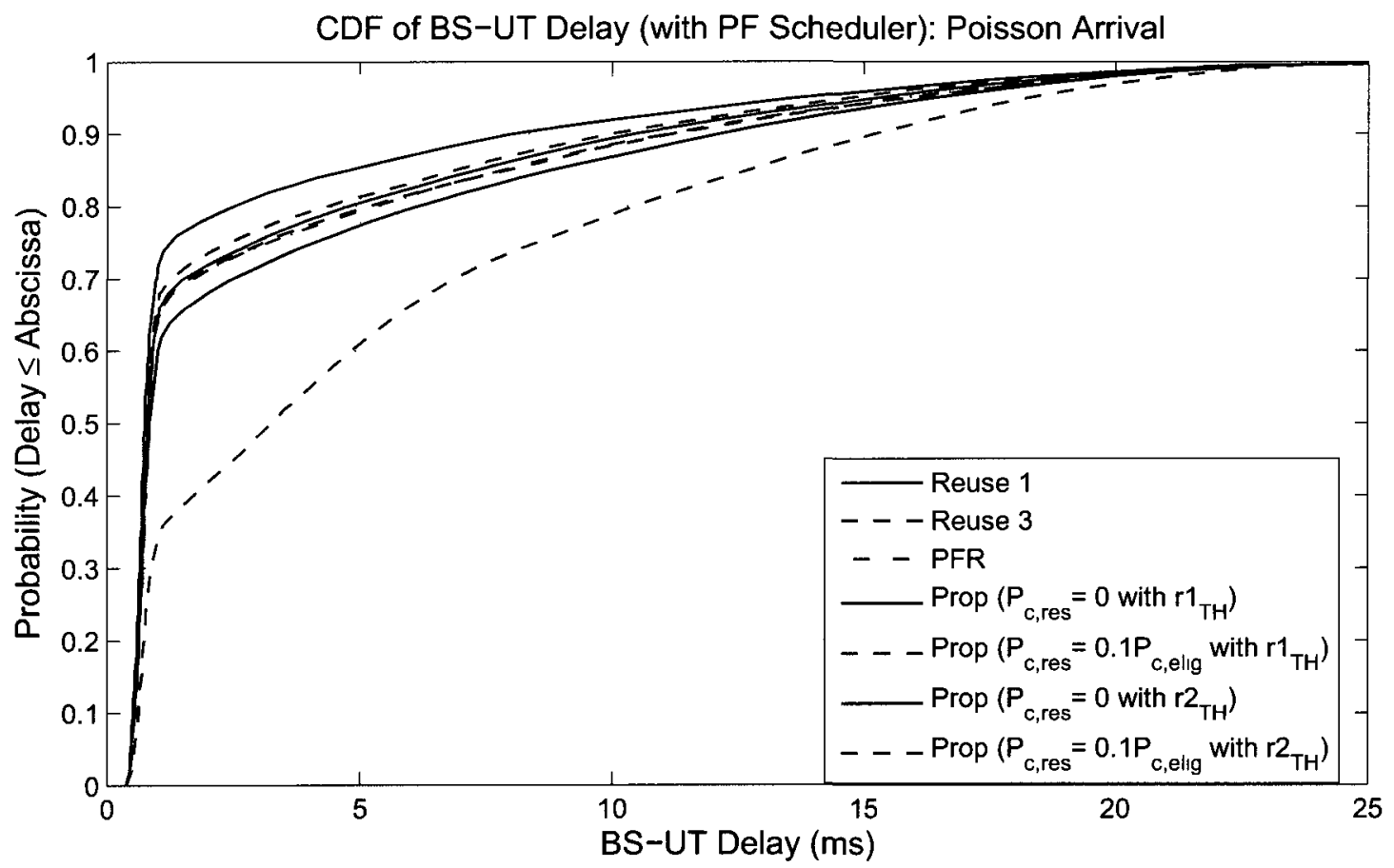

Figure 4.14: CDF of BS-UT delay: proportional fair scheduler (includes hot-spot sectors) 


\section{Chapter 5}

\section{A Distributed Algorithm with Neighboring Cell Coordination}

\subsection{Introduction}

In this chapter. an interference avoidance scheme for LTE downlink is presented. which uses dynamic inter-cell coordination facilitated through X2 interface among neighboring UTRAN eNBs. Proposed scheme is evaluated by extensive simulations and compared with a number of reference schemes available in the literature such as reuse 3. a PFR and SFR with different effective reuse factors as dinemed in ('hapted 2 . It has been observed that the

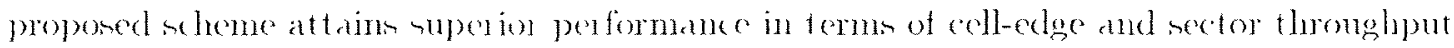
compared to those in the reference schemes.

The semainder of this chapter is organized an follows. The proponed scheme is described in Section 5.2. Section 5.3 provides LJE simulation environment and parameters. Simulation results are discussed in Section 5.4 followed by a summary in Section 5.5 . 


\subsection{Description of the Proposed Scheme}

Let un comsider a netwok layout an shown in Fin. 3.1. With the exerption that LTE 1 erminology to denote a basc-station. i.e. oNB. In ned. Inter-eell interference is categorized into two groups. ie.. intra-e $\mathrm{NB}$ and inter-eNB interference as shown in lig. 5.1. Les receive

dommant interference from the first-tier of interferers: 2 from own-eNB and $t$ from cells of other neighboring NBBn. as illustrated in the figure. Based on mutual interference situation and $U E$ rate requirements resoulce restrictions are prepared using two algorithms. one for intra-eNB and the other for inter-eNB interferers. Interference originated from cells of own (NB should be handled separately as eNB can take appropriate measures itself without the need for inter-s, $\backslash B$ communication through $X 2$ interfice. Bubla algorithus involve preparation of utility matrix and applying Hungarian algorithm [9] on the utility matrix in an itcrative mamer in oreler to find resource units to be estricted in the neighboring cells. Ihungarian algorithm is optimal for one-terone resource mit to $\mathrm{CE}$ allocation: however. it becomes sub-optimal when it is used iteratively to assign more than one resource unit to a UL.

The restrictions on the usage of resource units are determined from time-to-time at a time-interval within the channel coherence time. i.e. depending on the speed of the mobile. This interval is denoted as resomes restriction refresh interval. Ones the resomere mit restrietion list is avalable at a sector. the scheduler can perform resoure mit scheduling baned on its own criteria. Two variations of the proposed scheme have been studied: in one. the restricted resoure mits are not userd at all and in the of here. these resonre mits are used, however, only with reduced power (for example, with $10 \mathrm{~dB}$ lower).

\subsubsection{Intra-eNB Inter-Cell Interference Avoidance}

A novel method is med to apply Hungarian algorithm for intra-e NB interference avoidance among three sectors (belonging to the same (NB) as follows. For at particular resource mit. 


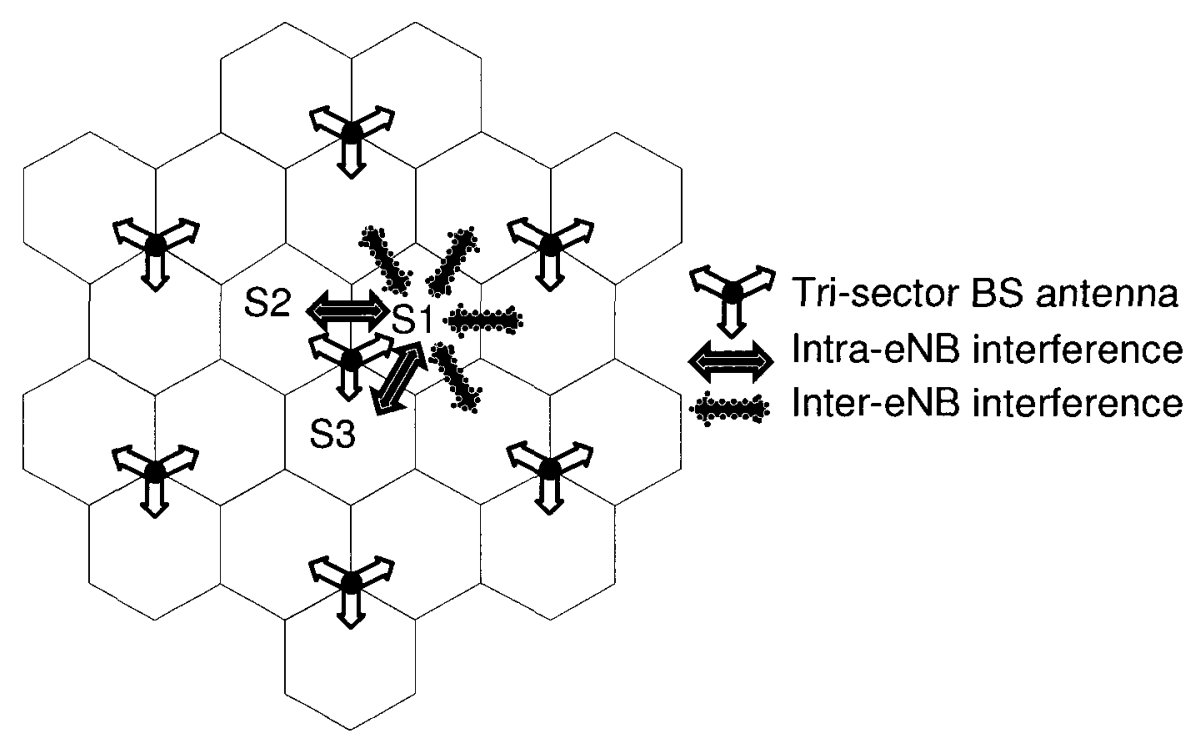

Figure 5.1: Intra and inter-eNB inter-cell interference.

a sector can restrict only one dominant intra-eNB interferer. A utility matrix covering all three sectors of an eNB is constructed as follows.

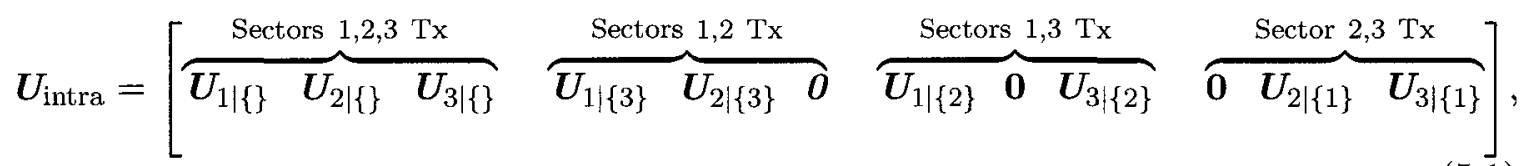

where each element of the above composite matrix is itself a matrix of size $M \times N ; N$ and $M$ are the number of resource units and the number of UEs per sector, respectively. The first three elements are the utility matrices for sectors 1,2, and 3 respectively, given all three sectors use the resource concurrently (i.e., no intra-sector restriction). The next set of matrices under the second curly brace are the utilities in Sectors 1, 2, and 3 when Sector 3 is restricted. These utility matrices conditioned on the possible concurrent intra-eNB 
interecell interferem are of the form below:

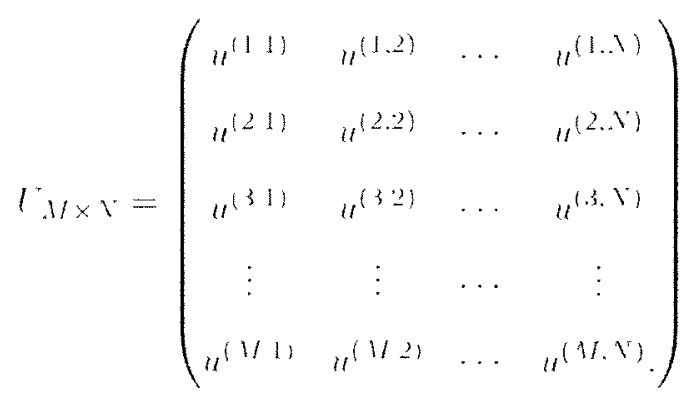

The utility measure $u^{(m, n)}$ is the poorluct of the achievable rate on resource unit $n$ if it is assigned to UE $m\left(r^{(m n)}\right)$ and the current clemand factor of UE $m$ (i.e... $d^{(m)}$, which is dehued an in section 3.2 of ('hapter 3 ). when both intrate NB interforers are active. When an intra-eXB sector is restricted. a penalty (in terms of rate) is int rodneed in the calculation of the mility as below.

$$
u^{(m . n)}= \begin{cases}r^{(m n)} \times d^{(m)}: & \text { all transmit. } \\ \left(r^{(m . n)}-r_{p}\right) \times d^{(m)}: & \text { one restricted. }\end{cases}
$$

where $r_{p}$ is the rate penalty considered in the utility measure to account for resource loss due to restriction imposed to one of the intrateNB sectors. In simulations, $r_{p}=1.5 \mathrm{hps} / \mathrm{Hz}$ in comsidered suth that average number resourer units restricted by intra-e $\mathrm{NB}$ avoidance

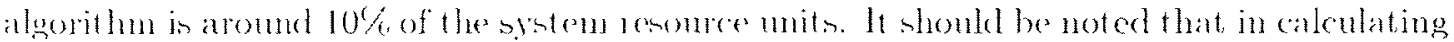

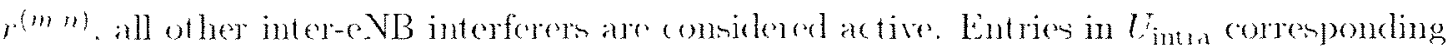
to LE having demand factors lesin than 1 (i.e. rate satisfied in the past) are set to zero so that restrietions are made only for the rate deprived lbs. Then. the Hungarian algorithm is applied to $U_{\text {intra }}$. In each iteration, algorithm selects best resource units for UEs in three different sectors so that the sum of utilities of the chosen resource units is maximized. Note that an entry from a matrix with restrietion is chosen only when the rate inuprovement due to interference suppression exceeds the penalty $r_{p} . L_{\text {mtra }}^{r}$ is mplated after each iteration as 
followis.

- If a chomen entry is from the matrix where resounce mil restriction is mot seguired. for eximple $L_{1 \mid\{\}}$. utility entrien for the comesponding resourer mit for all Lis in $l_{1 \mid\{3\}}^{*}$.

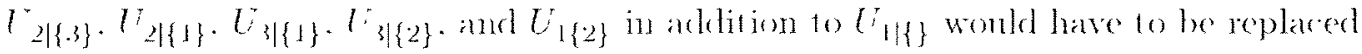
by zoros. Howerer. nility entres in $l_{2 y\}}$ and $l_{3 \mid\{\}}$ remain unchanged in order to allow future iteration to reselect this renoures unit.

- If a chosen entry is from the matrix where a resonce unit restriction is required. for example $L_{1 \mid\{2\}}$ (sector 2 has restriction on the selected resource unit). following atelions ale reprired.

Place the renoures mit inclex in rentriction list for werer 2

Entries corresponding to this resource mit for all LEs in all matrices except $l^{\prime} 3 \mid\{2\}$ have to be replaced by zeros. In this case. future itemations will allow resonres unit to be weel only by a lite in sector 3.

The above stejs are repeated until all entrien in $U_{\text {Inta }}$ are zero. In this processis, each sector prepares resoure unit restrictions for its intra-cNB neighbors. The number of required iterations varies depending on the number of rate deprived UEs as well the utility valum of the matrix.

\subsubsection{Inter-eNB Inter-Cell Interference Avoidance}

Similar $16[17.18]$ and as in the previous chapter. each sector prepares resource mit restrictums for inter-eNB interferers, based on dominant received interference from four inter-eNB interferers. This algorithm involves preparation of utility matrix $U_{\text {nter }}$ by using heuristics and applying Hungarian assignment algorithm to this matrix. Then, neighboring eNBs are communicated about these resource restrictions over $Y_{2}$ interface. The details of this algorithm are discussed below. 


\section{Preparation of Utility Matrix}

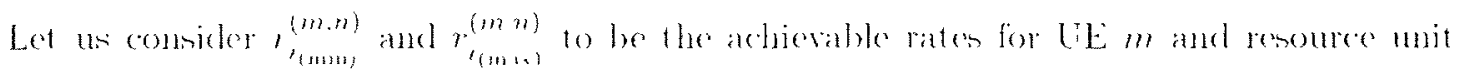

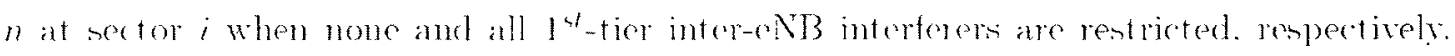

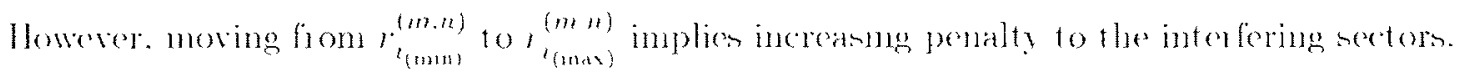
ins more and mole interferess are to be restrected.

A threshold-baned strategy is uned to cletermme which interferers ane to be restricted. Baned on its demand fatctor and chamel conditions, a UE (an restrict two nost dominant interferers at most. This limits the number of renultmg resource unit restrictions in the neighboring sectors. In order to construct the inter-eNB utility matrix. the following steps are repeated for each LE and resomer unit.

- Four inter-eNB dominant interferers are sorted in descencling order into at clominant interferer set.

- $r_{(m, m)}^{(m, n)}$ is calculated considering the presence of all inter-ell inter-eNB dominant interforem and taking intra-eNB restrictions into accomt.

- If $r_{{ }^{(m u)}}^{(m n)} \geq r I_{T H}$. no interferers are to be restricted if resource unit $n$ is assigned to UE $m$ irrespective of its demand factor. In this case. UE $m$ is then either having a strong desired link fom sorving BSt or is exper iemeing weak interfenene

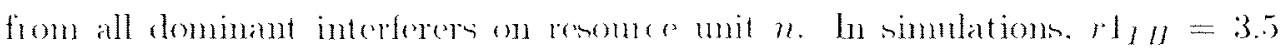
b) $/ \mathrm{H} / \mathrm{H}$, in need.

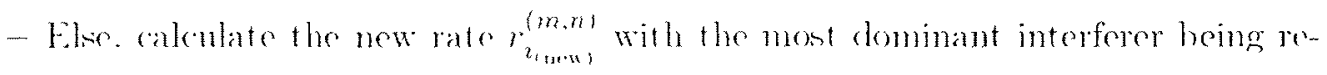
stricted.

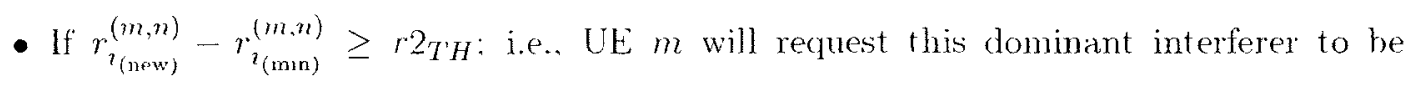
rentricted irrespective of its demamel. $r 2 r n=2$ bps/ $/ \mathrm{H}$ has been used in simulations.

- Else if $d_{r}^{(m)} \geq 1$ (UE $m$ has been rate derived in the past). $r_{l_{(m+n)}^{(m, n)}}^{(m,}=0$. and $r_{l_{(n e w)}^{(m . n)}}^{(m)} \geq 0$. 


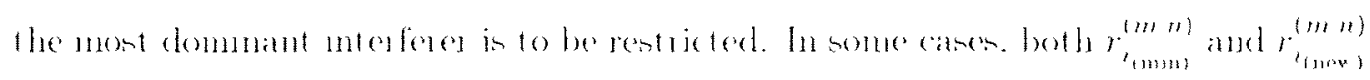
san be fare. If restricting two most dominant interferers provides achicable rate. thene will be marked for restriction.

Note that the above throbold valnem are chesen such that the number of resouree mits restricted by inter-oNI3 algorithm is on areange around 1.5-20\% of the arailathle system

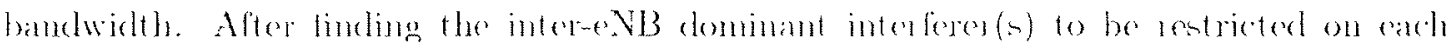
resomce unit and each UE. achirable aten $r_{2}^{(m n)}$ ale calculated. Now. the ntility of resonnce unit $n$ for UË $m$ can be expressed as:

$$
u_{m, n}^{(i)}=\lim _{m} d_{n}^{(m)}
$$

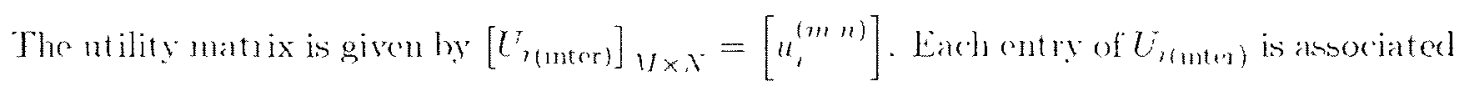
with corresponding interferer(b) to be restricted in addition to the achievalule rate and demand when resomere mit $n$ is used by lit: $m$.

\section{Applying Hungarian Algorithm to Utility Matrix}

Hungarian algorithm is applied to in an iterative manner as earlier. In each sector, steps given belon are followed to prepare inter-e NB resonece units restrie tions.

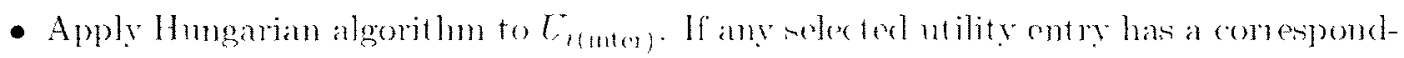
ing interfores restretions. the rentriction lint will be updated with the manked interfores for the resouree mit.

- Update the columns of the utility matrix corresponding to assigned resondre units with zeros. Now, apply the Hungarian algorithm to the updated utility matrix.

- Repeat above steps until all entress of the ntility matrix are zero. The mumber of required iterations is bounded by $\lceil N / M /\rceil$. 


\section{Inter-eNB Communication using X2 Interface}

For a particular resoures unit. Fig. 5.2 shows an example sermario of inter-eNB intercell restrictuons. In this figure. the green (solid line) and rod (dakhed line) arrows indi-

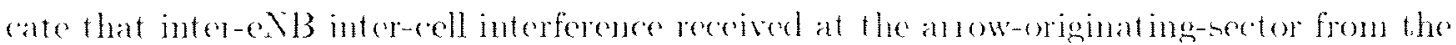

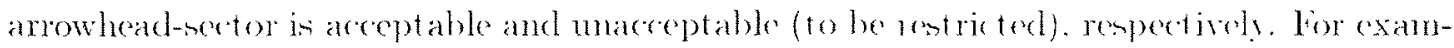

ple. for a resource mit of interest. sector $B$ can tolerate merference from sector $A$. but the opposite is not the an there is a red (dashed) arron from sever it fowand $B$. In this rase. either sector $A$ or $B$ has to be restricted for this resomere mit. In this case. eNB corresponding to sector $A$ communicates with the eNB corresponding to sector $B$ using $X 2$

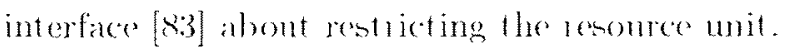

It is cxpected that a pair of sectors wilt have rentretions fon the same resoure wuit in

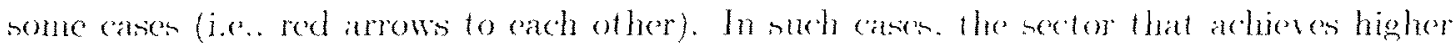
utility survives. The negotiation of resolution of this fype of (onflie ting restrictions is also carried over I2 interface.

Currently. $x 2$ interface supports information exchange between eNBa primarily for mobility management, load management, and interference coordination, which is controlled by X2AP protocol [84]. Protocol message LOAD INFORMLATION is used to indicate UL interference power in there kevelo (low. medium. and high). In oseler for the proponed sedheme

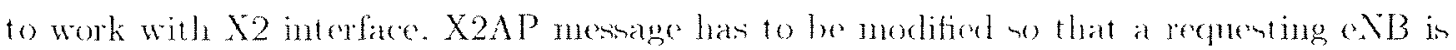
not omly able to pass the index of the resoures mits refuented to be rentreted but aloo the utilities it estimates on those resolure mits. If two eNBs wish to restrict a resouree mit to each other. the deeision would result in favor of the e.XB foresees higher ntilization on that resource unit. In the current message format. instead of passing the interference information eNB can pass utility information. However. 3 levels (i.e. 2-bits) will prohably be too course for the utilities to be momingfully compared. A higher quantization level such as 16-levels (i.e., t-bits) utility information may be recpired which would recquire increased 


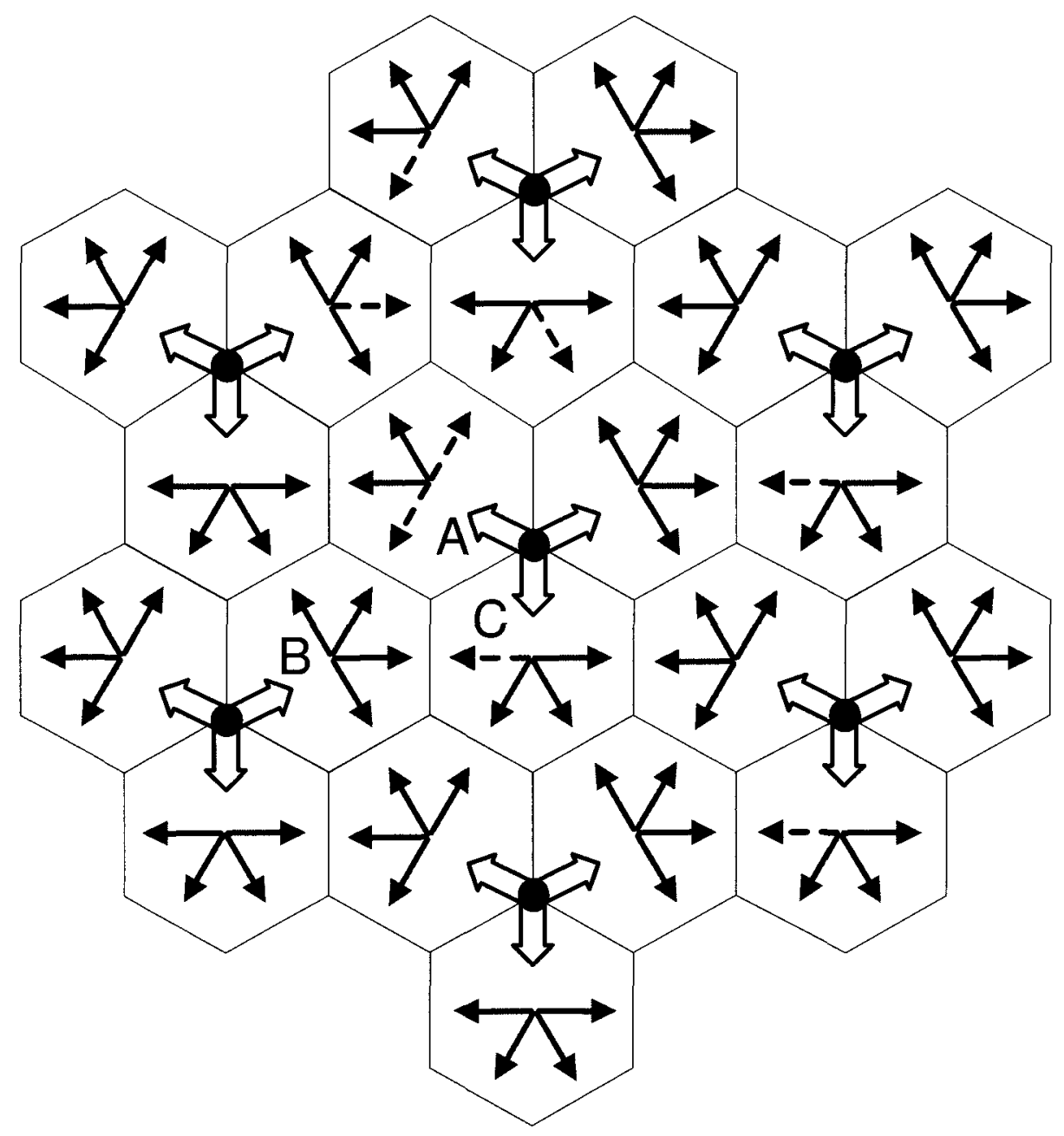

Figure 5.2: Graphical representation of inter-eNB PRB restriction.

rate for eNB-eNB signaling.

\subsection{Simulation System and Parameters}

Considered simulation and system parameters are taken mostly from [33] and [89] as summarized in Table 5.1. Time-frequency correlated 6-taps extended spatial channel model (SCME) with power delay profile as defined in [90] is considered. Independent lognormal shadow fading with a standard deviation of $8 \mathrm{~dB}$ has been assumed. $20 \mathrm{MHz}$ system band- 
Table 5.1: Srstem and Simmation Paranneters

\begin{tabular}{|c|c|}
\hline Parameter & Assumption \\
\hline Collutar Layomt & 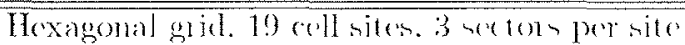 \\
\hline Inter-site Distaner & 500111 \\
\hline Path-lons & $L_{1}=12 \times .1+37 .\left(6 \log _{111}(D) . D \mathrm{in} \mathrm{km}\right.$ \\
\hline Shardowing & 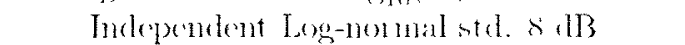 \\
\hline Penctration Loss & $10 \mathrm{~d} 13$ \\
\hline Antemat Pattern & $A(\theta)=-\min \left[12\left(\frac{\theta}{\theta_{i+1 B}}\right)^{2} \cdot 20\right] \cdot \theta_{3,13}=\pi 0^{\prime}$ \\
\hline Carrier / Bundwidth & $206 \mathrm{HL} / 20 \mathrm{MH}$ \\
\hline Channel morlel & (6-Tap SCNE \\
\hline CE spreals of interest & (30) $\mathrm{kin} / \mathrm{h} 11$ \\
\hline Sector TX power & $46 \mathrm{dBn}$ \\
\hline Miminnun UE Distance & $\geq 35,111$ \\
\hline
\end{tabular}

width constitutes 100 resource units. A resource unit consists of 12 subcarriem (eath of 15 KH\%) in frequency and 7 OFDN symbols in the time dimention. Fom and thres OFDM symbols per resoure unit are used for downlink reference and control signalis. respectively. giving $7 T$ OFDN svmbols per resource mit for dat a tralfic. Therefore. a resource unit can carry 77 information bits with QPSK rate $1 / 2$ Nodulation and Coding Soheme (MCSS).

AMC is used with varions MCS modes with QPSK. 16-, and 64-QAM and coding wates ranging from $1 / 8$ to $4 / 5$. Link adaptation is performed using at tesuluted and truncated form of Shannon bound, matched to link level performance curves with above mentioned modulation level and coding rates, as follows [91].

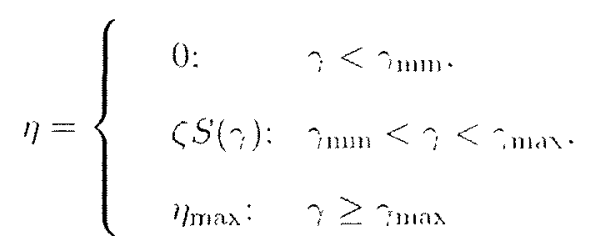

where $\eta$ is the spectral efficiency in bps/Hz, $\gamma$ is the SINR seen on resource unit and $\zeta$ (0.75 used in simulation) is the attenuation factor applied to the Shannon bound given by $S(\gamma)=\log _{2}(1+\gamma)$ which achieves $\eta_{\max }(1.8 \mathrm{hps} / \mathrm{Hz})$ at $\eta_{\text {max }}(19.2 \mathrm{~dB})$ or beyond and 0 at hum $(-6.5 \mathrm{~dB})$ or lower. Automatic Repeat reQuest (ARQ) has not been considered 
Thlble 5.2: Power Allocation to Physical Resouree Blocks

\begin{tabular}{|c|c|}
\hline Scheme & Allocated power / resource unit \\
\hline Renise 1 & $P_{1 / N}$ \\
\hline Rense: & $3 P_{1} / \mathrm{A}$ \\
\hline PFR 1.3 & 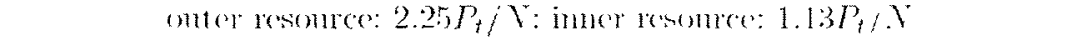 \\
\hline$S F R \quad 1.5$ & onter resoures: $1.5 P_{t} / \mathrm{A}$ : innex resonres: $0.75 P_{t} / \mathrm{A}$ \\
\hline SFR 2.0 & onter resounce: $2.0 P_{1} / \mathrm{A}$ : inner resonec: $0.5 P_{1} / \mathrm{A}$ \\
\hline$S F R 2.5$ & muter resource: $25 P_{t} / \mathrm{X}$ : inner resoure: $0.25 P_{t} / \mathrm{A}$ \\
\hline$S F R 2.75$ & onter resource: $2.75 P_{1} / \mathrm{N}$ : inner resumes: $0.13 P_{1} / \mathrm{A}$ \\
\hline Proposerl 1 & 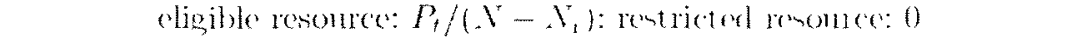 \\
\hline Ploposed? & 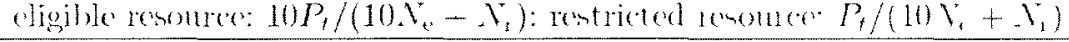 \\
\hline
\end{tabular}

in simulations. For fair comparison. total transmit power per sector is kept constant in all schemers, which is $\approx P_{l}$. Accordingly, power allocated to resource units for different schemes are shown in Table 5.2. In the table. $P_{f}(46 \mathrm{dBm}), V^{*}(100) . V_{1}$. and $V_{\text {. a }}$ are the total power per sector. system bandwidth in terms of number of resoures units. and the number of restricted (from intra and inter-eNB), and unrestricted resource mits. respectively. As shown in the table. restricted resource nnits are umused in proponed scheme 1 and noed with $10 \mathrm{~dB}$ lower power in proposed scheme 2.

\subsection{Simulation Results and Discussions}

The performance of the proposed interference avoidance scheme is compared to that of the reference schemes in terms of edl-edge and average sector thromglnut. Cell-edge thronghput

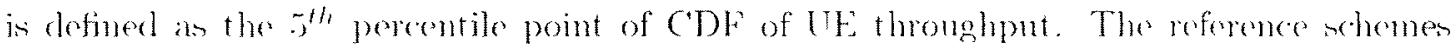
simulated ane rense 1 . reuse 3 . SitR (with effective rene of 1.5. 2.0. 2.5. and 2.75), and PFR (offective rouse of 1.3$)$.

Statistics are collected from a total of 300 drops. In each drop. UEs are uniformly distributed according to a density of $12 \mathrm{UEs} / \mathrm{sector}$. Simulation time span is $25 \mathrm{~ms}$ (50 resource unit time) in each drop. Resource restriction refreshment interval considered is 6 resource mit duration. This time is 3 ms (i.e.. a time-slot of 0.5 mo rorresponds to a 


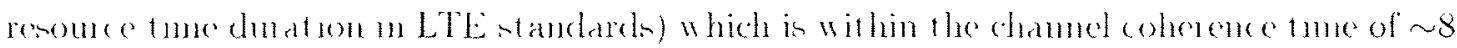
ms for the LE speed of $30 \mathrm{~km} / \mathrm{hr}$ and the operatmo frecpuency of $2.0 \mathrm{GH}$

The tes are placed in the central 21 sectors among the total 57 sectors of 19 sites. For the proposed scleme. allocation algorithms are run in these 21 sectors. Statistice are collected from the central e $N^{2} B$ (3 sectorn) onlw. Interferences in calculated usmg central cell apporath.

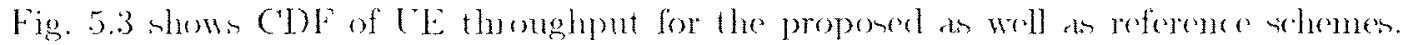
The lowe tall of $\mathrm{CDH}^{2}$ in zoomed in Fig. 5.4 in order to view the cell-edge throughput clearly: Fig. 5.5 companes cell-edge and average sector throughput among all simulated

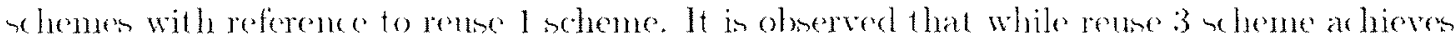
$168.4 \%$ impresement in cell-edge thronghyut companed to rene 1 sehene. it suffers fiom sedor throughput degualation by $19.2 \%$. The PFR scheme imprones cell-edge throughput by $149.7 \%$. however. with $26 \%$ reduction in sector thoughput. SFR schemes with offectwe reuse of 2.0. 2.5. and 2.75 show cell-edge throughpul improsement by $21.4 \% .69 .4 \%$ and $111.7 \%$ with degradation of sector throughput by $4.3 \%, 8.6 \%$ and $26.1 \%$. respectively. SFR scheme with effective reuse of 1.5 neither improves cell-edge nor sector through put compared to reuse 1 scheme. Comparing with reuse 1 scheme, proposed scheme 1 improves cell-edge thoughput by $266.1 \%$ with rn impuovenent in sector throughput by $3.9 \%$. Proposed sheme 2 show inferior cell-edge and superior sector throughput compared to thow in proponed

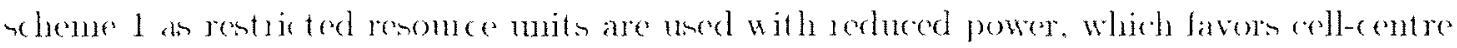
TEs whle harms those at the celledge Howeser. compared to reuse 1 sebene proponed scheme 2 obtains $171.3 \%$ improvement in celledge thromghput while imporing the sector throughput by $7.2 \%$.

The performance gain in the proposed scheme is achieved with the cost of increased overhead sequired for LE-BS forelback as well an eNB-eNB communication over $Y 2$ interface. 


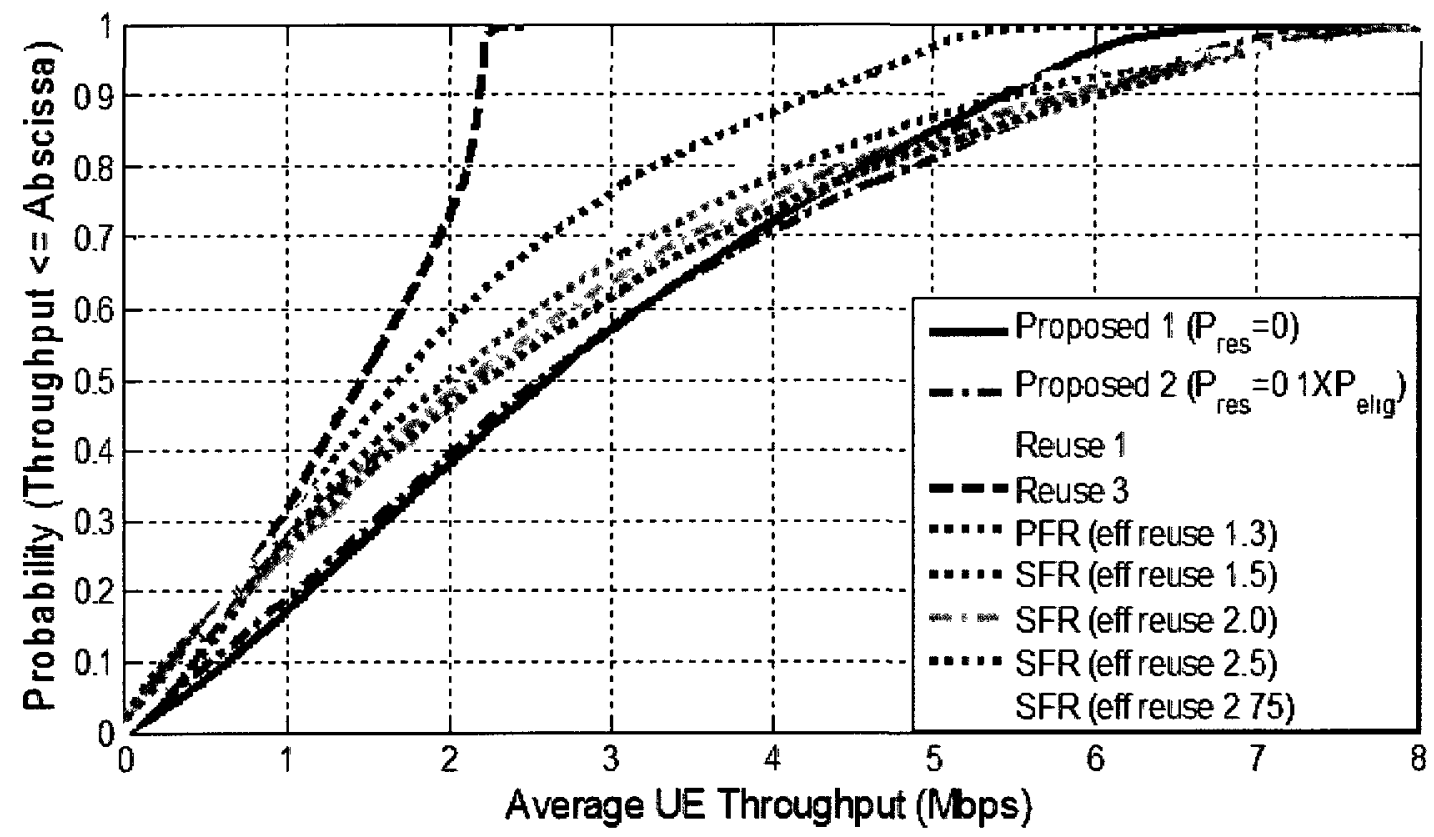

Figure 5.3: CDF of UE throughput.

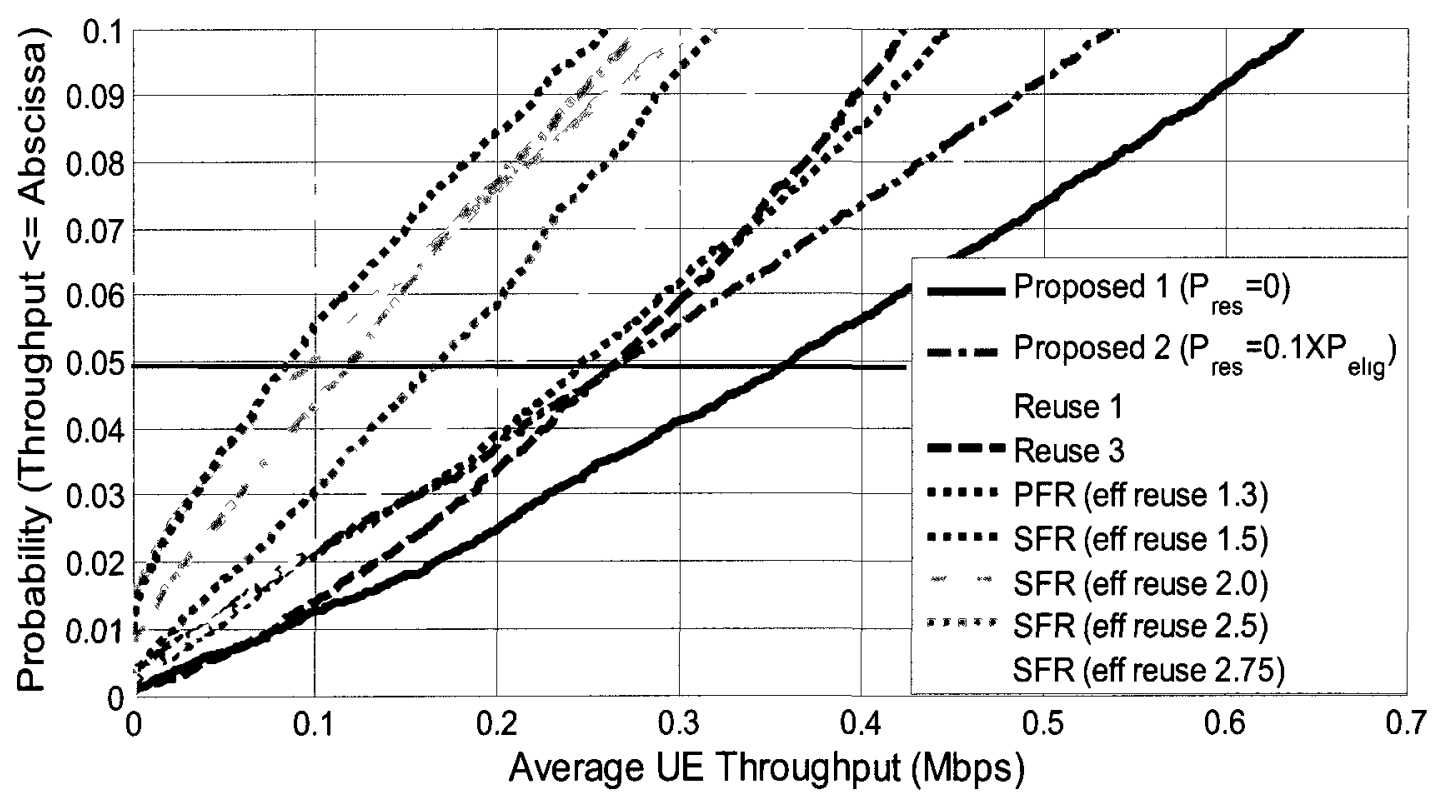

Figure 5.4: CDF of UE throughput (zoomed to show cell-edge throughput). 


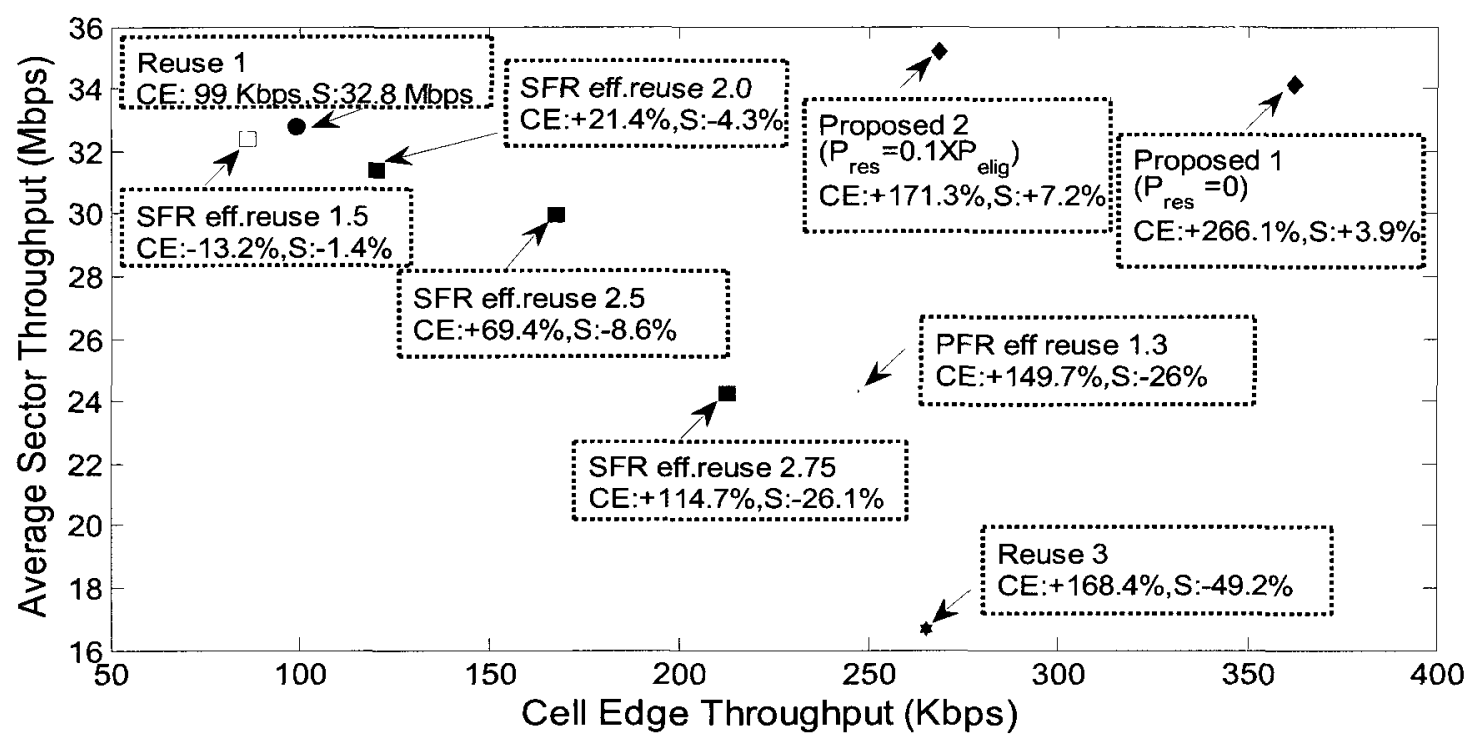

Figure 5.5: Cell-edge vs. average sector throughput.

\subsection{Summary}

An interference avoidance scheme for downlink LTE system that uses dynamic inter-cell coordination supported by $X 2$ interface is presented. Two variations of the proposed scheme have been compared with the reference reuse 1 scheme as well as the static partition based interference avoidance schemes in the literature. It has been observed that although static schemes achieve improved cell-edge throughput, they suffer seriously in terms of sector throughput. On the other hand, the proposed schemes not only achieve higher cell-edge throughput but also show improvement in average sector throughput compared to those in any static schemes. 


\section{Chapter 6}

\section{A Cluster-Based Centralized}

\section{Approach}

\subsection{Introduction}

In this chapter. the performane of a novel cluster-based dynamic inter-eell interference coordination scheme using hinary integer linear programming optimization technique has been investigated that aims to maximize a throughput-and fairness-based utility. The inter-dependency of inter-coll interference among the clusters is modeled in the constrained optimisation formulation. Defferent utility functions for two different coordinatson cluster

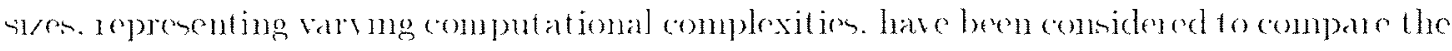
performance. The cell-edge and hector thomghput values an weell as user fammens levels of the proposed schenes are compared with these obtained from the meoordinated interference scenario. To the best of ou knowledge a cluster-based dynamic interference coordination taking inter-cluster interforence rependency, scheduling, user throughput status, etc.. into account in an ILP optimization formulation has not been studied yet. The primary objective of this study is to quant ify a hievable gain of clymamic intesference coordination considering 
nerghboring interference chusters of diflerent stes.

The interforence coorlination problem sated in (3.1)-(3.5) is refermulated as a clusterbased approath. The anthor studied a duster-based integer programming approath to interference coordination problem in a simplistir network secelario furt in [16] and lates in a Jarger notwork in [19]. Based on these previous work. this chapter considers a reduced coordination chuster size that results in lese computational complexity. A detailed complexity

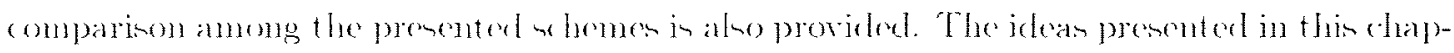
ter are closely related to the coordinated fast scheduling part of the coordinated multi-point transmission and reception (CONP) concept of the LTE-Arlvanced technology [92].

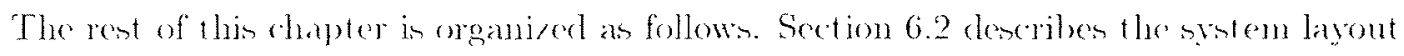
considered. The formulation of the algorithm is presented in Sertion 6.3. The simulation and system paraneters are deseribed in Sertion 6.1. Peformance results and discusted in Section 6.5. The complexity comparison among the schemes is provided in Section 6.6 followed by a briff smmary in Section 6.7 .

\subsection{System Model}

This study has also been conducted in the context of LTE: therefore. a network layout as in Chapter 5 that comints 19 cell siten cald with 3 hexagonal sectom. Directional transmit

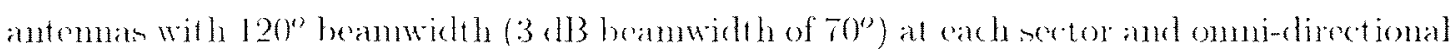

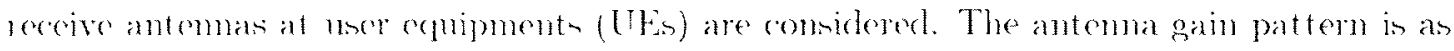
provided in Chapplors 1 and 5.

The system noses cell-specific orthogonal reference signals [4] as assmued in previous chapters and UEs know the reference signals of the neighboring first-tier sectors: therefore, UEs can estimate interference from the first-tier sectors separately. For a downlink transmission to a LE in any sector. One of its first-tier sectors is likely to be the most clomimant interferes. If fig. 3.1 is taken as all example again. it will he seen that a cell-edge UE in 
Table 6.1: Lint of Symbels Lhed

\begin{tabular}{|c|c|}
\hline $1{ }_{1}$ & Whe hast demment interfening wetor \\
\hline 12 & seromel deminatut menterng sector \\
\hline$m$ & le index \\
\hline 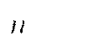 & RB mader \\
\hline M & mumber of lim persector \\
\hline$x$ & 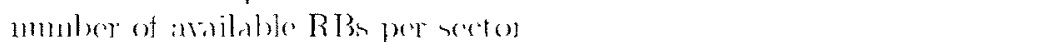 \\
\hline$P$ & powe $18 B$ \\
\hline$P_{l}$ & 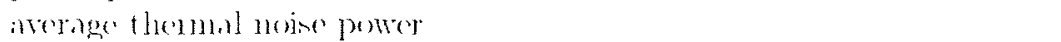 \\
\hline $\mathcal{H}^{(m+n)}$ & 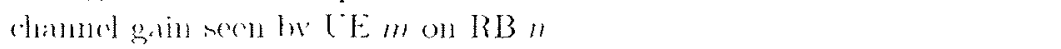 \\
\hline$-(311)$, & 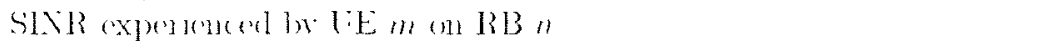 \\
\hline$(,+m n)$ & 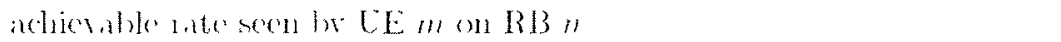 \\
\hline$d^{(m)}$ & I'E demand tactor \\
\hline$I^{(\prime \prime)}$ & indicator to show whethen $R B \|$ is restricted or not \\
\hline$R^{(m)}$ & time average thoughput achiered b. UE in \\
\hline$R$ & arerage throughput acioss all lVE \\
\hline $\mathcal{G}^{(1)}$ & 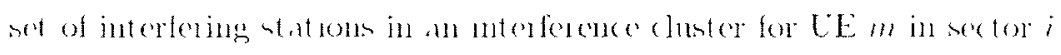 \\
\hline
\end{tabular}

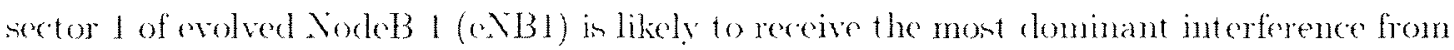
sector 2 or 3 of eNBI (alepending on the [1E location). or from sector 2 or 3 of eNB2. or from sector 3 of rNB3. or fiom seetor 2 of eNBT due to their relative local ioms and antenna directivit:

As mentioned earlier, in addition to its higher path-loss, a cell-edge UE receives significant interference from the nearby sectors. As a consequence. these UEs are expected to see more poor-guality resource unith baving low SINRs. A resomrce mit is defined as the

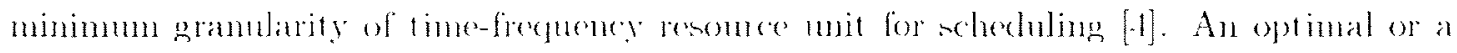
sub-optimal allocation scheme with an objextive of maximising only notwork lusonghput will tend to overlook such disidvantaged LiE due to their pour contribution to the total thronghput. Therefore. it is rrucial to atroid interference on such LE in oreler to guarantere their minimum required rates.

The list of symbols used in this chapter is given in Table 6.1.

Maximization of user rates is only meaningful when user traffic is insensitive to clelay. i.e. elastic traffic [is]. Therefore a utility moasure as a function of rate and user achieved 


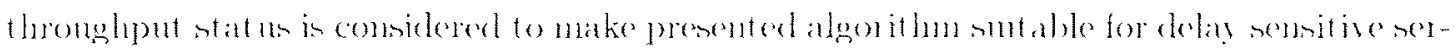

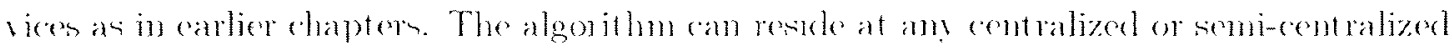
logieal entity to run centrally or in a semi-dist ributed mamuer.

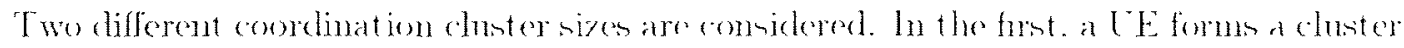
with the two mont dominant interferers (i.e. duster size of 3 ). and in the second. It forms

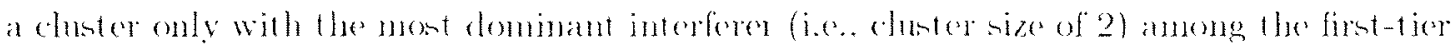

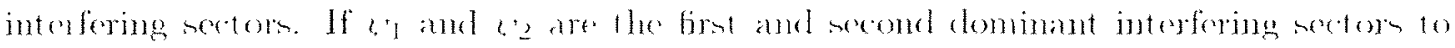
UE $m$ in sector 2 . then the dusters of sizes 3 and 2 for $12 \mathrm{~L}$. respectively are constructed with the indicess of the following interforing sectors:

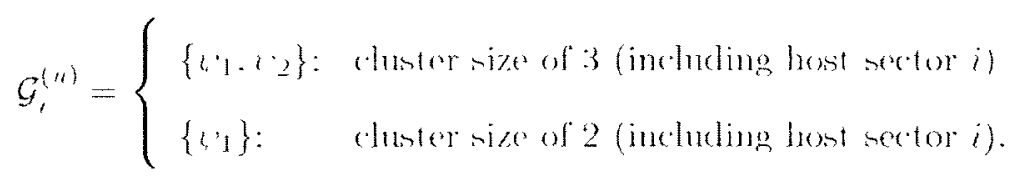

Thene clusters remain une hanged an hong as the L'E locatione do not change. Onee the dumberse determined, we calculate the conditional signal-to-interference plus noine ratios (SINRs) LEs experience for different interforer restriction possibilitios. namely. in the canc of cluster size of 3 , when none, one, and two interferer( $s$ ) is (are) restricted. For a $\mathrm{RB} n$, we

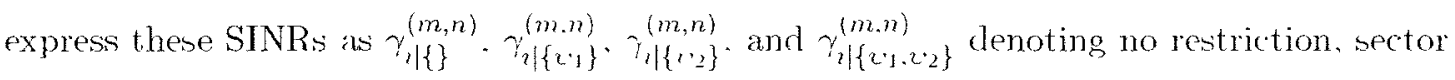

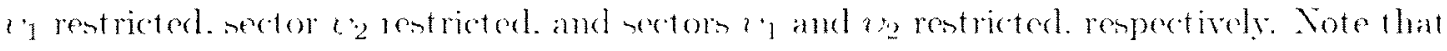

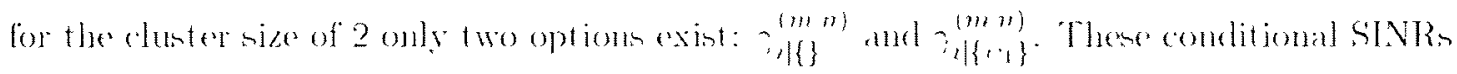
are calculated from the follow ing expression:

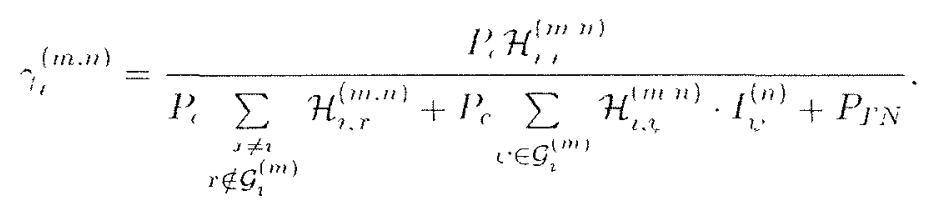

where the channel gain for the desired link. in-cluster, and ot her interferer links are $\mathcal{H}_{e,}^{(m . n)}$. 


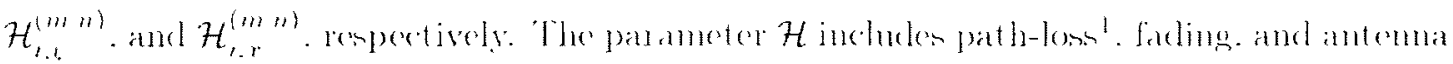
gain. The average thermal nowe powed experienced withm the $R B$ is denoted he $P_{t}$. The

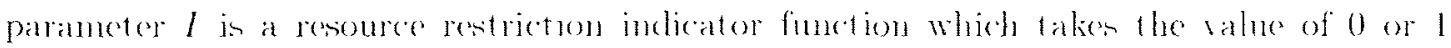
depending on whether a particulan resoures block in restrieted in a rector or not. The allocated power per RB in expressed by $P_{1}$.

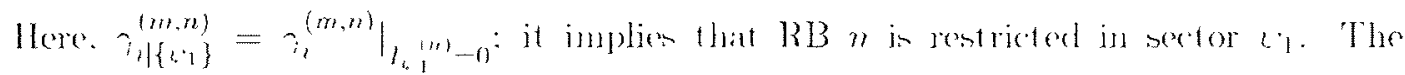
decision of which $R B$ in 10 be restricted in which ser tor is deremined by the solution of the optimization problem as described in the next section. The achievable rates for the corresponding conditional SINRs are obtitined by adaptive modulation and coding (AMC)

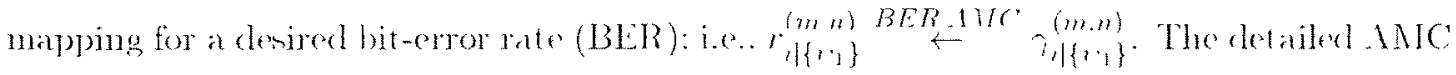
molel is discussed in Chapter 5.

We consider two different utility scenarion for different degrees of emphasis on throngh-

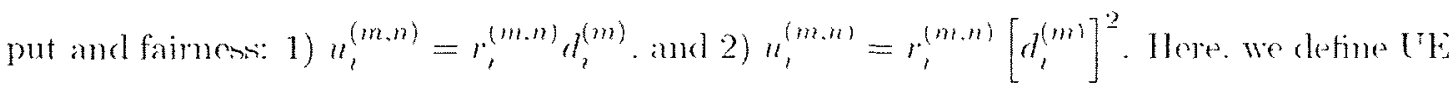
demand fact or $d_{l}^{(m)}$ an follows: $d_{l}^{(m)}=\hat{R}_{l} / l_{l}^{(m)}$. where $R_{l}^{(m)}$ in the average thronghput of lit mover a certain past time-window (a time duation of $10 \mathrm{RB}$ is (onsidered in simulations). and $\bar{R}_{\imath}$ is the average throughput across all UEs and is given by $\bar{R}_{\imath}=\left(\sum_{m=1}^{M} R_{1}^{(m)}\right) / M$. where $M$ is the number of UEs per sector. The latter scenario implements greater emphasis on faimess in scheduling RB. A [E near the cell-edge will likety have a higher $d^{(m)}$. Therefore. the utility incorporating $\left[d_{2}^{(m)}\right]^{2}$ provides adrantigen 10 mate deprived tilis to boost their perfomance. It shoukd be noted that althongh a wility erenario propertional to $\left[l_{1}^{(m)}\right]^{3}$ could provide further enhancement to cell-erlge thromghput. it is mot comsidered in this study due to the fact that it would over-penalize the cell throughy

\footnotetext{
'distance dependent attenuation and shadowing.
} 


\subsection{Problem Formulation}

Ne Commate the ntility maxinisation problem an follows:

maximise

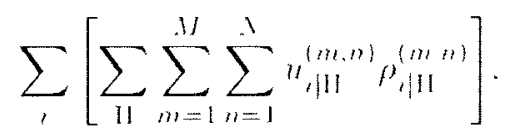

silhjert to

$$
\begin{aligned}
& p_{1|1|}^{(m)} \in\{0.7\}: \forall m . \forall n . \\
& I_{,}^{(n)}=\sum_{n} \sum_{m=1}^{M} p_{l \mid \Pi}^{(m, n)}= \begin{cases}0 ; & \mathrm{RB} n \text { is restricted in } \imath \\
1: & \text { other wise. }\end{cases}
\end{aligned}
$$

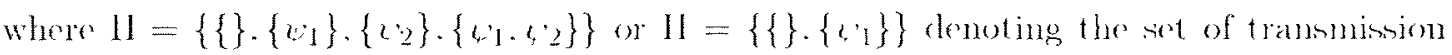
restriction ponsibilities of in-chuster dominant interfering sectoms for cluster siyes of 3 and 2. respectively. The constratuts in $(6.4)$ iudicate that the problem is of binary integer type and those in $(6.5)$ imply that if $R B n$ is not rontrieted in 2 . it can be asigned to only one Ute irrespective of what happons in the tominant interfering sectors.

For cluster size of 3 . if the first and second clominant interferers to $i$ are 4 ' 1 and ' 2 , respectively, then the restriction possibilities are as follows: 1) $\eta_{1}$ and $\eta_{2}$ are not restricted

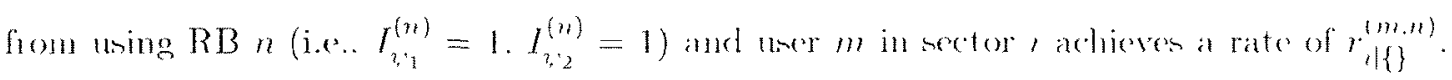

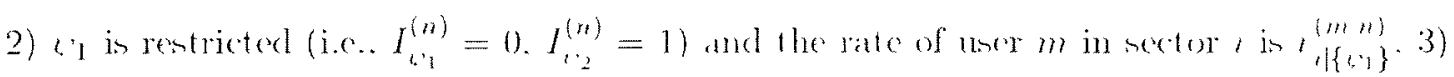

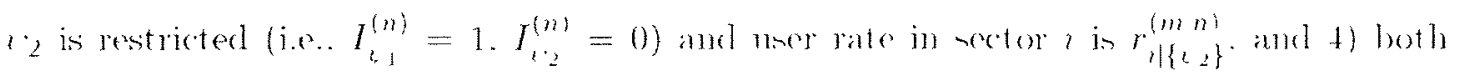

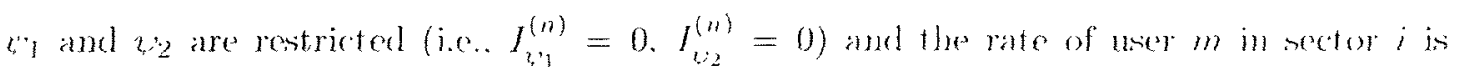
${ }^{2}\left\{\begin{array}{l}(m, n) \\ \left\{\psi_{1} \cdot \psi_{2}\right\}\end{array}\right.$. In calculating the conditional SINRs and raten, it is ansumed that the sectors outside the cluster always use the RB: therefore. the conditional utilities in (6.3) become constant making the formulated optimization problem linear.

Clearly sectors $w_{1}$ and 1,2 impose restrietions to thein on nominant interfering sectors. and this inter-relation would propagate in the network. These rentrictions and coneurrent 


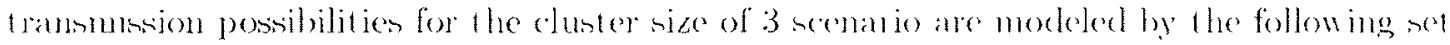
of comstraints:

$$
\begin{aligned}
& f_{i \mid\{i, 1\}}^{(m, n)}+l_{i, 1}^{(n)}=0 \text { or } 1 . \\
& \rho_{\left.1 \mid l_{2}\right\}}^{(m, n)}+I_{l_{2}}^{(m)}=0 \text { or } 1 \text {. } \\
& \rho_{1\left\{x_{1}, n_{2}\right\}}^{(m, n)}+l_{l_{1}}^{(n)}=0 \text { or } 1 \text {. } \\
& \rho_{1\{(n, 1)\}}^{(m+n)}+I_{b 2}^{(m)}=0 \text { or } 1 \text {. }
\end{aligned}
$$

For the cluster size of 2 , the above set of constraints reduces to

$$
f_{z \mid\{(\cdots)\}}^{(m+n)}+I_{i \cdot 1}^{(n)}=0 \text { or } 1
$$

Howerer, wolving this problem network-wide as given by (6.3) through (6.6) or (6.7) with all arailable $\mathrm{RB}$ s at a time is computationally prolibitive due to the large mumber of variables and comstraints. Therefore. the problem is broken down into a number of smatler sub-problems and each sub-problem is solved iteratively. Each sub-problem only takes a sub-set of available $\mathrm{RBs}$ (for instance, $\kappa \in\{1,2, \cdots, N\}$ : we assume $N=10 \mathrm{in}$ simulations) and assigns them among UEs following (6.3) through (6.6) or (6.7).

It is recognized that scheduling hats its own effect on coll-edge and sector throughput. In order to decomple the effect of scheduling. a comsistent scheduling prine iple is uned for all studied sehemes. The following contraints moded scheduling. Where a CE in assigned a maximum of two RBs in each iteration:

$$
\sum_{\Pi} \sum_{n} \rho_{\imath \mid \Pi}^{(m . n)} \leq 2: \quad \forall i, \forall m
$$

The preudo code of the algorithun is given in Table 6.2. where cach sub-problen is solved iteratively until all RBs are aswigned in all sectors following (6.3) to (6.8). 
Tithe 6.2: Psendo Code of the Algorithm

Initialize the list of massigned $R B s \mathcal{L}=\{1,2 \ldots \ldots$.

while $\mathcal{L} \neq\{\}$ do

Take a set of RBs. h. from massigned set $\mathcal{L}: s \in \mathcal{L}$.

Solve optimization problem given by $(6.3)$ to $(6.8)$.

Update $R . \bar{R}$. and $d$ for all $(\mathrm{E}$. $\mathrm{in}$ all sectors.

Remover RBs from $\mathcal{L}$.

end while

\subsection{System and Simulation Parameters}

As this scheme is studied in the context of LTE system. system and rimulation paraneters are as described in Chapter 5 with a fow exeptions. However for realability. Table 6.3 in provided. where system and simulation parameters are summarized. Here. 10 Mllz of system bandwidth (i.e. 50 resource umits) in used instead of $20 \mathrm{MH}$. This assumption was taken to speed up simulation run-time. The chamel nodel large-scale path-loss antenna patterm. AMC functions. otc. remain the same as in Chapter 5. MATLAB along with optimization solvers YALM]P [86] and TOMLAAB/CPL.EX [93] is used.

\subsection{Simulation Results}

For each utility scenario. we consider a corresponding reference scheme which also maximizes the same utility parameter with the difference that the reference rebeme does not have the apability of interference coortination (namely, no ICIC). Therefore. the gain observed in the proposed scheme in entirely due to inter-eell interference coordination. The cellexlge throughput (mostured as the $5^{\text {th }}$-percentile point of the CDF of time-averaged CE throughput), average sector throughput (averaged over central 3 sectors), the $95^{\text {th }}$-percentile UE thronghput, and Jain's fairness index [29] have heen used in order to compare the performance of the proposed schenes. Coordination chuter sizen of 2 and 3 representing different computational complexities are comidered. 
Tahle 6.3: System and Simmlation Parameters

\begin{tabular}{|c|c|}
\hline C'cllnlan lerout & $\begin{array}{l}\text { Hexigonal grid. 19 adl sites. } \\
3 \text { soctors per sito }\end{array}$ \\
\hline Inter-site dintanes & $5010) \mathrm{m}$ \\
\hline Canrieg forefucoucy and handwidth & 2.0 GIl, and $10 \mathrm{MHL}$ (5) RBs) \\
\hline Path-losis cxponent & 3.76 \\
\hline Lognonual shatowing & Indrejoudent annomg links \\
\hline Shadowing stamelard deriation & $8 \mathrm{~dB}$ \\
\hline LE spreds & $30 \mathrm{~km} / \mathrm{hn}$ \\
\hline Penotration lons: & $10 \mathrm{~dB}$ \\
\hline Antomat ronfiguration & Single-input siugle-ontput \\
\hline BS antcuma gain & $14 \mathrm{AB}_{1}$ \\
\hline UE antenna gain & () $\mathrm{dBi}$ \\
\hline UE noise hgura & $7 \mathrm{~dB}$ \\
\hline AMC morles & $\begin{array}{l}\text { Attcmatrd Shammon bomnd } \\
\text { for QPSK, } 16 \text { - and } 64-\mathrm{QAN} \\
\text { with wrying rates }\end{array}$ \\
\hline Chamol model & $6-t a p$ SC:MLE \\
\hline Total inetor TX power & $.46,1 B n$ \\
\hline UE $\operatorname{los}(-\mathrm{in}$ distance & $35 \mathrm{~m}$ \\
\hline Traftic model & Fill butler \\
\hline
\end{tabular}

In cach of the central 21 sectors. $10 \mathrm{UEs} / \mathrm{sector}$ are placed randonly for each simnlation drop. Interferers are coordinated in these sectors only: the remaining sectors act an interference contributors only, where it is assumed that all RBs are always used in these sectors. Each drop is simulated for 50 RBs time duration and a total of 200 drops is considered for each utility scenario and for each studied scheme. Statistics are collected from the central 3 sectors belonging to Coll I. Liser demand $d$, is calculated from the past throughput achieved wer 10 RBss time cluation.

The CDF: of time awerged UE thronghput is shown in Fig. 6.1. In the inset of the figure. the tail of the CDF is zoomed for the clarity to observe the $5^{\text {th }}$-percentile point (i.e., cell-edge throughput). The observed performance parameters from this figure is also summarized in Table 6.4. In all cases, $u=r d^{2}$ scenario with ICIC shows larger gain in terms of cell-edge throughput compared to $u=r d$ scenario. Also, in the ICIC schemes, the $u=r d^{2}$ scenario achieves less sector throughput and less $95^{\text {th }}$-percentile UE thronghput 


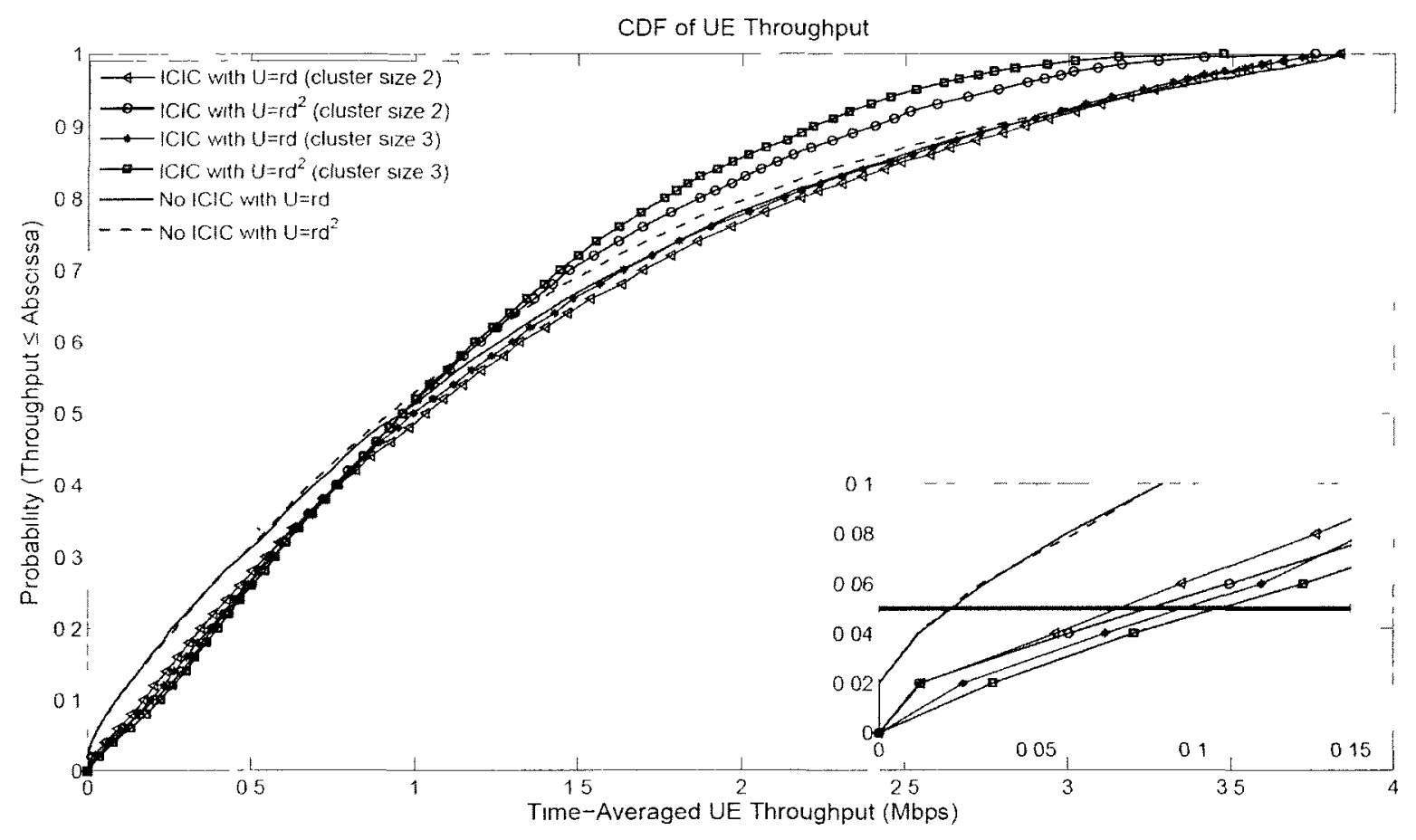

Figure 6.1: CDF of time-averaged uscr throughput.

Table 6 t: Comparison of Cell-Edge (-5h Percentile) $95^{\text {th }}$ Percentle, and Total Sector Thonghput

\begin{tabular}{|c|c|c|c|}
\hline $\begin{array}{l}\text { Studied } \\
\text { Schemer }\end{array}$ & 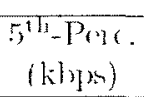 & $\begin{array}{c}9.3^{-11}-P_{t+16} \\
(\mathrm{Nl} p \mathrm{p})\end{array}$ & $\begin{array}{l}\text { Total Sector } \\
\text { Thromglyme (Mhps) }\end{array}$ \\
\hline Xo IC'IC witls $n=r d$ & 23.2 & 330 & 12.11 \\
\hline NoICIC with $u=r d^{2}$ & 20.9 & 3.29 & 11.79 \\
\hline ICIC $n$ ith $u=\Rightarrow l($ cluster size 2$)$ & 76.3 & 3.26 & 12.76 \\
\hline ICIC woth $u=m t^{2}$ (cluster sice 2$)$ & 825 & 2.78 & 11.12 \\
\hline ICIC with $\|=r d($ clunter size 3$)$ & 09.3 & 3.23 & 12.56 \\
\hline 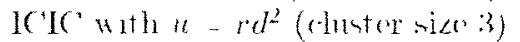 & 109011 & 273 & 11.01 \\
\hline
\end{tabular}

showing a clear trade-off between cell-edge and sector throughput. The scheduling weight does not provide any noticeable gain in cell-edge throughput for the reference scheme.

While the coll-erge performance an be entrome ed by a fartor of 5 for the clunter size of 3 with $u=r d^{2}$ senalio. sector throughput is aflected aluesty. Howeres. in the and of cluster size of 2 . it is obscrved that the cell-edge thoughput an be improved by a factor of 3 to 1 . while the sector thronghput is comparable or evon better than those in the reference no ICIC rase.

We compdre achieved fairness index using Jain's fairnens index in Fig. 6.2. It is observed that shemes with ICIC for all utility seenarios show better faimesis compared to those where ICIC is not used. The $u=1 d^{2}$ secnario with IC IC for the chuster size of 3 exhibits the 


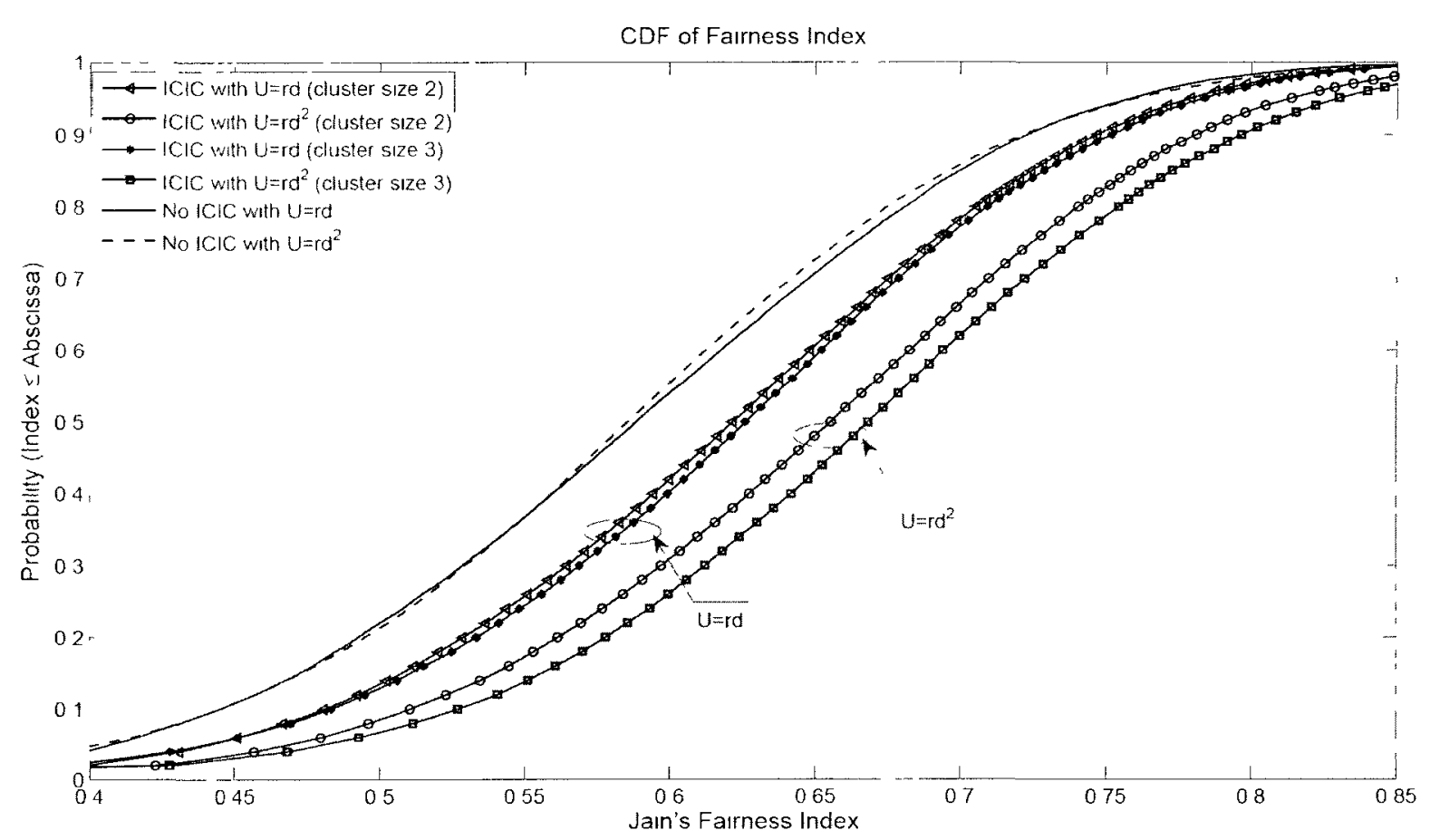

Figure 6 2: CDF of Jain's faimess index.

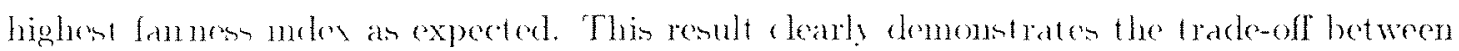
the enhamed cell-edge thronghput and degraded rector themghput.

\subsection{Simulation Time Comparison}

The romputational complexity of an ILP solver depenets on the mumber of variables. A comparison of required simulation time for each allocation iteration among studied schemes is provided in Table 6.5. The stated number of variables are for all the 21 sectors having users in them for cach iteration of the algonthm. Wo note that the number of binary

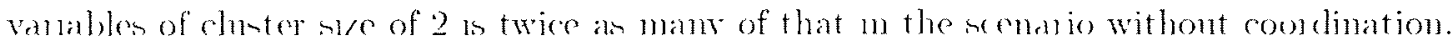
And. the sermario wath eluster size of 3 recpuren la ice an many variables compared to these in cluster size of '2. The arorage computatiomal time taken by the CPLEX solver per Iteration of the algorithm for the wo ICIC case in $16 \mathrm{~ms}$. while thin for cluster sizen of 2 and 3 are $76 \mathrm{~ms}$ and $300 \mathrm{~ms}$. respectively. The optimization constraint processing times required by YALMIP are $189 \mathrm{~ms} .520 \mathrm{~ms}$, and $1.38 \mathrm{sec}$ for no ICIC. chuster size of 2. and size of 3. respectively.

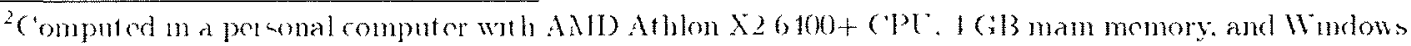
XP gt-bit OS
} 
Table (1.5): Simnlation Time Compartison

\begin{tabular}{|c|c|c|c|}
\hline $\begin{array}{l}\text { Sturlied } \\
\text { Socmatio }\end{array}$ & $\begin{array}{l}\text { So. of } \\
\text { Coniablom }\end{array}$ & $\begin{array}{l}\text { YAlanP Time } \\
\text { (reeditention) }\end{array}$ & 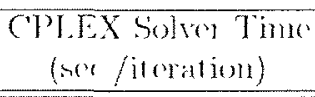 \\
\hline Xo IC'IC' & 11.25 & 0.184 & $0.016 ;$ \\
\hline IClo with chuster size 2 & 2310 & 0.520 & 0.076 \\
\hline 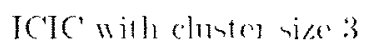 & 1620 & 1.378 & 0.300 \\
\hline
\end{tabular}

\subsection{Summary}

In this (haples. we has presented a dymamie inter-cell interference coordination (IC'IC) scheme tor downlink OFDNA syntem. Two different utility parameters have becn defined to moclel different levels of user fairness. Furthermore, two different coordination cluster sifus representing different complexities have ben comsidered. The problem is decomponed into a muntres of smalle submproblems and solved iteratively.

It is observed that schemes employing ICIC outperform the corresponding reference schemes withont coordination. with regard to cell-edge performance. sector thronghput. and fairnest. In particular. The utility scenario $u=r d^{2}$ with ICIC for the chuster size of 3 achieves 5 times coll-edge throughput. substantially better faimess. and slightly degraded sector thronghput compared to those in the corresponding reference scheme without ICIC. at the expense of substantial computational complexity. However. it is onserved that around 3-

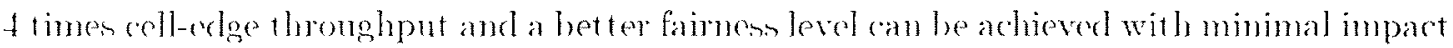
to or eren some gain in sertor throughput companed to these in the eferene scheme when the coordination chuter size is 2. requining only a reasenable increase in computational complexity 


\section{Chapter 7}

\section{Conclusions}

In thin themis a titerature review on interference aveidance has been provided and then claborate descriptions of the proposed schemes on dymanic inter-ell interference coordination are prenented.

In Chaptes 3. a general optinization framework that maximises the sum-utility for the interferenee coerdination problem is formulated. Besides chamed quality the utility takes users' achieved thromghput status into acconnt and provides advantage to the celledge user terminals. Three different approaches have been considered that reflect different coordination means. notwork architectures. and complexities. as outlined from Chapter 4 10 Chapter 6. In all proposed approatedes. performanes has been compared to schemes where interecell interforence condination in cither not used or used in a statie mamer. The reference schemes use the same scheduling criterial and work with the same utility limetion an those in the proposed schemes. Therefore. the observed performance gain solely represent the strength of interference coordination in the presented schemes. It is observed that proposed schemes always significantly outperform the reference schemes in terms of coll-edge thronghput and fairness. and with a minimum impact on notwork throughput or gatin in somer (atsen. 


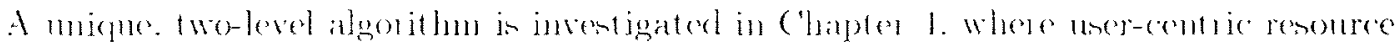
gentriction recuent is prepared by the sector-level algonthm. While the sector-level algorithm is banerl on henristic. the central algonithm is fommlated wing an ILP that resolven any"

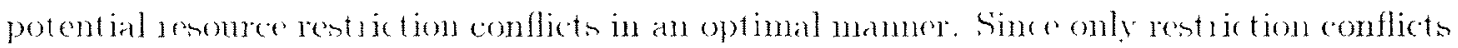
are handled at thes stage. the overall complexity of the scheme is much lent than that in the onieinal problem formulated in Chapter 3. Two different asen have been investigated: in

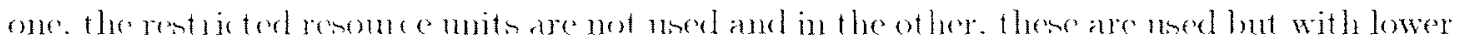
transmit porver. Reference schemes to which the proponed schemes are compared are Reuse 1. Reuse 3. and a PFR. Both full-buffer (i.e., BS always has data to send) and traffic model

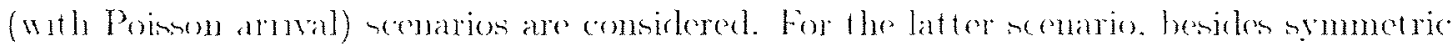
Iraffic where sach BS has the sume average arrisal wate we aloc consider the case where some secters are in the hot-ypot having higher traffic arrival rate. We une two different schedulers-iterative Humgarian and proportional fair. It is observed that Rense 3 scheme arheves the highest cell-edge throughput. however, with significant degradition in cell throughput due to resemes partitioning. and Remse 1 achieves the highest cell throughput with the poorest performance with respect to cell-edge throughput. On the other hand. the cell-edge performance of different variations of the proposed schemes can reach close to the level of Reuse 3 while their cell throughunt is comparable to that in Rense 1.

A distributed algonthm with neighboring (e)l coordination is presonted in Chapter 5 . The algorithm dest not require a central controller and resoures coomelination is performed Using BS to BS commumiation uning an interface surb as the X2 interface of the ITE systems. The interference originated from transuitters within the same BS in coordinated using a novel method based on Hungarian algorithm in a multi-cellular (i.e.. multi-sector) context. The inter-BS interference is handled similar to the previous scheme in Chapter 4. however, resource entrietion conflicts are resolved by inter-BS communication over the $\mathrm{X} 2$ interface. A number of reforence schemes have been considered such as Reuse 1, Reuse 


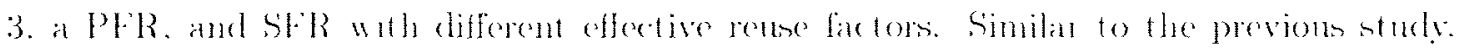

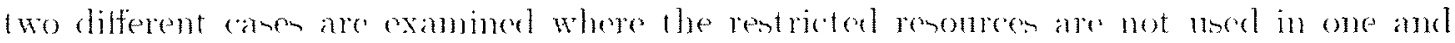
uned with lowe poner in the other. It in observed that the proposed selemes ran attain coll threnghput quite rose to or shghtly betted than that in Reuse 1 while achieving a companable or slighty better coll-edge throughput that in athierod in Rense:3.

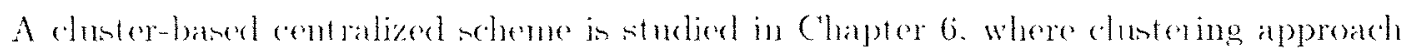
significanty reduces the omplexty of original problem fonmulated in Chapter 3 . Although far-away interferers may not affect signal qualities. the inter-dependency of interference propagates throughput the whole network. Therefore. inter-cluster relationship is modeled

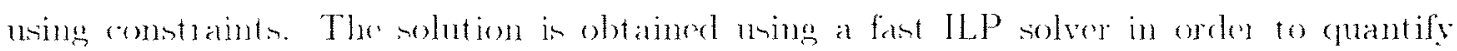

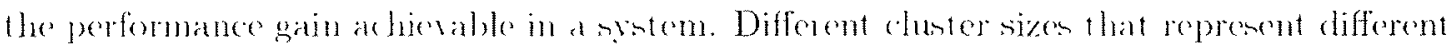
computational complexity and differont utility functions for varing levele of faimeso have been sturlied. The presented solemem achiexe signifieant gain in coll-edge throughput with-

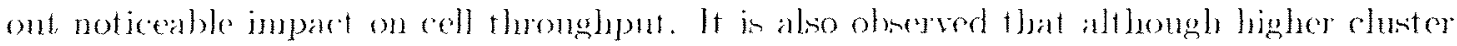
size infurexpentially high complexity. the differential performance gain does not seale accordingly and observed to he molest.

While hoth the two-level algorithm with partial central procesing and the cluster-based centralized algonithm can be applied to systems in which central procensing in foasible. the

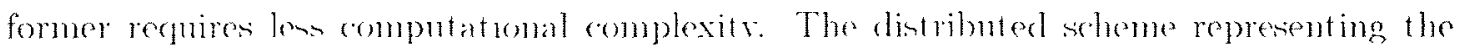

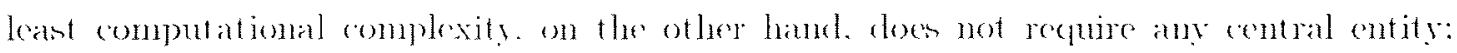

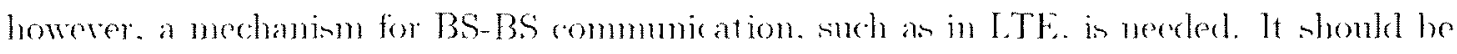
noted that although the LTE specilications do not encomage contratized RRMI sebemes, some of the key features of the future LTE-A systents are based on centralized processing. Therefore, al] three presented schemes can be applied to sich future systems. 


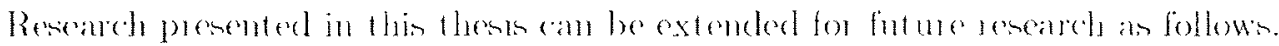

\section{Utility functions}

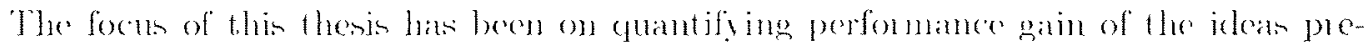
sented on trmamic interferener coortination. Therefore. simple and intuitive utility functions have been incorporated given the fare that both the propesed and references

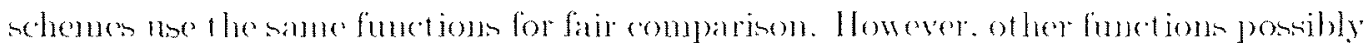
with additional Qos parametem may he explored which may further enhance network performance.

\section{Power control in conjunction with resource restriction}

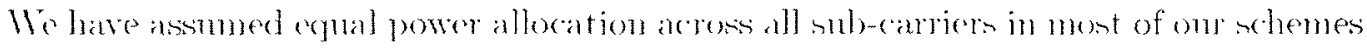
with the exception that a variation of the proposed scheme unes the restrieted fesomere units with much lewer power than the unrestricted resoneses. Although it has been shown that power control does not exhihit significant gain in thronghput for an OFDNA-based sistem that aheady acheres chamed selectivity ame multiuser diversity gain using AMC [63]. power control will have significant inupact on cell-edge performance. This research can be extended to include power control along with resouree restrictions.

\section{Inchusion of Multiple-In Multiple-Out (MIMO) antemua configuration with} different combining algorithms

Only SISO antema configunation has bern used in this thesis for simplicity. Future research may inchude MINOO antennas with different rembining methodis as well ats with transmit and receive diversity techniques.

\section{Integration of ICIC with other interference mitigation techniques}

The dynamic ICIC schemes presented in these these can be combined with other 


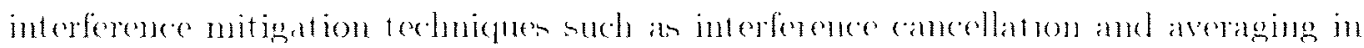
order to asosess total mitigation gain in the network.

5. Combining with Physical (PHY)-layer Coordinated Multi-Point Transmission and Reception (CoMP)

As mentioned. the ideas presonted in this thesis are guite smilar to coordinated scheduling pant of the omerging ConP tedmotogs. Thene shemen can be combined with PllY-layer ConP procensing to absesin orerall interference avoidance gatin of the system. 


\section{References}

[1] A. Ballard, "A new multiplex technique for communication syotcms." IEEE Transactzons on Pouer Apparatus and Systems, vol. 10. pp. 1054-1050. Oct. 1966.

[2] Part 11: Wireless LAN Medum teress Control (MAC) and Physucal Layer (PHY) Sperfications. LEE Standard 802.11-2007. Dex. 2007. Arailable online at hitp://standards.iece.org.

[3] "WiMAX and the IEEF, $802.16 \mathrm{~m}$ air interface standard." [Online] Amilable: http:/ www mathorks.com, White Paper. WiMAX Form. Apr. 2070.

[4] E-UTRA and E-UTRAN Overall description: Stnge 2 (Release 8). 3GPP Techmical Specification TS 36.300 V8.7.0. Der. 2008. Available online at http://www.3gpp.org.

[5] Requerements for Further Adrancements for E-LTRA (LTE-Adunced) (Relrase s'). 3GPP Technical Specitiontion TR 3(j.913 V8.0.0. Jun. 2008. Avalable online at $h+1): / /$ ww.3gpp.org.

[6] WINNER II System Concepts Descrptzon. WINNER II Deliveral)] DG.13.14. Jan. 2008. Availahle online at http://www.ist-wimner.org.

[7] Inatial Report on Advanced Multiple Antenna Systems. WINNER+ Deliverable D1.4. Jan. 2009. A vailable online at http://projectsceltic-initiative org/wimert. 


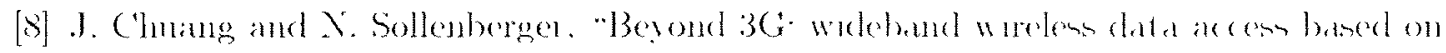

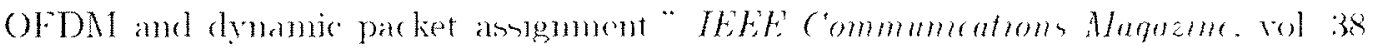
p). is 8 T. Jul. 2000 .

[9] H. W. Kum. "The Humgarian method for the assigmment problem " Natal Re searth Loustues Quarterly. vol. 2. pp. 8307.1955.

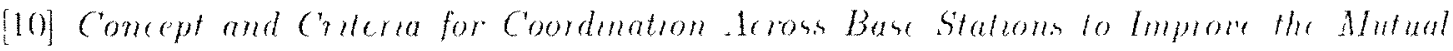
Interference Situation. WINNER I Deliverable D3.3. Jun. 2005 Available online at http://www.int-winner.org.

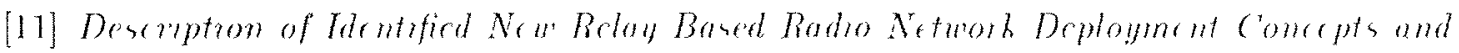
First Assessment by Comparison Aqamst Benelmarhs of Hell-Known Diploument Concepts Ling Enhanced Ratho Intertare Technologes. HINNER I Deliverab]e D3.1. Now. 2004 Available online at http://wwwist-wimner.org.

[12] Description of Identificd New Relay Based Radio Neturort Deployment Concepts and First Assessment by Comparison Against Benchmaiks of Will-Knoun Deploymont Concepts Uang Enhanced Radıo Interfacr Technologıes. WINNER I Deliverable D3.2, Feb. 2005. Available online at http://www.ist-winner.org.

[1:3] Proposal of the Best Sutted Deploument Concepts for the Identefied Sermarnos and Related RAN Protocols. WTAXER I Deliverable D3.5. Jan. 2006. Avalable anline at http://www.st-wimer.org

[11] M. Rahman and H. Yanikomenoglu. "QoS provisioning in the alsonce of $A R Q$ un collular fixed relay networks through intercell coordination." in Proc. IEEE Global Communcations Conference (GLOBECOMg006), San Franciscu, Califormia, USA. Nor. 2006.

[15] Interference Avordance Concepts. ITIXNFR II Deliverable D4.7.2. Jum. 2007. A wallable online at http://www.ist-wimner.org. 
[16] M. Rahmen and H. Yanikoneroglu. "Multeell downlink OFDXI sulxhammel allocations using dymanis intercell coordination" n Prot. IFEE Global Commanuahoms Conferene (GLOBECOMEg07). Washngton DC'. ISA. Nov. 2007.

[17] - - "Interference a widance threugh dynanic downlink OFDNL subehamed allocation using intercell coosdination." in Proc. IEEE Vohedur Techmonogy Conference (ITC)008-Spming). May 2008. pp. 1 (630 1635.

[18] - Enhancing cell-erlge performance: A downlink dynamic interference avoidance scheme with inter-cell coordination," IEEE Transactions on Worless Communuctions, vol. 9. pp 1+11-1425. Apr 2010

[19] . "Inter-eoll interference coordination in ofduna networhs: at nowel appuroath betsed on integer programming." in Proc. IEEE Vehcular Technology C'onferene (VTCO010Sprong). Nay 2010.

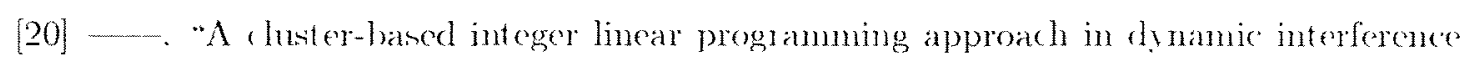
coordination," submetted to IEEE Transartons on on Veharular Technology. Jun. 2011.

[21] M. Rahman, H. Yanikomeroglu, and W. Wong, "Interference avoidance with dynamic inter-cell coordination for downlink I.TE system," in Pror. IEEE Wreless Commumatrons and Neturotimg Conference (Wr N(')009). Apr. 2009.

[22] M. Salem. A. Arlinoyi. Y Rahman. H. Yanikomerogln D. Falcener, atmel Y -1). Kim "Apparatur and method for alloxating subchameds and contollong interference in OFDMA sistems." 2000.

[23] M. Salem, A. Adinoyi, M. Rahman. H. Yanikomeroglu, D. Falconer. Y. D. Kim, and E. Kim. "Fairness-aware joint routing and scheduling in OFDMA-based nulti-cellular. fixed relay networks." in Pror. IEEE Internatyonal Conference on Communications (ICC2009). Dresken. Germany. Jun. 2009. 
[24] M. Salem. A. Adinoyi. M. Rahman. 11. Yanikomerogh. D. Falconer. Y.-1). Kim. E. Kim. and Y.-C'. ('heong. "An overview of ratio resource management in relay-embanced OFDNA-based networks." ISEE C'onmmmetions Surveys and Tutorals, rol. 12.

[2.5] M. Salem. A. Adinoyi. M. Rahman. H. Yanikomerogh. D. Faleoner, and Y. D. Kint. Faimess-aware radio resource management in OFDMA-based cellular fixed yelay networks." HEEE Thansacton on Hom less Communcations. vol. 9. pp. 1628 1639. Nay 2010 .

[26] F. A. Bokhari, H. Yanikomeroglu. W. K. Wong, and M. Rahman, "Fairness assessment of the adaption token bank fair quening scheluling algorithm." in Proc. IEEE Vehicular Terhnology C'onference (ITCOOog-Fall). ('algary. Canala. Sop. 2008.

[27] . "Crems-layer resoures scherhling for multimedia traffic in the downlink of $4 \mathrm{~g}$ wireless multicarrier networks." EURASIP Joumal on Wheless Commumutions and Netuorking.

[28] P. Djukic, M. Rahman, H. Yanikomeroglu. and J. Zlang. Evolved Cellular Nelwork Planning and Optzmization for LMTS and LTE. Auerbach Publications. CRC Press. Taylor \& Francis Group, 2010. ch. 12, pp. 433-454.

[29] R. Jain. D. N. Chiu, and W. Hawe. "A chantitative measure of faimess and disclinimation for resource allocation in shated systems." DEC. Research Report TR-30t. $19 \$ 4$.

[30] V. H. MacDonald. "The cellular concept," Bcll System Technecal Journal, vol. 58, pp. 15-41, Jan. 1979.

[31] A. C. Stocker. "Co-channel interference and its avoidance in close-spaced systems." IEEE Transactions on Vehu'ular Technology. vol. VT-31. pp. 145 150. Aug. 1982. 


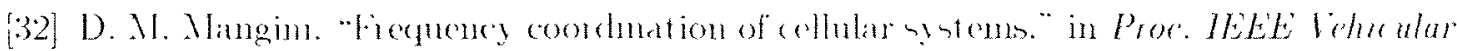

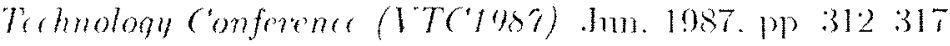

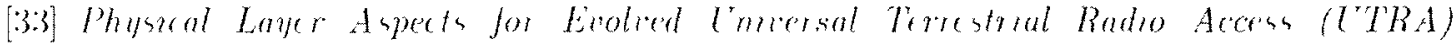
(Release 7). 3GPP Technical Report TR 25.811 V7.10. Sej). 2006. Arailable online at $h+1] \% / /$ ww .3gpporg.

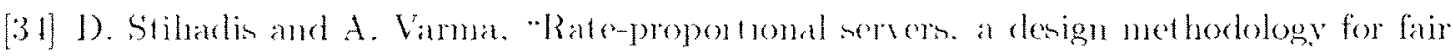
queneing algorithms." IEEE/ACM Transactions on Nftworhing, vol. 6. pp. 164-174. Apr. 1998.

[35] K. Begain. G. I. Rozed. A. Pfonng. . and M. Telek. "Performance analysis of GSM network with mtelligent underlas-oves lay." in Proc. Sf unth Internatzonal Symposimm on C'omputers and Communcatoms (ISC'C'-2002). Jul. 2002. pp. 135141.

[36] M. Shariat. A. U. Quddus, and R. Tafazolli. "On the efficiency of interference coordnation schemes in emerging cellular wineless netwonkn." in Proc. IEEE Sympostum on Personal, Indoor and Mobule Radno Communucutions (PIMRC 2008), Sep. 2008.

[37] OFDMA Downlmk Inter-Cell Interference Mitrgation. 3GPP Project Document R1-060291. Foh. 2006. Available online at hitp://www.3gpp.org.

[38] Soft Fingurney Rouse Scheme for LTRAN LTE. 3GPP Projert Docment R1-0.50507.

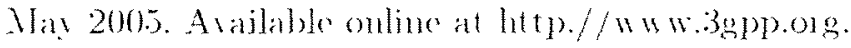

[39] Further Analysis of Soft Frequency Reuse Scheme. 3GPP Project Document R1-0.50841. Sep. 2005. Available online at http://www.3gpp.org.

[40] Performance of Inter-Cell Interference Mitıgation with Semi-Statıc Frequency Planning for EUTRA Doumlmk. 3GPP Project Docmment R1-060368. Feb. 2006. Available online at http://www.3gpp.org. 


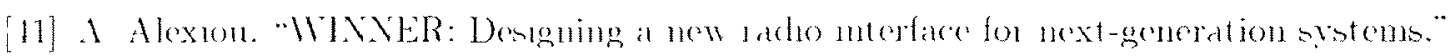
Bell Labu Tirhmeal Joumal. vol 2. pp. 1935. Ang. 2007.

[12] II Stemad. T. Ottomon. A. Ahlen. and A Svembon. "Attaining both coverage and

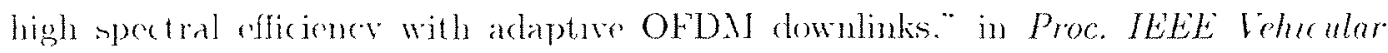
Trehnology (onfermen (VTC2003-Fall) Oct 2003. pp. 24802490.

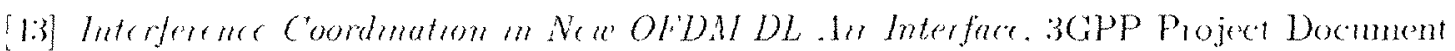
R1-0.50 407. May 2005. Available onlune at http://www.3gpp.org.

[4.4] Multi-cell Simulation Results for Interfereme Coordination in New OFDM DL. 3GPP Project Doc ument R 1-0.50501. Jun. 2005. Araldale online at http.//w ww.3gpporg.

[45] Multi-cell Sumulation Results for Interference Co-ordmation in New OFDM DL, 3GPP Project Document R1-050694. Sep. 2005. A atalable online at ht p://ww 3gpp.org.

[16] Dounhik Inter-Cell Interfernere Coordmation/Auoidance - Enaluation of Frequency Re'use. 3GPP Project Document R1-1061374. Nay 2000. Available online at http://www.3gpp.org.

[4] DL Power Allocation for Dymame Interference Avoidance, 3GPP Project Document R1-1)70010. Jan. 2007. Available online at http:// a ww.3gpp.org.

[18] Y. Xiang. J. Law and C. Hartmamn. "Inter-e dl inter ference mutigatıon throngh flexible

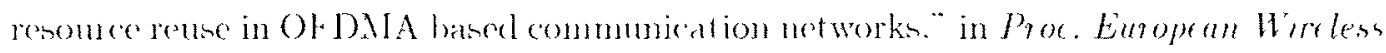
3007. A jpr. 2007.

[49] K.-W. Lee, J.-W. Ko, and Y.-H. Lee, "Fast cell site selection with interference avoidance in packet based OFDM cellular systems," in Proc. IEEE Global Telecommunicatıons Conferener (GLOBECOM-2006). Nov. 2006. 


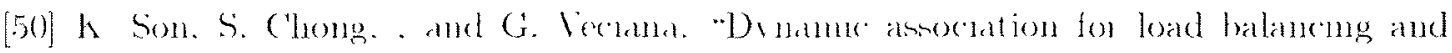

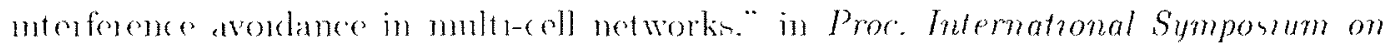

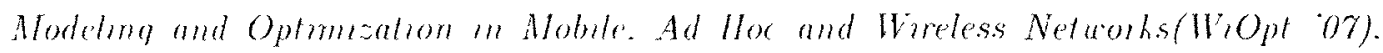
Apr. 2007 .

[51] Y Chandanekhar. J. Andrewn. and A Gatherer. "Fomocell netwonks: a surey," IEEE Commumentions Magazme. p) 5067 Sep. 2008.

[52] H-C. Lee. D.-C Oh, and Y.-H Lee. "Nitigatron of inter-fentocell interference with adaptive fractional trequency rense," in Pro. IEEE International Confererece on Commumrateons (ICCOO10) Cape Town South Afruca. Ma 2010

[53] R. An. X. Zhrong. G. C'ato. R. Zheng. and L. Sang. "Interference avoidance and adaptive fraction frequency reme in a hieradital cell structure." in Proc. IELE Wheless Commumeations and Neturortmi Conference (WCNCO010). Sydney. Australia. Apr. 2010 .

[54] Z. Bhanucha, A Sanl. G. Auer, and H. Hads, "Dymamic resource partitioning for downlink femto-to-macro-cell inter ference avoidance." EURASIP Journal on Wireless Communcations and Networking. 2010

15.5] Further Discusaton on Adaptene Fiactional Frequency Reust. 3GPP Projed Document R1-072702. Jun. 2007. Aralable online at hetp://wи w.3gpp.org.

[56] S. II Ali and V. (. M. Leung. "Dyname ficcuency allocation in fractional frequency"

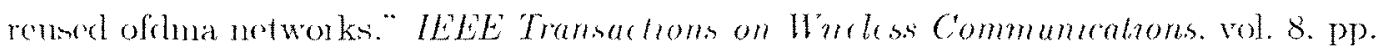
4286-4295. Aug. 2009.

[57] A. L. Stolyar and H. Viswanathan, "Self-organizng dynamic fractional frequency rense in OFDMA systems." in Pror. IEEE Confrence on Computer Communations (INFOCOM 2008$)$. Apr. 2008. pp. 691690. 


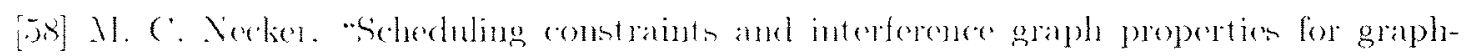

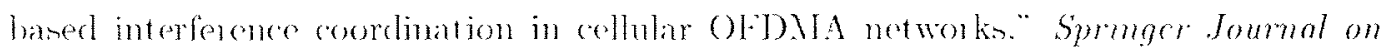

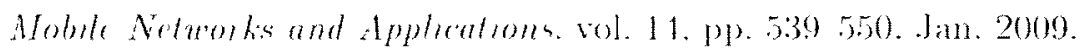

[50] R. Y. Chang. Z. Tao. J. Zhang. and C.C. J. Kuo. "Mnlticell OFDMA downlink resoures allocation uning a graphic framework." IEEE Transartion on Vehealar Terhnology. wol. 58. pp. 31943507 . Sep. 2009.

[60] K. Son. Y. Yi, and S. Chong. "Utility-optimal multi-pattem rense in multi-cell networks." IEEE Transactions on Wireless C'ommunuatzons, vol. 10. pp. 142-153. Jan. 2011.

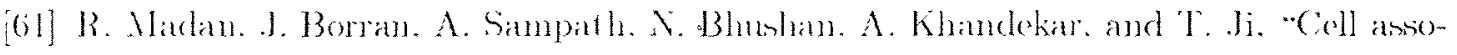
"intion and interferenco coordination in heterogenoms LTE-A cellular notwork." IEEE Journal on Sclected Areas in Communeations. wol. 28. pp. 1479 1489. Dee. 2010.

[62] ('. Y. Wong. R. S. Cheng. K. B. Letalief. and R. D. Murch. "Multineer OFDM with adaptive subcarrier. bit. and power allocation." IEEE Journal on Sclected Areas in Communcations, vol. 17. pp. 1747-1757. Oct. 1999.

[63] W. Rhee and .J. M. C'ioffi. "Inerease in capacity of multiuser OFDM system using

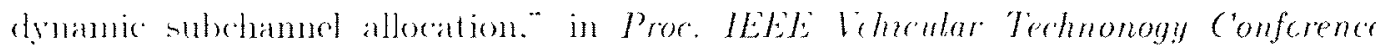

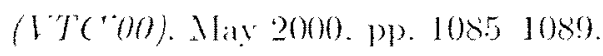

[64] 1). Nigato and E. Howain. "Adaptive fair subcarrie/ate allocation in mult irate ofdma networks: malio link level quening performance analysis," IEEE Transactoons on Vehecular Technology, vol. 55, pp. 1897-1907. Nov. 2006.

[65] H. Kim, Y. Han, and J. Koo, "Optimal subchannel allocation scheme in multicoll OFDMA systems." in Proc. IFEE Vehenlar Technonogy Conference (VTC2004Sprmg). Nay 2004. pp. $1821 \quad 1825$. 


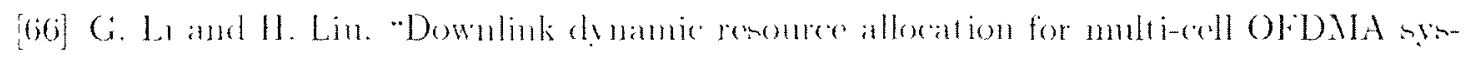

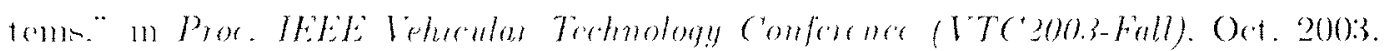
p). 16981702 .

[67] L. Venturn. X. Prasade and X. Wang. "Coordinated scheduling and power allocalion in clownlink multicell OFDMA networks." HELE Trmsactoons on Thentar Technology.

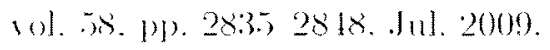

[68] M. Assad. "Optimal fractional frequenc: rense (FFR) in multicellular OFDNIA syrstem." in Proc. IEEE Vehuzular Technology Conference (VTC2008-Fall). Sep. 2008.

[69] Y. ('an and V. O. K. L. "S.cheduling algorithm in broadband wiredess networkin."

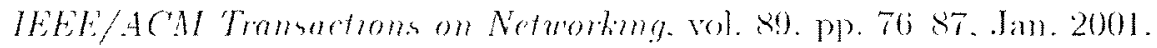

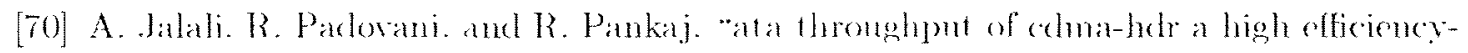
hoh datal rate personal communication witeless sistem," in Proc. IlEE l'eherular Tretmonogy Conferme (VTC 2000-Sprmg). Nay 2000. pp. 18541858.

[71] P. Viswandth. D. N. C. Tse, and R. Laroia. "Opportunistic heamforming using dumb antennas." IEEE Transaction on Information Theory. vol. 48. pp. 1277-1294. Jun. 2002 .

[72] X. Rahman and H. Yamikomerogh. "Enhancing coll-edge performence: a dommlink dy-

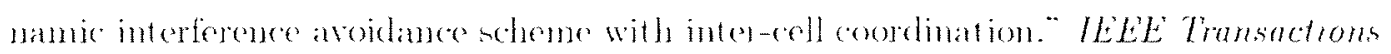
on Wireltas Communications. wol. 9. p). 1111-1125. .1pr. 2010.

[7:3 Z. Mang. Z. Feng. and P. Zhang, "An iterative hungarim algorithm based coordinated spectrum semsing strategy." IEEE Communications Letters, vol. 15, pp. 49-51, Jan. 2011. 


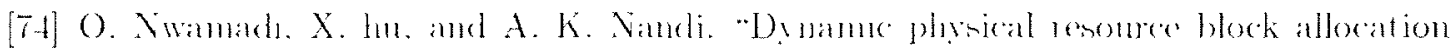
algorithms for uplink long term colution." HET (ommumatoms. vol. 5. p]) 1020) 1027. A H. 2011.

[75] Further Adnancemonts for E-LTTRA Physubl Layer Aspects (Redrase 9). 3GPP Terhnical Sperification TR 36.811 V0.4.1. Fob. 2009. Avalablo online at $h+t]$ : / www.3gpp.org.

[76] IEEE 802.J6m Evaluation Methodolomy Documfnt (EMD). IEEE 802.16m Project Document IEEE $802.16 \mathrm{~m}-08 / 004 \mathrm{r} 2$. Jul. 2008. Available online at hrtp: $/ /$ ww w.iefe $802.0 \mathrm{rg} / 16 / \mathrm{tgm} / \mathrm{doc}$.

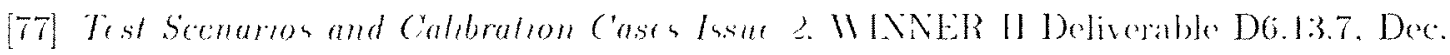
2006. Avalable online at htp://www.ist-winner.org.

[78] F. P. Kelly A. K. Maulloo. and D. K. H. Tan. "Rate cont rol for commmication network: shadow pricen proportional faimess and intality:" Journal of the Operational Rescurch Sochety. vol. 49. 1) 23. 237 252. Mar. 1998.

[79] B. Al-Manthari. N. Nasser, and H. Hassanein, "Downlink scheduling with fconomic considerations for future wireless networks." IEEE Trensactions on Vehicular Tech-

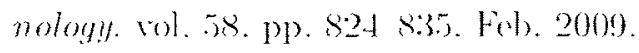

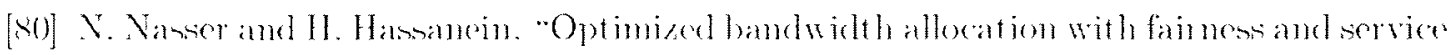
differentiation in multimedia wireleso networks." Wholess Commumatzons and Mobele Computing. vol. 8. pp. 501-511. May 2008

[81] M. Garey and D. S. Johnson. Computers and Intrartability: A Gunde to the Theory of NP-Completeness. W.H. Freeman and Company, 1979.

[82] M. Rahman. I. Yanikomerogh. M. H. Ahmed. and S. Mahmoud. "Opportunistic nonorthogonal packet scheduling in fixed broadband wireless access networks." 


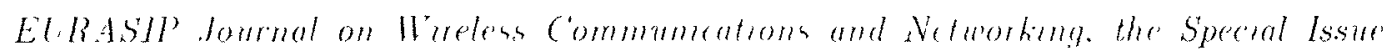
on RRM min.3G+Systems. 2006 .

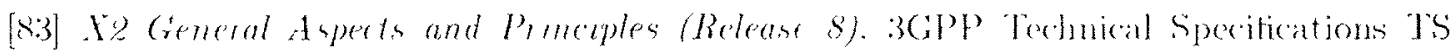
36.420. Der. 2008. Avalable online at http://wh w.30pp.ong.

[84] X2 Appluation Protocol (X\%AP) (Release s). 3GPP Techmical Specificatione TS

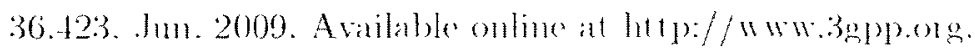

[85] WINNER Il Channel Models. WINNER II Delivelahls D1.1.2 V1.2. Sep. 2007. A vailable online at http://www ist-winner.org.

[86] J. Löberg. "YALMIP: a toolbox for modoling and optimistion in NATLAB." in Proc. CACSD Conference. Taipei. Taiwan. 2004.

[87] M. Berkelaar. K. Eikland. and P. Notehaert. (2009) Ip_tolve version 5.5. Available online at http:// /psolve.sourceforgenet/5.5.

[R8] F. Burgoios and J. C. Lassalle. "An extension of mmkten algorithm for the assigmment problem to rectangular matrices." Communications of the ACM. rol. 14. no. 12, pp. 802-804. 1971.

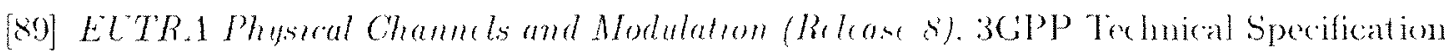
TS :36.211 V8.2.0. Mar. 2008. Available online at h1tp://ww.38pp.org.

[90] D. S. Banm. J. Salo. M. Milojeric. P'. Kÿ̈ti. and J. Hansen. "An interim channel model for beyond-3G strstems." in Pror. LEEE Thhrula. Technology Conference (VTC:005-Spring). Nay 2005. pp. 3132-3136.

[91] E-UTRA Radio Frequency (RF) System Scenarios (Release 8). 3GPP Technical Specification TS :36.942 V1.2.0. Jum. 2007. Available online at http://www.3gpp.org. 


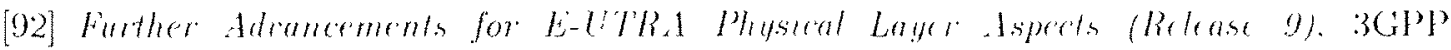
Terhnical Sperification TR 36.814 V9.0.0. Nar. 2010. Arablable ouline at http://ww.3gpp.org.

[93] TOMLAB Optimization Fool. (2009) Version 7.2 . Arailable online at htt $\mathrm{p}: / /$ ww tomopt.com 


\section{Appendix A}

\section{List of Publications}

[M1] W. Rahmon. "Achaptive modulation d coding-baned pachet scheduling whth mterbase station coordination in fixed cellular boadband wioleso networks " W.A.Se. thesis. Catreton University, Ottawa. Canadar. 2004.

[M2] M. Rahman. H. Yamikomeroglu. M. H. Ahmed. and S. Malmeud. "Impron ing base station coordination based packet scheduling whemes in fixed broadband wireless access networks." in Proc. IEEE International Conference on Communzcations (ICC2005). Seoul, Korea. May 2005.

[M:3] M. Rahman. H. Yanikomenoglu. M. H Ahmed and S. Malmond. "Opportmus-

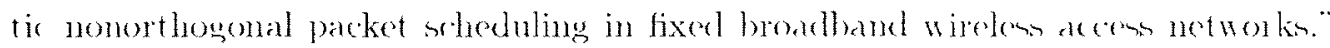

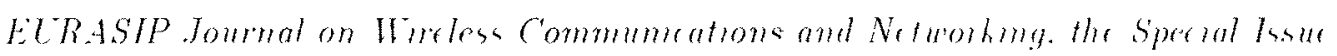
on RRM m. 3(i+ Systems. 2006.

[P4] Concept and Cnteria for Coordination Across Base Stations to Improve the Mutual Interference Situation. WINNER I Delive able D3.3. Jun. 2005.

[P5] Description of Identified Ne'u Relay Based Rado Neturot Deployment Concepts and First Assessment by Comparison Agaunst Benchmonks of Well- 


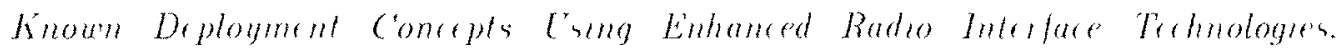
WINYER I Deliserable D3.1. Now. 2004. Arablabe onlme at http//wwwistwmmer.org/Deliverahleboctments/D3.1 1.1.pde.

[Po] Description of Identified New Relay Basad Radio Nrtumli Deployment Concepts and First Assessment by Comparason Aqamst Benchmorks of Well-

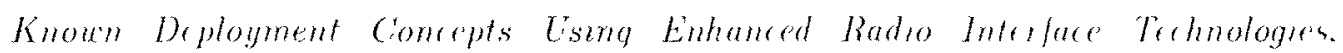
WINNER I Deliverable D3.2. Feb. 2005. Available online at htp://wwwibtwiuner.org/DeliverahleDocuments/D3.2v1 1.pulf.

[P7] Proposal of the Best Suited Deployment Concepts for the Identifud Sconarnos and Related RAN Protocols. WIXXER I Deliverable I):3.5. Jan 2006 A wilable onlme at hltp://ww.ist-wimner.org/DeliverableDocuments/D3.5.pell.

[P8] M. Rahman and IH. Yanikomerogh. "QOS provisioning in the absence of $\triangle R Q$ in celhular fixed relay networks throngh intercoll coortination." in Proc. IFEE Globol Commumation Conference (CLOBECOMZO06). San Francinco. Califomia. USA. Nov. 2006.

[P9] Interference Avondance Concepts. WINNER Il Deliverable D4.7.2. Jun. 2007. Avail-

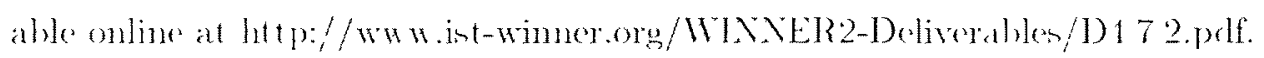

[P10] M. Rahman and H. Yanikomorogh. "Multicell downhm OFDM nubdemnel allocations usme dynamic intercell coordination." in Proc. HEEE Global Communations Conferme (CIJOBECOM2007). Washington DC. ISA. Nov. 2007.

[P11] M. Rahman and H. Yanikomeroglu, "Interference avoiclance through dynamir downlink OFDMA subchammel allocation using intercell coordination," in Proc. IEEE Tehucular Terhnology Conference (VTC2008-Spring). Nay 2008. pp. 1630 163.5 


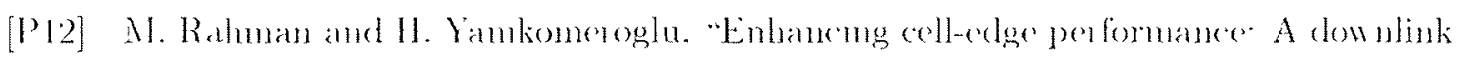

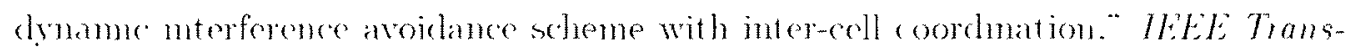
action on Hicless Commumcatons. vol. 9. Apul 2010. pp. 1414-112.)

[P13] M. Rahman and H. Yanikomeroglu. "Inter-cell interference coordmation in OFDAL networks: a novel approach based on integer programming." in Proc. IEEE Vehermlar Technology Conferemer (ITC2010-Sprng). Taipei. Taiwan. Mar 2010.

[P14] M. Rahman, H. Yanikomeroglu, and W. Wong, "Interference avoidance with dynamic inter-cell coordination for downlink LTE system." in Proc. IEEE Wireless Commumatrons and Networking Conference (IICNC2009). Buclapest. Hungary. Apr. 2009

[P'15] M. Ralmuan and II Tamikomeroglu. "A chusten-baned integer linfar programming approah in drnanic interference coordination." submitted to IEEE Tiansartons on Vehrcular Technology. Tume 2011.

[P116] M. Rahman and H. Yanikomeroglu. "A distributed ICIC, algorithm with neighbor coordination", manuscript in-preparation for a possible submission to an IEEE magazine.

[PN17] M. Salem. A. Aelinosi. M. Rahman. II. Yambomerogh. D. Faleoner and Y.-D. Kim. "Appatatus and method for alloc ating sub hamek and contolling interference in OFDMIA sistems." Patent filed by Samsung Korea. Korea petent applacation no: P2008-00.51726 (apphation date: 11 June 2008: IS patont application no: 12/341,933 (application date: 22 December 2008); international patent application no: PCI/KR2009/002119 (filing date: 23 April 2009).

[PN18] M. Salem. A. Adinoyi. M. Rahman, H. Yanikomerogh. D. Falconer. Y.-D. Kim. and E. Kim. "Fainess-awane joint rouling and scheduling in OFDNA-based multi- 


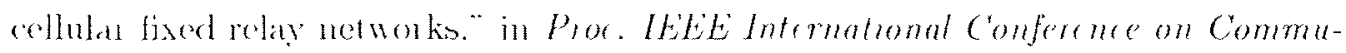
matzoms (ICCO009). Droselen. Germany .Im. 2009.

[PN19] M. Salem, A Admori. M. Rahman. II. Yanikomerogh. D. Fakoner. Y.-D. Kim. E. Fins. and Y.-C'. Cheong. "An onervew of radio resouree management in relatyonbanced OFDXIA-based networks." to appean m IEFE Commumation Surveys and Tilomals. 2010.

[PN20] M. Salem, A. Adinovi. M. Rahman, H. Yanikomerog]u, D. Falconer, and Y.-D. Kim, "Farnesh-aware radio resource management in OFDNA-based cellular fixed relay networks." submitted to IEEE Transartion on Wireless Communcations. sulmitted Vor 2008 . revised .J11. 2009

[PN21] P. Djukic. N. Rahman. H. Yanikomeroglu. and .I. Zhang. "Adranced radio access networks for LTE and heroud." in Lrotued Cellular Network Plammo and Optrmazation for LMTS and LTE. I. Song and S. Jia. Eds. Anerbach Publications. ('RC Press. Taylor de Francis Gromp. 2010.

[PN22] F. A. Bokhari, H. Yanikomeroglu, W. K. Wong, and M. Rahman, "Fairness dusessment of the adaptive token bank fair queuing scheduling algorithm," in Proc. IEEE

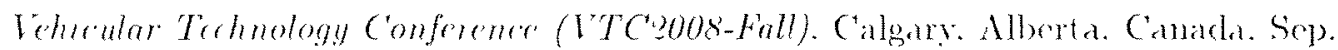
$20(1)$.

[PN23] F. A. Bokhari. H. Yanikomenoglu. W. K. Wong. and N. Rahman. "Cross-later resoure shednling for multimedia traffic in the downlink of 4 (a wireles multirarrier networks," EURASIP Journal on Wueless Communzcatrons and Networking. Speral Issue on Famness in Radno Resource Management for Woreless Netuorks. 2009. 
Remarks on the Prefix of the List of Publications

M Master"s work

P PhD work incluted in the thesis

PI Intended publication trom PhD wolk

PN PhD work not inchuled an the thenis 